\title{
UNDER THE RADAR: ASSESSING ATTITUDES TOWARD CHILD SEXUAL ABUSE USING THE IMPLICIT ASSOCIATION TEST
}

\author{
A thesis submitted to \\ the Faculty of Graduate Studies and Research \\ in Partial Fulfillment of the requirements for the degree \\ Master of Arts \\ by
}

Nicolas Kessous

Department of Psychology

Carleton University

July 2009

(C2009 Nicolas Kessous 


$\begin{array}{ll}\begin{array}{l}\text { Library and Archives } \\ \text { Canada }\end{array} & \begin{array}{l}\text { Bibliotheque et } \\ \text { Archives Canada }\end{array} \\ \begin{array}{l}\text { Published Heritage } \\ \text { Branch }\end{array} & \begin{array}{l}\text { Direction du } \\ \text { Patrimoine de l'édition }\end{array} \\ \begin{array}{l}\text { 395 Wellington Street } \\ \text { Ottawa ON K1A ON4 } \\ \text { Canada }\end{array} & \begin{array}{l}\text { 395, rue Wellington } \\ \text { Ottawa ON K1A ON4 } \\ \text { Canada }\end{array}\end{array}$

Your file Votre référence

ISBN: 978-0-494-58442-2

Our file Notre référence

ISBN: 978-0-494-58442-2

NOTICE:

The author has granted a nonexclusive license allowing Library and Archives Canada to reproduce, publish, archive, preserve, conserve, communicate to the public by telecommunication or on the Internet, loan, distribute and sell theses worldwide, for commercial or noncommercial purposes, in microform, paper, electronic and/or any other formats.

The author retains copyright ownership and moral rights in this thesis. Neither the thesis nor substantial extracts from it may be printed or otherwise reproduced without the author's permission.
AVIS:

L'auteur a accordé une licence non exclusive permettant à la Bibliothèque et Archives Canada de reproduire, publier, archiver, sauvegarder, conserver, transmettre au public par télécommunication ou par l'Internet, prêter, distribuer et vendre des thèses partout dans le monde, à des fins commerciales ou autres, sur support microforme, papier, électronique et/ou autres formats.

L'auteur conserve la propriété du droit d'auteur et des droits moraux qui protège cette thèse. Ni la thèse ni des extraits substantiels de celle-ci ne doivent être imprimés ou autrement reproduits sans son autorisation.
In compliance with the Canadian Privacy Act some supporting forms may have been removed from this thesis.

While these forms may be included in the document page count, their removal does not represent any loss of content from the thesis.
Conformément à la loi canadienne sur la protection de la vie privée, quelques formulaires secondaires ont été enlevés de cette thèse.

Bien que ces formulaires aient inclus dans la pagination, il n'y aura aucun contenu manquant. 


\begin{abstract}
Child sexual abuse is both legally and ethically proscribed, and engenders serious mental and physical problems for its victims. In order to protect children and prevent would-be or seasoned offenders from striking, it is imperative that we come to understand why CSA happens in the first place and why it recurs. Many theorists have identified attitudes supportive of CSA as probable causes. The Implicit Association Test (IAT) assesses attitudes by measuring cognitive associations between categories. Together with selfreport measures, the IAT may provide a more complete picture of attitudes toward CSA. Thirty-four incarcerated child molesters and 21 incarcerated non-sexual offenders completed a novel IAT designed to assess implicit attitudes toward CSA, in addition to a self-report questionnaire assessing explicit attitudes toward CSA. Although child molesters did not ultimately display more deviant implicit attitudes toward CSA than non-sexual offenders, they did display more deviant explicit attitudes toward the subject.
\end{abstract}




\section{Acknowledgments}

I first and foremost want to thank the Association for the Treatment of Sexual Abusers, the Social Sciences and Humanities Research Council, Carleton University, and the Fonds québecois de la recherche sur la société et la culture for their financial support; none of this work would have been possible without their generous contribution.

A heartfelt expression of gratitude is sent Kevin Nunes' way for his help in designing this project, his support throughout its completion, and his assistance in preparing this manuscript; your unfailing commitment to your students sets you a breed apart. I am additionally grateful to Adelle Forth and Ralph Serin for their invaluable advice and constructive feedback; this project wouldn't have turned out the way it did without them. I would also like to thank Etelle Bourassa for so capably handling the administrative aspects of this thesis, and for infusing my graduate experience with full-hearted warmth and kindness. Kelly Babchishin, you've been a first-class research partner, and I thank you for your company in Kingston. Chantal Hermann and Rikki Sewell, you are the bestest lab-mates ever; I couldn't have hoped for better additions to our team.

Special thanks also go to to Carolyn Bourgeois, Anita Cumbleton, Yolanda Fernandez, Carmen Gress, Cindy Hudson, Daryl Kroner, Richard Laws, Petrina Lemieux, Jan Looman, Wadgy Loza, Greg Maillet, Wendy McMahon, Jeremy Mills, Ed Peacock, Geris Serran, Bill Walker, and Jennifer Walsh for helping make this project a reality.

Finally, I would like to dedicate this thesis to my family, for supporting me from conception to convocation, and to Caleb Lloyd, for coming along at just the right time. To my friends Andrea Lee, Ian McPhail, Diane Sliz, Ashley Towns, and Tennyson Yang, I simply cannot imagine the last two years without you. I thank you for the good times we've shared, and for always being there for me when the going got tough. Suffice it to say, you made my stay here in our nation's capital one that I will never forget... 


\section{Table of Contents}

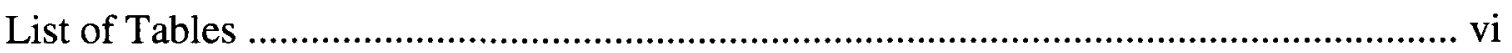

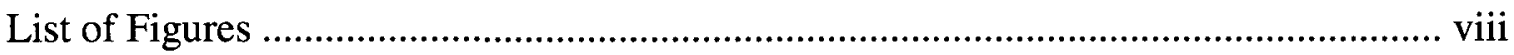

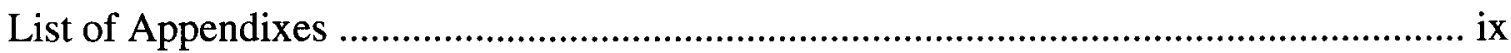

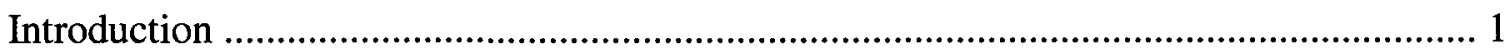

Child Sexual Abuse in Social Context ........................................................... 2

Definitions of Child Sexual Abuse ........................................................................ 3

The Scope, Nature and Impact of Child Sexual Abuse ........................................ 7

Typologies of Child Molesters ............................................................................... 10

Theories of Child Sexual Abuse ............................................................................ 11

Cognitive Distortions in Child Molesters .......................................................... 16

Attitudes and Behavior ......................................................................... 18

Explicit and Implicit Attitude Assessment ................................ 20

The Implicit Association Test ......................................................................... 22

Cognitive Foundations of the Implicit Association Test ...................................... 23

Implicit Assessments of Attitudes in Child Molesters .......................................... 25

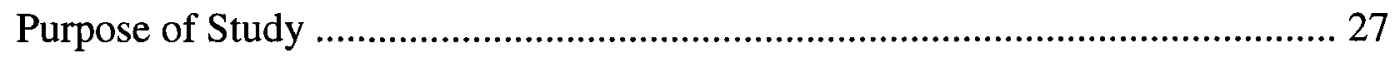

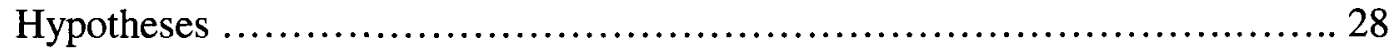

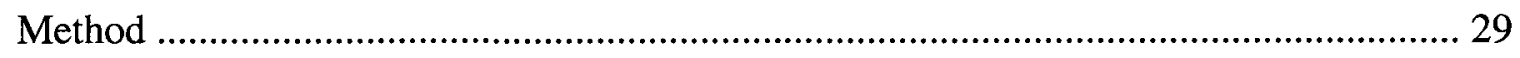

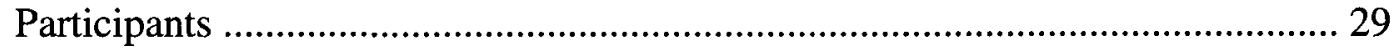

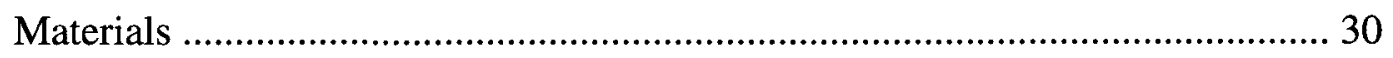

The Attitudes toward CSA IAT ...................................... 30 
Developing the Attitudes toward CSA IAT ........................... 34

The Sex with Children scale .................................... 36

The Balanced Inventory of Desirable Responding .................... 38

Language proficiency and background information ................... 39

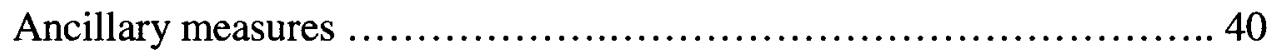

Coding manual ....................................................... 40

The Static-99 …................................................. 40

The Stable-2007 .................................................... 41

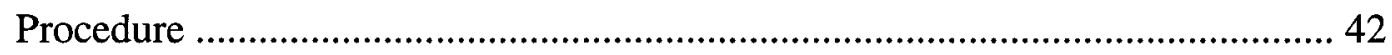

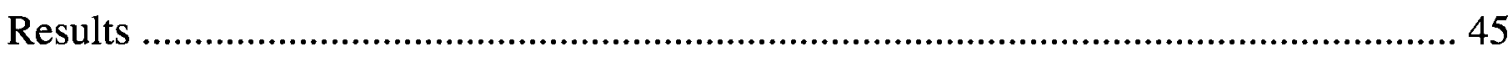

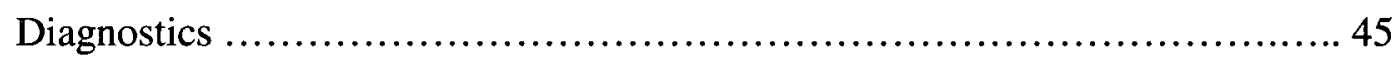

Offender and offence characteristics ......................................... 45

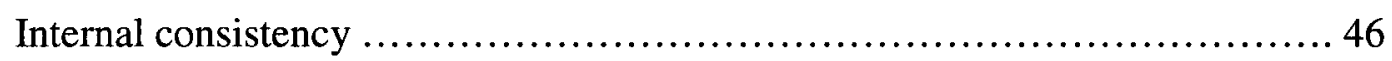

Language proficiency ................................................... 48

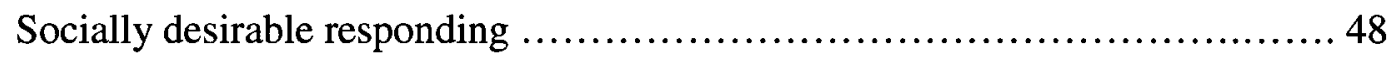

Implicit attitudes toward CSA ….................................................................. 48

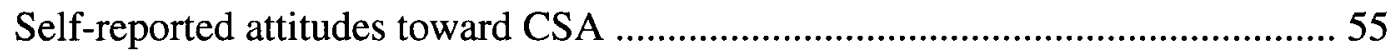

Relation between implicit and explicit attitudes toward CSA ….......................... 56

Relation between attitudes toward CSA and risk of sexual recidivism ............... 56

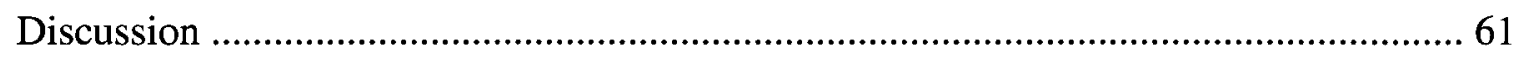

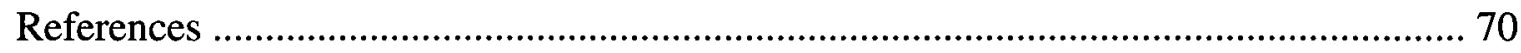


List of Tables

Page

Table 1: Sexual Offences Against Children in the Criminal Code of Canada ................... 5

Table 2: DSM-IV-TR Diagnostic Criteria for Pedophilia .............................................. 6

Table 3: Offender and Offence Characteristics .................................... 31

Table 4: Stimulus Words Representing the Four Categories of: Sex with Adult, Sex with

Child, Good and Bad 33

Table 5: Frequencies of Stimulus Words Selected as Representing the Categories of: Sex with Adult and Sex with Child 37

Table 6: Frequencies of Stimulus Words Selected as Representing the Categories of:

Good and Bad . 37

Table 7: Correlations between Offender and Offence Characteristics and the Two

Measures of Attitudes toward CSA 47

Table 8: Child molesters' and Non-Sex Offenders' Scores on the CVT and the BIDR .. 49

Table 9: Correlations between the CVT, the BIDR and the Two Measures of Attitudes toward CSA 50

Table 10: Child Molesters' and Non-Sex offenders' Scores on the Attitudes toward CSA IAT and the SWCH scale 52

Table 11: Correlations between Potential Covariates 54

Table 12: Correlations between the Implicit and Explicit Measures of Attitudes toward CSA 57

Table 13: Child molesters' Combined Static/Stable Ratings 59 
Table 14: Correlations between the Combined Static/Stable Ratings, the Attitudes Supportive of CSA Item of the Stable-2000 and the Measures of Attitudes toward

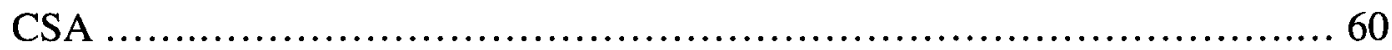




\section{List of Figures}

Page

Figure 1: Illustration of the Attitudes toward CSA IAT ................................................. 32

Figure 2a: Example of a combined trial from the Attitudes toward CSA IAT ................. 35

Figure 2b: Example of a reversed-combined trial from the Attitudes toward CSA IAT .. 35

Figure 3: Complete study of which the current project was a part ................................... 43 


\section{List of Appendixes}

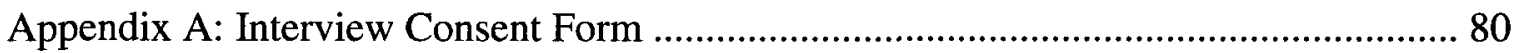

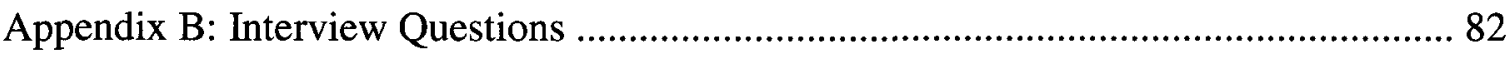

Appendix C: Rating Scales Consent Form ……………............................................ 86

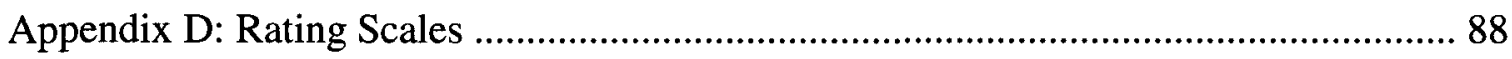

Appendix E: Pilot Study and Study Proper Consent Form ........................................... 93

Appendix F: Sex with Children Scale ...................................................................... 95

Appendix G: Balanced Inventory of Deceptive Responding .......................................... 97

Appendix H: Clarke Vocabulary Test ........................................................................ 100

Appendix I: Background Questionnaire ............................................................... 104

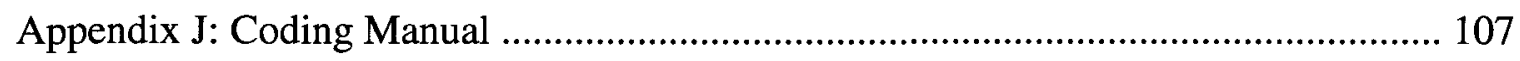


Under the Radar: Assessing Attitudes toward Child Sexual Abuse Using the Implicit Association Test

Once claimed to be at $100 \%$ risk of re-offending, Peter Whitmore is often described as one of our country's most infamous pedophiles. The now 38 year-old man's criminal career began early in adulthood and now boasts countless victims. Whitmore's lust for children has compelled him to devise schemes as elaborate as launching a babysitting business and impersonating a childcare professional so as to secure access to potential victims. Under the guise of trust, Whitmore callously allowed unsuspecting parents to willingly hand over their children to him for abuse. His charges range from fondling to forced fellatio and attempted anal intercourse (Canadian Press, 2006). What would compel a mature adult to sexually assault innocent children? There is, after all, no shortage of deterrents. For one, child sexual abuse (CSA) is both legally and ethically proscribed. In addition, CSA engenders serious mental and physical problems for its victims (Canadian Centre for Justice Statistics, 2001). In order to protect children and prevent would-be or seasoned offenders from striking, it is therefore imperative that we come to understand why CSA happens in the first place and why it recurs.

Many theorists have identified attitudes supportive of CSA as probable causes. Attitudes toward CSA are commonly identified using self report-measures (e.g., Bumby, 1996; Hanson, Gizzarelli, \& Scott, 1994; Laws, Hanson, Osborn, \& Greenbaum, 2000; Mann, Webster, Wakeling, \& Marshall, 2007). Such measures, however, are susceptible to self-presentation biases. That is, child molesters may seek to portray themselves positively by reporting their attitudes inaccurately. The Implicit Association Test (IAT; Greenwald, McGhee, \& Schwartz, 1998) assesses attitudes by measuring cognitive 
associations between categories. Because the IAT measures automatic reactions to how certain categories are paired, it is relatively unaffected by such self-enhancing motives. As such, one's performance on the IAT may reveal attitudes that self-report measures may not. Together with self-report measures, indirect measures such as the IAT may ultimately provide more accurate assessments of attitudes toward CSA.

Prior to introducing the research project at hand and its hypotheses, the reader will first be provided with a comprehensive but concise introduction to the subject of CSA, based upon an extensive survey of the available literature. Adopting a multi-disciplinary perspective on the matter, contributions from sociology, law, clinical psychology, and fundamental and applied psychological research will be explored. Next, the issue of CSA will be examined from a societal perspective, and defined according to two seminal sources. Results from a landmark government study on the scope, nature and impact of CSA will subsequently be outlined. Given that not all child molesters are alike, different typologies of child molesters will consequently be presented. Researchers have proposed many theories to attempt to explain why CSA occurs; at this point, five major theories will be reviewed. Implicit theories commonly held by child molesters will then be described, followed by a definition of attitudes, and a description of the different means by which researchers can assess them. Penultimately, a prominent measure of implicit attitudes, the IAT, will be introduced, along with its theoretical foundations in cognitive psychology. Lastly, but surely not leastly, how researchers have to date employed the IAT to assess attitudes toward CSA will be reviewed.

\section{Child Sexual Abuse in Social Context}

With a few exceptions, societies across the world have, since their inception in 
history, explicitly condemned CSA (Seto, 2004). Apart from curious instances, like the awkwardly titled song "Thank Heaven for Little Girls," penned by Lerner and Loewe for Gigi's musical soundtrack (1996, track 4), modern society frowns upon the sexualisation of children. Although the desecration of children's innocence at the hands of sexual predators has always been met with public outrage, the issue of CSA has recently sparked heightened curiosity amongst the international community. This is evidenced, in part, by a surge in media attention as reflected by the amount of airtime and editorial space dedicated to the subject. National, provincial and local news broadcasters and publishers are increasingly reporting on individual cases of CSA: in 2004, the American network $N B C$ launched the vigilante series "To Catch a Predator" as part of its Dateline newsmagazine (Keller). And in 2007, the Canadian newspaper The National Post published the four-part series "Predators Among Us" (Humphreys, Hanes, Brean, Rook, Vallis, \& Blackwell). CSA has even garnered attention from the artistic community. Child molesters are cast as primary characters and satirized in popular television comedies like South Park (Parker \& Stone, 1997) and Family Guy (MacFarlane, 1999). The issue of CSA is also explored in more tactful and sombre fashion in television dramas, like the Law and Order franchise (Wolf, 1990), and in film, like the fictional drama Mysterious Skin (Araki, 2004) and the Oscar-nominated documentary Capturing the Friedmans (Jarecki, 2004).

Definitions of Child Sexual Abuse

Many disciplines concern themselves with CSA, including sociology, psychology, social work and the law. As such, the academic literature is scattered with countless definitions of CSA. Following are both the legal and clinical definitions of CSA, as 
Under the Radar 4

outlined in law and clinical psychology's seminal texts, the Criminal Code of Canada (Department of Justice Canada, 2009), and the Diagnostic and Statistical Manual of Mental Disorders, Fourth Edition, Text Revision (DSM-IV-TR; American Psychiatric Association (APA), 2000).

Although the term child sexual abuse cannot itself be found within the pages of the Criminal Code of Canada, myriad offences are encompassed under this category (Part V: Sexual Offences, Public Morals and Disorderly Conduct). Under the code, sexual offences against minors include, amongst others, sexual interference, invitation to sexual touching, and sexual exploitation (see Table 1). Sexual interference and invitation to sexual touching pertain to complainants under the age of 16 . Whether the complainant consented or not to the act is irrelevant (for exceptions see Section 150.1(2)). Sexual exploitation pertains to complainants 16 years of age and older, but less than 18 years of age (referred to as young persons). If the accused has had sexual intercourse with an immediate blood relative and was fully aware of the familial bond at the time of the offence, the accused would also be guilty of incest (Section 155).

Although every instance of CSA does not necessarily imply that pedophilia is at play, pedophilia is the only clinical disorder that includes CSA as one of its criteria (albeit not a necessary one, as sexual interest in children is sufficient to warrant a diagnosis). Pedophilia is an Axis I disorder listed under the "Paraphilias" section of the "Sexual and Gender Identity Disorders" chapter of the DSM-IV-TR (APA, 2000). To warrant a diagnosis of pedophilia, the manual requires that three specific criteria be met (see Table 2). The clinician must also specify if the client is mainly attracted to males, females or both; if the client has engaged in incestuous relations; and if the client is exclusively 
Table 1

Sexual Offences against Children in the Criminal Code of Canada

$\begin{array}{lll}\text { Section Number } & \text { Offence } & \text { Definition }\end{array}$

151

152

153
Sexual interference

Invitation to sexual exploitation

Sexual exploitation
Every person who, for a sexual purpose, touches, directly or indirectly, with a part of the body or with an object, any part of the body of a person under the age of 16 years

Every person who, for a sexual purpose, invites, counsels or incites a person under the age of 16 years to touch, directly or indirectly, with a part of the body or with an object, the body of any person, including the body of the person who so invites, counsels or incites and the body of the person under the age of 16 years

Every person commits an offence who is in a position of trust or authority towards a young person, who is a person with whom the young person is in a relationship of dependency or who is in a relationship with a young person that is exploitative of the young person, and who $(a)$ for a sexual purpose, touches, directly or indirectly, with a part of the body or with an object, any part of the body of the young person; or $(b)$ for a sexual purpose, invites, counsels or incites a young person to touch, directly or indirectly, with a part of the body or with an object, the body of any person, including the body of the person who so invites, counsels or incites and the body of the young person 
Table 2

DSM-IV-TR Diagnostic Criteria for Pedophilia
Criteria
Definition

A

Over a period of at least 6 months, recurrent, intense sexually arousing fantasies, sexual urges, or behaviors involving sexual activity with a prepubescent child or children (generally age 13 or younger)

B

The person has acted on these sexual urges, or the sexual urges or fantasies cause marked distress or interpersonal difficulty

C

The person is at least 16 years of age and at least 5 years older than the child or children in Criterion $\mathrm{A}$ 
attracted to children, or indiscriminately attracted to both children and adults. Older adolescents engaged in a stable, sexual relationship with a 12- or 13- year old are excluded from this diagnosis.

Legal and clinical definitions of CSA are laden with discrepancies. Law and psychology are two distinct fields, each with their own focus and purpose. In general terms, law is concerned with the lawful and forward functioning of society, whereas clinical psychology is concerned with the mental health of the population. Although CSA and pedophilia are related concepts, they remain distinct. CSA is discussed in legal arenas, whereas pedophilia is the domain of clinicians. An individual may be a pedophile and not a child molester; conversely, an individual may be a child molester and not a pedophile. To elaborate, a child molester sexually assaulted or solicited sexual contact from a child. Although a pedophile may also have done so, he may also have merely fantasized about it. Additionally, perpetrators and victims' age differ in legal and clinical definitions of CSA. According to the DSM-IV-TR, the victim must be less than 14 years of age. Although the Criminal Code of Canada previously defined victims as individuals aged 14 years or younger, it has recently increased that number to 16 years of age. According to the Criminal Code of Canada, the perpetrator must be 14 years of age or older. Conversely, the DSM-IV-TR requires the perpetrator be 16 years of age or older, and five years older than the victim. Fourteen to 16 year old child molesters, as well as older child molesters less than five years older than their victims, are thus not eligible for a diagnosis of pedophilia.

\section{The Scope, Nature and Impact of Child Sexual Abuse}

At the turn of the last century, Health Canada endeavored to provide a current account 
of child maltreatment in our nation. The result was the very first "Canadian Incidence Study of Reported Child Abuse and Neglect." Its most recent findings appeared in the 2001 edition of the Annual Family Violence in Canada: A Statistical Profile report, an annual publication helmed by Statistics Canada's Centre for Justice Statistics. Health Canada's research initiative provides a wealth of information on the scope, nature and impact of CSA.

During 1998, welfare workers across Canada dealt with a staggering 135,573 cases of child maltreatment, a sample of which was analyzed for the government's landmark study. Child maltreatment took on many forms. Of the many incarnations of child maltreatment, CSA was the least common type (10\%), preceded by emotional maltreatment (19\%), physical abuse (31\%) and neglect (40\%). When it did occur, CSA was most often characterized by: fondling of the child's genitals (68\%), completed oral, vaginal or anal sex $(21 \%)$, attempted oral, vaginal or anal sex (14\%), exposure of the genitals to the child (12\%), sexual exploitation (6\%) and sexual harassment (4\%). Sexual exploitation refers to sexual abuse for ends other than sexual gratification (e.g., financial gain), whereas sexual harassment refers to compelling children to engage in sexual activities.

Most forms of child maltreatment were initiated by primary caregivers. Conversely, CSA was most commonly initiated by relatives other than the primary caregivers (44\%) and by non-relatives ( $31 \%)$, followed by biological fathers (8\%), step-fathers ( $8 \%)$, biological mothers (3\%), and step-mothers (2\%). The majority of victims of sexual abuse were girls, with more than twice the rate of victimization of boys (69\% and $31 \%$, respectively). Boys between four to seven years of age were the most prominent victims 
of CSA, with three times the rates of victimization of other boys (i.e., zero to three, eight to 11 , and 12 to 15$)$. Girls between four to seven years and 12 to 15 years of age were the most prominent victims of CSA, with two times the rates of victimization of other girls (i.e., zero to three, and eight to 11 ).

CSA impresses immediate harms upon its victims, which arise during or soon after the attack. Physical harm was most prevalent in cases of physical abuse (44\%), followed by neglect (9\%), sexual abuse (8\%) and emotional maltreatment (1\%). Sexual abuse and emotional maltreatment resulted in similar kinds of surface injuries, like cuts and bruises. Emotional harm, on the other hand, was most prevalent in cases of CSA (47\%), with 38\% of cases necessitating treatment. Emotional harm was also significant, albeit to a lesser extent, in other forms of maltreatment (33\%, with 50\% requiring treatment). CSA also impairs longer-term child functioning. Within the "physical, emotional, or cognitive" class of impairments, child victims of sexual abuse were more depressed and anxious than victims of other forms of maltreatment. Within the "behavioral" class of impairments, child victims of sexual abuse predictably exhibited more age-inappropriate sexual behaviors than victims of other forms of maltreatment.

Health Canada's study boasts methodological advantages over other prevalence studies commonly found in the literature. Analyzing data from welfare cases, its findings are not as limited as those drawn from police reports, university and clinical samples. First, there is reason to believe that CSA is underreported to police. Second, university samples represent well-functioning victims, whereas clinical samples represent struggling victims, both of which may have endured different types of sexual abuse. These limiting factors combine to bias conclusions on the prevalence, nature and impact of CSA. Also, 
studies on the impact of CSA often employ comparison groups that have never been victimized. In this survey, we may quantify the impact of CSA relative to other types of abuse. (For more information on common methodological issues in evaluating the prevalence of CSA, see Goldman \& Padayashi, 2000.)

\section{Typologies of Child Molesters}

Theorists have devised many nomenclatures of child molesters. One of the earliest typologies was devised by Groth, Hobson, and Gary (1982). In their seminal article, the authors differentiate between two types of sex offenders against children: the child molester and the child rapist. Propensity toward violence embodies the distinguishing characteristic. Child molesters are non-violent sex offenders. They coerce their victims into compliance through indirect means, like psychological manipulation and passive forms of aggression; in other words, they commit sex-pressure assaults (Groth \& Burgess, 1977). Conversely, child rapists are violent sex offenders. They coerce their victims into compliance through explicit threats of harm or physically subdue their victims; in other words, they commit sex-force assaults (Groth \& Burgess, 1977).

Groth et al. (1982) proceed to describe the two types of child molesters: the fixated offender and the regressed offender. Fixated offenders are individuals who, in an instance of arrested psychological development, do not outgrow their childhood attraction to other children. They essentially fail to effectively substitute the objects of their childhood attraction for age-appropriate objects, as they progress from childhood to adulthood (i.e., by becoming attracted to adolescents in adolescence and adults in adulthood). Regressed individuals are individuals who have traveled a normal developmental path into adulthood. They entertain normal sexual relationships with adults until a life stressor 
takes an emotional toll upon their psychic balance, at which point they regress to the safety of childhood, and find themselves attracted once again to children.

Imbuing their rhetoric with Freudian terms, Groth et al.'s (1982) taxonomy is psychodynamically flavored, which effectively renders it outdated. The authors are also surprisingly humanistic in their depiction of the child molester: child molesters are described as individuals whose quest toward self-fulfillment is unduly foiled by external events utterly beyond their conscious control. They are exempt from responsibility and conceptualized as victims of past and present events. Immature and helpless, they do their best to mend the scars left onto them by life: "it is through the sexual activity with a child that the offender attempts to solve unresolved issues of his development and fulfill unmet needs in his life" (Groth et al., 1982, p. 137).

Finkelhor and Araji (1986) provide a continuous alternative to the previous, categorical dimensions. In addition, their depiction of the pedophilic individual takes into account dispositional determinants, deflecting attention away from environmental shortcomings. The two continuums upon which pedophiles' behavior vary are the strength and the exclusivity of pedophilic interest. The strength of pedophilic interest refers to the extent to which a child molester is motivated to engage in sexual activities with children, whereas the exclusivity of pedophilic interest refers to the extent to which a child molester confines his sexual activities to children. According to Finkelhor and Araji's depiction, the pedophilic individual is internally motivated to prey upon children and orients himself toward them, albeit to different extents.

\section{Theories of Child Sexual Abuse}

The accurate classification of sexual offenders against children is of much 
consequence, as it holds implications for the effective treatment of this population. Depending on particular characteristics of an offender, certain types of treatment ensue. The latter classifications are too parsimonious to be of any use in clinical contexts. Classifications that extend from theories of CSA are more comprehensive and, therefore, of greater use to clinicians. Researchers have devised many theories to explain why CSA occurs. Some theories are one-dimensional, whereas others are multidimensional. Given that most of the factors comprised in the one-dimensional models of pedophilia are included in their multidimensional counterparts, one-dimensional models have been purposefully omitted from the following review, in favor of the following major, multidimensional theories: the Four-Factor Model, the Integrated Model, the Quadripartite Model, the Pathways Model, and the Integrated Theory.

Scouring the literary landscape for similarities amongst the many single-factor explanations of pedophilia, Finkelhor and Araji (1986) compiled the theories yielded by their exhaustive search to produce a four-factor model. This particular model stipulates that the sexual abuse of children engages four factors into play: emotional congruence, sexual arousal, blockage, and disinhibition. First, pedophiles identify with children and find engaging in sexual relationships with them emotionally fulfilling. Second, pedophiles construe children as sexual objects and find engaging in sexual relationships with them, or even fantasizing about them, sexually gratifying. Third, pedophiles are unable to find emotional solace and sexual relief within normal, adult relationships. From this blockage arises sexual interest in children. Blockage can be due to arrested development, as in an instance of the oedipal complex gone awry, or to situational constraints. For example, a husband cannot access strange women to fulfill his adulterous 
fantasies, and so he preys on his own offspring to meet his sexual needs. Lastly, pedophiles are not easily dissuaded by and see it fit to violate societal mores forbidding sexual congress with children.

Hall and Hirschman's quadripartite model of sexual aggression against children (1992) is an adapted version of the authors' previous model of sexual aggression against women (Hall \& Hirschman, 1991). According to it, the motivation to sexually offend against a child is driven by four dispositional features: physiology, cognition, affect, and personality. First, child molesters exhibit deviant patterns of physiological sexual arousal, being aroused by children (either exclusively, or in addition to adults). Second, child molesters entertain thoughts that justify sexual aggression against children. Third, child molesters have difficulty moderating internal affective states. They aggress against children in an attempt to ward off distressing thoughts and feelings of, for example, depression. Fourth, child molesters' personality may be impaired by traumatic childhood events, like being abused themselves. These four features are intricately connected to one another. Much like taking a wrong step in a room scattered with mousetraps, one feature's activation is soon followed by the other features' activation, in a chain reaction of sorts. However, one feature takes precedence over the others, with its activation threshold being lower than the others. Whichever feature takes precedence over the others characterizes a particular subtype of sexual aggressor, of which there are four. Marshall and Barbaree's integrated model (1990) uncovers the biological processes that underlie men's sexually aggressive behavior toward women and children, and narrows in on the learning experiences that serve to mediate the behavior. The authors propose that the biological underpinnings of sexual and aggressive behaviors are similar. 
Men must therefore learn to dissociate sexual and aggressive impulses, and must withhold from succumbing to aggressive propensities when engaging in sexual activity. This proposition assumes that men are inherently sexually aggressive. Appropriate means of sexual expression (e.g., sexual behavior directed at age-mates) must therefore be learned, and restraints on sex and aggression acquired. Several factors affect the male child's ability to learn to curtail his aggression. Childhood experiences in the home shape the growing boy's ability to discriminate between sex and aggression, to perceive the two as either inclusive or exclusive. Sexual and physical abuse exacerbates the biological propensity to associate sex and aggression by teaching the child that the two are actually compatible. Conversely, care and love undermine the tendency to associate sex and aggression, by teaching the child that the two are indeed not compatible.

Boys who endured a troubled upbringing must learn to compensate for the psychic injuries left to them by their past (e.g., low self-esteem). Such means of compensation are provided by a society that tends to endorse patriarchal values in the likes of male dominance over other people and nature, and violence as an appropriate means of solving conflict. Even in a male who has managed to discriminate between sex and aggression, and who has effectively learned to restrain himself from succumbing to his aggressive propensities, strong situational events may still unshackle the acquired constraints: intoxication, anger, prior arousal, perception of social endorsement, stressful events. In a sinister, yet amusing comment on the difficulty of acquiring behavioral restraints over sex and aggression, Marshall and Barbaree observe that "it is a wonder more men do not become sex offenders" (1990, p. 264).

Ward and Siegert's pathways model (2002) builds upon the aforementioned models by 
retaining their strengths and addressing their limitations. The model postulates that four sets of psychological factors engender the sexual abuse of children: intimacy and social skills deficits, distorted sexual scripts, emotional dysregulation, and cognitive distortions. These factors, however, are not rigid, unwavering concepts. To the contrary, they are described by the authors as mechanisms. First, child molesters are weary of their surroundings and, fearing rejection, avoid congregating and bonding with others. Second, child molesters do not grasp the inappropriateness of having children as sexual partners. Third, child molesters are unable to maintain behaviors that favor task completion and cease behaviors that thwart task completion. Although all factors combine to bring about CSA, only one takes the lead. This leading factor is always dysfunctional. The other factors (be they dysfunctional or not) service the primary one. Ward and Siegert outline five pathways to CSA. The first four pathways' trajectories depend upon which of the four psychological factors takes precedence over the others. All four factors are equally weighted in the fifth pathway.

Ward and Beech's integrated theory of sexual offending (ITSO; 2006) is an interactive model that engages biological, ecological and neuropsychological factors into perpetuity. It is the most complex and multifaceted model to date. Biological functioning is determined by evolution, genetics and hormones, whereas social learning is determined by social and personal circumstances. Deficient biological functioning and social learning combine to impair neuropsychological functioning. The individual becomes unable to properly process and organize incoming information from his environment, which causes him to perceive the world through distorted lenses. The individual consequently begins to set inappropriate goals and to implement inappropriate means of achieving those goals, 
because the information from which they are derived is inaccurate. From these impairments in neuropsychological functioning emerge clinical symptoms in the likes of emotional problems, social difficulties, cognitive distortions and deviant sexual interests. Impaired with these symptoms, the individual is finally brought to action and sexually offends. The offence serves to exacerbate the individual's personal circumstances, which ultimately sets the entire process into perpetual, self-feeding motion.

\section{Cognitive Distortions in Child Molesters}

A recurring factor within all of the aforementioned models of CSA is that they each posit cognitive distortions as potential causes. Ward and Beech's ITSO (2006), however, most aptly positions cognitive distortions within the grand scheme of child molestation by integrating cognitive distortions within a multifaceted framework of causes and effects, and by appropriately acknowledging their role as both clinical indicators and behavioral instigators. Psychiatrist Gene Abel first elaborated the concept of cognitive distortions in an attempt to elucidate the cognitive world of child molesters. Abel described cognitive distortions as inner processes (e.g., justifications, perceptions, or judgments) used by child molesters to rationalize child molestation and protect themselves against the negative feelings that committing such destructive acts usually produce in most individuals (Abel, Gore, Holland, Camp, Becker, \& Rathner, 1989). Ward and Keenan (1999) have identified five implicit theories that child molesters commonly possess. Implicit theories are akin to beliefs, and are believed to underlie cognitive distortions. Although their account of child molesters' core misconceptions is probably not comprehensive, it provides a glance into how child molesters might possibly be thinking. The first theory pertains to children: children as sexual objects. Child 
molesters conceptualize children as sexually driven objects who actively seek out and covertly desire and enjoy sex. From this, child molesters assume that any sexual relationships with an adult will serve to fulfill children's inner sexual strivings. Children are thought to possess the ability to know and assert what is best for them, much as an adult would, even though sexual matters are still well beyond their mental grasp. The second theory pertains to the act itself: nature of harm. Child molesters believe that sexual abuse is unlikely to harm a child, and if it does, it can always be worse. Essentially though, sex with a child is seen as beneficial to the child. Any impending harms are due to society's inaccurate perception of sex with children. The third theory pertains to child molesters themselves: entitlement. Entitlement refers to the belief that some humans are intrinsically inferior to other superior humans like themselves, and that it is a privilege for them to submit. The fourth and fifth theories pertain to the world at large:

uncontrollability and dangerous world. Child molesters believe that there is no use fighting what cannot be controlled. The sexual abuse of a child is unavoidable. Child molesters attribute the causes of their behavior to external factors like supernatural forces, the victim, past sexual abuse, stress, alcohol or drugs. Child molesters also construe the world as laden with hazards, which can lead to two conceptualizations of children: a) children are threatening and must be put back in their place, or b) children act as shields from the adversities of the adult world and provide a sense of comfort and security, perhaps even belonging and acceptance.

Ward and Keenan (1999) suggest that child molesters may hold a few or many of these implicit theories, but that they are typically not "consciously articulated and facilitate the processing of offense-related information" (p. 835). That is, they are 
cognitions that service other cognitive processes. Although these core fallacies were merely the product of theoretical conjecture aimed at explaining child molesters' most distorted cognitions, the existence of the five implicit theories has been evidenced by research. Interviewing a group of child molesters, Marziano, Ward, Beech and Pattison (2006) recently provided preliminary empirical support for Ward and Keenan's quintipartite model of pedophilic cognitions.

\section{Attitudes and Behavior}

Given that the project at hand addresses attitudes toward CSA, a definition of this particular construct is therefore in order. Attitudes can be likened to evaluations, be they of people, objects or otherwise. Some attitudes are explicit, whereas others are implicit. Implicit attitudes are one of many varieties of implicit cognitions, which are defined as representations of past experiences that configure forming experiences and alter behavior. Unlike explicit attitudes, implicit attitudes are not available through introspection (Greenwald \& Banaji, 1995). Attitudes, be they implicit or explicit, may influence behavior. According to Fazio's (2001) Motivation and Opportunity as Determinants (MODE) model, motivation and opportunity to think about a previously evaluated object determine behavior toward that object. For an attitude to guide behavior, its owner must be motivated to think about the target of the behavior and have an opportunity to do so. Attitudes can still influence behavior if these prerequisites are not met; however, the attitude must be highly accessible (i.e., in awareness and not buried deep in cognition).

The question of whether attitudes can predict behavior assumes that the former always precede the latter. However, in some instances, attitude formation follows behavior. During the course of relieving cognitive dissonance that may have arisen, new cognitions 
or attitudes are created (Aronson, 2000). Molesting a child may challenge the perpetrator's perception of himself as nothing short of a good person. Although changing the dissonant behavior sounds like the most obvious solution, it may not be. Attempting to stop molesting children would involve admitting that one is a bad person (or at the very least did a bad thing). Other solutions include: changing the dissonant cognition (e.g., molesting children is not bad, but good), or adding new cognitions (e.g., children enjoy being touched that way). Once a set of reparative cognitive actions have been implemented, mentalistic equilibrium is achieved, dissonance is relieved, and the previously dissonant, but still destructive behavior is left unchanged. For this very reason do researchers in the area of attitudes caution against cause-and-effect conclusions in the typically correlational study of attitudes (see Mihailides, Devilly, \& Ward, 2004). Ward and Siegert (2002) best express the problem: “[...] Dysfunctional implicit theories (cognitive distortions) may predispose an individual to offend, a stable dynamic risk factor. Another offender might only display distorted thinking when seeking to excuse his reprehensible behavior" (p. 330).

Having illustrated the bi-directional relation between attitudes and behavior, it should also be noted that some attitudes and behaviors intuitively thought to be related to each other are sometimes truly not related. Although Mann et al. (2007) demonstrated that child molesters at higher risk of molesting children again endorsed more CSA-supportive beliefs than child molesters at lower risk of doing so, other research suggests that no such association actually exists. In their meta-analysis of the predictors of sexual recidivism, Hanson and Morton-Bourgon's (2004) findings refuted the widely accepted existence of a link between attitudes supportive of CSA and the likelihood of sexually abusing 
children in the future. That is not to say that child molesters do not endorse more attitudes supportive of child molestation than non-sexual offenders. Although variations in child molester attitudes may still account for past criminal behavior, such attitudes may neither be necessary nor sufficient to bring individuals who have already perpetrated CSA at anytime in the past to once again commit such acts in the very near or distant future. Still, Hanson and Morton-Bourgon's survey of the literature did not include the measure used by Mann et al., or any measures of implicit attitudes, thus limiting their conclusions. Further investigation into the issue is therefore warranted, as there may still exist a link between explicit and implicit attitudes toward CSA and risk of sexual recidivism.

\section{Explicit and Implicit Attitude Assessment}

The world of attitude assessment is commonly divided into two realms: that of explicit and implicit measures, named after the two different types of attitudes. Explicit measures, such as self-report questionnaires, are adequate for measuring explicit attitudes, because explicit measures call for introspection and explicit attitudes are introspectively accessible. To measure implicit attitudes, however, implicit measures are required, because implicit attitudes are not introspectively accessible and implicit measures do not call for introspection (Greenwald \& Banaji, 1995). Both means of attitude assessment are often depicted as psychometric rivals, with implicit measures typically thought to tap into constructs explicit measures cannot possibly assess. Rather, both means of assessment are complementary. To elaborate, implicit and explicit measures can together draw and consolidate different types of information from whichever one attitudinal construct is being assessed (i.e., its explicit or implicit elements; Greenwald \& Farnham, 2000; Hofmann, Gawronski, Gschwendner, Le, \& Schmitt, 2005; Nosek \& Smyth, 2007). 
Contrary to popular belief, implicit measures can, together with explicit measures, forge a new era of attitude assessment, where both can provide information that the other cannot, ultimately producing a more comprehensive assessment of attitudes. As far as attitudes toward sexual behaviors are concerned, there is reason to believe that explicit and implicit measures designed to assess such cognitions are indeed related (Jellison, McConnell, \& Gabriel, 2004).

Presently, attitudes are most often assessed using self-report measures (Olson \& Zanna, 1994). Some examples of self-report measures used to assess attitudes toward CSA include the MOLEST scale (Bumby, 1996), the Sex with Children (SWCH) scale (Mann et al., 2007), and the Hanson Sex Attitude questionnaire (HSAQ; Hanson et al., 1994). On average, child molesters report more deviant attitudes on self-report measures than do non-offenders (Bumby, 1996; Hanson et al., 1994; Mann et al., 2007). As mentioned previously, self-report measures seek to tap into particular phenomenological experiences of interest and do so through introspection. However, relevant information may not be accessible, because self-knowledge has been suppressed or is not wellformed. Self-knowledge may also be edited, censored or deliberately feigned (Nosek, Greenwald \& Banaji, 2007). Although one may attempt to safe-proof the completion of self-report measures against deception using the Balanced Inventory of Deceptive Responding (BIDR; Paulhus, 1984), the utility of self-report measures remains limited in that they remain susceptible to deceptive motives. Editing, censoring and feigning selfknowledge are often motivated by the desire to be perceived in a socially desirable fashion (Ward, Hudson, Johnston, \& Marshall, 1997). This process is known as selfpresentation (Schlenker \& Pontari, 2000). If outgoing information emanating from the 
self can be intentionally misreported, less biased means of assessing attitudes toward sensitive matters like CSA are therefore required. Indirect means of assessment that do not call for introspection have paved the way toward less biased assessments. The most prominent of these measures is the IAT.

\section{The Implicit Association Test}

Administered on a computer, the IAT involves the categorization of stimulus words into categories. Two categories characterize concepts and two categories characterize attributes. Participants must assign a series of words that appear on screen to one of the latter four categories, by pressing one of two keys on a computer keyboard. During one critical block of trials, one concept and one attribute are indicated by one key, whereas the other concept and attribute are indicated by another key. During a second critical block of trials, the concept-attribute combinations are reversed. The time required to assign stimulus words to their respective category depends on the extent to which a concept and an attribute that share one key are cognitively associated. A participant with a strong association between a concept and an attribute will experience greater ease in assigning stimulus words to their respective category than someone with a weak association, when the concept and attribute share the same response key.

The IAT was first conceived by Greenwald et al. (1998). During the course of three seminal experiments, Greenwald et al. sought to empirically evaluate the cognitive associations from which attitudes stem, through the use of their newly developed measure. Experiment 1 demonstrated that participants displayed positive or negative implicit attitudes toward objects typically viewed as such (flowers, insects, musical instruments and weapons). Experiment 2 demonstrated that participants from two 
populations with a history of political animosity exhibited different implicit attitudes toward one another. Experiment 3 demonstrated that Caucasian participants exhibited different implicit attitudes toward their in-group than toward African Americans.

Researchers have replicated Greenwald et al.'s study time and time again, adapting the IAT to measure a wide gamut of attitudes, from attitudes toward the self (e.g., selfesteem: Grumm \& Collani, 2007), to attitudes toward others (e.g., group attitudes: Nosek, Banaji, \& Greenwald, 2002) and various other topics (e.g., consumer brands: Maison, Greenwald, \& Bruin, 2004; tobacco and marijuana: Czyzewska \& Ginsburg, 2007; alcohol: De Houwer, Crombez, Koster, \& De Beul, 2004; phobic objects: Teachman \& Woody, 2003; and violence: Snowden, Gray, Smith, Morris, \& MacChulloch, 2004). Cognitive Foundations of the Implicit Association Test

The IAT is able to bypass conscious awareness directly into the non-conscious realm so as to effectively render an assessment of cognition that is less tainted by conscious motives than in self-report measures. We here distinguish between the unconscious and the non-conscious mind. The unconscious refers to the consciously inaccessible realm of the psyche (discredited home of repressed experiences, primeval urges and the like) as first laid out by Sigmund Freud (1923/1990). The unconscious is relatively inaccessible, although psychoanalytic proponents of hypnosis regard it as an effective, backhanded means of sleuthing about the underworld of our compartmentalized, yet ever so dynamic psyche. The non-conscious, on the other hand, refers to the modern depiction of the mind's engine room, as recently laid out by cognitive scientists.

The theoretical foundations upon which the IAT bases itself lie within the area of cognitive psychology, namely how information is organized in and accessed from 
memory. The classic conceptualization of memory is that of a three-store system (Atkinson \& Shiffrin, 1968), where external stimuli are first impressed upon sensory memory, shortly thereafter carried into short-term memory for temporary access, and eventually stored into long-term memory for eventual retrieval. If and once information reaches this final storage unit, it is duly organized. Theorists have proposed many models to decipher the brain's filing system, the most influential being Collins and Loftus' (1975) spreading activation model. According to it, information is organized in memory into a complex web of interconnected nodes. Much like dropping a pebble in still water will produce a ripple effect, activating one concept will propel ripples of activation around it. Every concept swept over by the neural ripples will subsequently be activated and rendered more available to conscious awareness. While completing the IAT, the time required to assign stimulus words to their respective categories depends upon the extent to which the categories that share one key are cognitively associated in memory.

Insights into cognitive psychology offer a glimpse into the IAT's inner-workings, and do so at a fundamental level of processing. However, the processes that influence performance on the IAT may be explored from a more phenomenological, experiential perspective as well. According to Mierke and Klauer's (2001; as cited in Fazio \& Olson, 2003) task switching account, the concept category is receded into non-awareness when it is compatible with the attribute category to facilitate the assignment of stimuli to either side of the screen. In the compatible condition, the participant may solely focus on the attribute category, because every word that comes up on screen (even if it properly belongs to the concept category) also belongs to the attribute category. When the pairs are reversed and the attribute category is no longer compatible with the concept category, 
participants can no longer solely focus on the attribute category. Their attention is split, as it should have been in the compatible condition (only to a lesser extent). However, the fact that participants disregard the instructions to assign words to their respective category does not affect the outcome of the IAT. In fact, knowing when it is that participants can disregard the instructions (i.e., knowing when the attributive category "cancels out" the subordinate concept category) indicates which association is stronger. (For additional accounts of the IAT's inner-workings, see Brendl, Markman, \& Messner, 2001; De Houwer, 2001; and Rothermund \& Wentura, 2001.)

\section{Implicit Assessments of Attitudes in Child Molesters}

As outlined previously, Ward and Keenan (1999) proposed five implicit theories commonly endorsed by child molesters: children as sexual objects, nature of harm, entitlement, uncontrollability and dangerous world. Interviews with child molesters revealed information that supported the existence of explicit elements to the five theories (Marziano, Ward, Beech \& Pattison, 2006). To date, studies employing the IAT have provided empirical evidence for the existence of implicit elements to the following four theories: children as sexual objects, entitlement, uncontrollability and dangerous world.

Children as sexual objects. Mihailides et al. (2004) measured the strength of association between the concepts of children versus not children and the attributes of sexual versus not sexual. In accordance with the researchers' expectations, child molesters experienced greater ease in assigning stimulus words to their respective category when children and sexual shared the same response key, than when not children and sexual shared the same response key. Gray, Brown, MacCulloch, Smith, and Snowdon (2005), and Nunes, Firestone, and Baldwin (2007) further demonstrated that 
child molesters tend to perceive children as sexual objects.

Entitlement. Mihailides et al. (2004) measured the strength of association between the concepts of mine versus not mine and the attributes of sexual versus not sexual. In accordance with the researchers' expectations, child molesters experienced greater ease in assigning stimulus words to their respective category when mine and sexual shared the same response key, than when not mine and sexual shared the same response key. Conversely, Nunes et al. (2007) found that both child molesters and non-sex offenders both perceived themselves as more powerful than others, and children as less powerful than adults, suggesting that feelings of entitlement may not necessarily pertain to child molesters exclusively, but to offenders in general.

Uncontrollability. Mihailides et al. (2004) measured the strength of association between the concepts of losing control versus not about control and the attributes of sexual versus not sexual. In accordance with the researchers' expectations, child molesters experienced greater ease in assigning stimulus words to their respective category when losing control and sexual shared the same response key, than when not about control and sexual shared the same response key.

Dangerous world. To those who perceive the world as a dangerous place laden with hazards, comfort and safety may be found in the company of children, who may be construed as shields against the adversities of the adult world. Although their findings did not reach significance, Nunes et al. (2007) found that child molesters perceived children as more pleasant than adults, thus providing preliminary support for the dangerous world theory. 


\section{Purpose of study}

To date, studies employing the IAT to assess cognitions in child molesters have focused on attitudes toward sex in general (i.e., sex as uncontrollable and entitled) as well as those toward children specifically (i.e., children as pleasant, attractive or sexual). However, no study has yet sought to investigate child molesters' attitudes toward the problematic act itself. That is, how do child molesters evaluate CSA? It makes intuitive sense to suggest that each one of Ward and Keenan's (1999) five implicit theories rests upon or follows from the more general postulate that sex with children is essentially good. In other words, the general implicit theory that CSA is good encompasses all five implicit theories, and represents the common thread that unites them all. If Ward and Keenan correctly mapped the most pervasive thought patterns of child molesters, child molesters should theoretically implicitly endorse CSA. In keeping with this assumption, the proposed study will seek to gauge child molesters' evaluation of CSA. Essentially, is sex with children good or bad? In order to determine whether child molesters view CSA positively or negatively, the proposed study assessed implicit attitudes toward CSA using an adapted version of the IAT. Specifically, the strength of association between the concepts of sex with adult versus sex with child and the attributes of good versus bad was assessed in a group of child molesters and a comparison group of non-sex offenders.

As mentioned previously, a relation between explicit and implicit attitudes toward non-criminal types of sexual behaviors has already been identified (Jellison et al., 2004). Given that neither of the three previous IAT studies on implicit child molester attitudes (i.e., Gray et al., 2005; Mihailides et al., 2004; Nunes et al., 2007) included an explicit measure of attitudes toward CSA in their test batteries, it was also deemed relevant to 
assess, in addition to attitudinal differences between child molesters and non-sex offenders, the relation between implicit attitudes toward CSA and their explicit variant. Moreover, it was considered important to determine whether variations in both implicit and explicit attitudes toward CSA were related to risk of sexual recidivism. Of the three aforementioned studies, only Nunes et al. (2007) recorded the estimated likelihood of reoffending of their participants. Although Hanson and Morton-Bourgon (2004) did not find an association between attitudes toward child molestation and likelihood of reoffending in their meta-analysis of predictors of sexual recidivism, two studies did find that the two factors were related: Nunes et al. found a link between implicit attitudes toward children and risk of sexual recidivism, whereas Mann et al. (2007) found a link between explicit attitudes toward CSA specifically and risk of sexual recidivism.

\section{Hypotheses}

Based upon the purpose of study, four main hypotheses were formulated. The four proposed hypotheses go as follow. First, child molesters were expected to display more positive attitudes toward CSA than non-sex offenders on the Attitudes toward CSA IAT (Hypothesis 1). Second, child molesters were expected to report more deviant attitudes toward CSA than non-sex offenders on a selected explicit measure of attitudes toward CSA (Hypothesis 2). Third, participants' performance on the Attitudes toward CSA IAT was expected to be related to their performance on the explicit measure of attitudes toward CSA (Hypothesis 3). Fourth and finally, child molesters' performance on both the implicit and explicit measures of attitudes toward CSA was expected to be related to their risk of sexual recidivism (Hypothesis 4). 


\section{Method}

\section{Participants}

An optimal sample size of 64 participants was calculated using $\mathrm{G}^{*}$ Power (Faul, Erdfelder, Lang, \& Buchner, 2007). The following three factors were taken into account, using values considered standard by Tabachnick and Fidell (2007): the anticipated size of the effect (i.e., medium; $r=.30$ ), the desired alpha level (.05), and the desired power (.80). The final participant pool ultimately comprised a total of 55 convicted offenders incarcerated in five federal penitentiaries located in the province of Ontario. Offenders were assigned to one of two groups based upon the nature of their index offence (i.e., the most recent conviction on their criminal record). The main group comprised 34 offenders who had been convicted of a sexual index offence against children under the age of 12 . The second group comprised 21 offenders who had been convicted of committing a nonsexual index offence of either violent or non-violent nature; participants who had ever been convicted of committing any variety of sexual offence were excluded from the nonsex offender group. This particular comparison group was selected in place of a nonoffending, community control to ensure that any differences in performance found between the two groups were in fact linked to the specific tendency to molest children, as opposed to general criminality. Some participants serving a sentence for one or more sexual offences against children had, at the time of testing, received treatment from either the institution that assigned them to their home institution and/or their home institution itself. However, efforts were taken to assess participants who had received minimal treatment, by assessing them soon after the commencement of their current sentence. Specifically, $44.1 \%$ of the child molesters that participated in the current study had 
received or were currently receiving some kind of treatment targeting sex offending during their most recent sentence. Fifty-one percent of all offenders who were approached to participate in the study ultimately consented to do so. (For offender and offence characteristics, see Table 3.)

\section{Materials}

The Attitudes toward CSA IAT. The novel IAT included four categories. The two conceptual categories characterized the concept of sexual activities with adults or children, and included: sex with adult and sex with child. The two attributive categories characterized the value attributed to these sexual activities, and included: good and bad. Let it be noted that judging an act to be essentially good or bad may be determined by factors beyond one's conception of morality, such as anticipated positive and negative consequences. The Attitudes toward CSA IAT was modeled after the procedural design outlined by Nosek et al. (2007; see Figure 1). To elaborate, the complete IAT procedure is divided into five individual steps. Steps 3 and 5 combine the conceptual and attributive categories, and are critical to the assessment of the cognitive associations between these categories. The following description of the Attitudes toward CSA IAT therefore focuses on these two steps, otherwise known as the combined and reversed-combined tasks.

During these two tasks, both conceptual categories (sex with adult, sex with child) were displayed in upper-case letters on either sides of the upper-screen. Both attributive categories (good, bad) were displayed in lower-case letters on either sides of the upperscreen, directly below the conceptual categories. A randomized series of conceptual words, presented in upper-case letters, and attributive words, presented in lower-case letters, appeared in the center of the screen (see Table 4). Participants assigned the 
Table 3

Offender and Offence Characteristics

Characteristics

Child Molesters

Non-Sex Offenders

(34)

(21)

Age (in years) ${ }^{1}$

$M=49.65(S D=12.23)$

$M=39.74(S D=13.15)$

Ethnicity

White

Black

$91.2 \%(31)$

$2.9 \%(1)$

$2.9 \%(1)$

$2.9 \%(1)$

$90.5 \%(19)$

$0 \%(0)$

Asian

North-American

Indian

$4.8(1)$

$4.8(1)$

Education $^{1}$

$<$ or = to Grade 6

$6.5 \%(2)$

$0 \%$

Grade 7 - 13

$64.5 \%(22)$

$70.6 \%(15)$

Post-secondary

$29 \%(10)$

Marital Status ${ }^{2}$

Single

$26.5 \%(9)$

$33.3 \%(7)$

$23.5 \%(8)$

$19 \%(4)$

$14.7 \%(5)$

$19 \%(4)$

Common law

$17.6 \%(6)$

$19 \%(4)$

from wife

Separated from

$14.7 \%(5)$

$9.5 \%(2)$

common law wife

Widower

$2.9 \%(1)$

$0 \%(0)$

Number of victims in index sex

$M=3.5(S D=3.13)$

N/A

offence

Time since most recent sex

$M=9.48(S D=8.80)$

N/A

offence (in years)

Gender of victims in index sex

offence

At least one male

$58.8 \%$

N/A

Relation to victims in index

sex offence

At least one unrelated

$79.4 \%$

N/A

\footnotetext{
${ }^{1}$ At time of testing

${ }^{2}$ At time of offence
} 


\begin{tabular}{|c|c|c|c|c|c|c|c|c|}
\hline \multicolumn{3}{|c|}{$\begin{array}{c}\text { Step I* } \\
\text { Concepts } \\
\text { (Practice only }-20 \text { trials) }\end{array}$} & \multicolumn{3}{|c|}{$\begin{array}{c}\text { Step 2 } \\
\text { Attributes } \\
\text { (Practice only }-20 \text { trials) }\end{array}$} & \multicolumn{3}{|c|}{$\begin{array}{c}\text { Step } 3^{* *} \\
\text { Combined task } \\
\text { (Practice }-20 \text { trials }) \\
(\text { Test }-40 \text { trials })\end{array}$} \\
\hline $\begin{array}{c}\text { SEX } \\
\text { WITH } \\
\text { ADULT }\end{array}$ & & $\begin{array}{l}\text { SEX } \\
\text { WITH } \\
\text { CHILD }\end{array}$ & Good & & $\mathrm{Bad}$ & $\begin{array}{c}\text { SEX } \\
\text { WITH } \\
\text { ADULT } \\
- \\
\text { Good }\end{array}$ & & $\begin{array}{c}\text { SEX } \\
\text { WITH } \\
\text { CHILD } \\
- \\
\text { Bad }\end{array}$ \\
\hline $\begin{array}{l}\bullet \\
\bullet \\
\bullet\end{array}$ & $\begin{array}{c}\text { MAN } \\
\text { UNDERAGE } \\
\text { MARRIAGE } \\
\text { ILLEGAL } \\
\text { WOMAN } \\
\text { CHILD }\end{array}$ & • & - & $\begin{array}{c}\text { smile } \\
\text { poison } \\
\text { sunshine } \\
\text { sickness } \\
\text { paradise } \\
\text { cancer }\end{array}$ & • & • & $\begin{array}{c}\text { smile } \\
\text { MAN } \\
\text { poison } \\
\text { UNDERAGE } \\
\text { sunshine } \\
\text { MARRIAGE }\end{array}$ & $\stackrel{\bullet}{\bullet}$ \\
\hline
\end{tabular}

\begin{tabular}{|c|c|c|c|c|c|}
\hline \multicolumn{3}{|c|}{$\begin{array}{c}\text { Step } 4^{* * *} \\
\text { Reversed concepts task } \\
(\text { Practice only }-40 \text { trials })\end{array}$} & \multicolumn{3}{|c|}{$\begin{array}{c}\text { Step } 5 * * * * \\
\text { Reversed-combined task } \\
\text { (Practice }-20 \text { trials }) \\
(\text { Test }-40 \text { trials })\end{array}$} \\
\hline $\begin{array}{c}\text { SEX } \\
\text { WITH } \\
\text { CHILD }\end{array}$ & & $\begin{array}{c}\text { SEX } \\
\text { WITH } \\
\text { ADULT }\end{array}$ & $\begin{array}{c}\text { SEX } \\
\text { WITH } \\
\text { CHILD } \\
- \\
\text { Good } \\
\end{array}$ & & $\begin{array}{c}\text { SEX } \\
\text { WITH } \\
\text { ADULT } \\
- \\
\text { Bad } \\
\end{array}$ \\
\hline • & $\begin{array}{c}\text { MAN } \\
\text { UNDERAGE } \\
\text { MARRIAGE } \\
\text { ILLEGAL } \\
\text { WOMAN } \\
\text { CHILD }\end{array}$ & • & • & $\begin{array}{l}\text { sunshine } \\
\text { MAN } \\
\text { cancer } \\
\text { ILLEGAL } \\
\text { paradise } \\
\text { MARRIAGE }\end{array}$ & $\bullet$ \\
\hline \multicolumn{3}{|c|}{ *** Counterbalanced with Step 1} & \multicolumn{3}{|c|}{$* * * *$ Counterbalanced with Step 3} \\
\hline
\end{tabular}

Figure 1. Illustration of the Attitudes toward CSA IAT using stimuli designed to measure participants' attitudes toward sex with children relative to with adults. Counterbalancing is concurrent (i.e., Steps 1 and 4 are reversed alongside Steps 3 and 5). For Steps 1 and 4 , whichever step is presented first always includes 20 trials, and whichever step is presented second always includes 40 trials. 
Table 4

Stimulus Words Representing the Four Categories of: Sex with Adult, Sex with Child, Good and Bad

\begin{tabular}{|c|c|c|c|c|}
\hline \multirow{2}{*}{$\begin{array}{c}\text { Item } \\
\#\end{array}$} & \multicolumn{2}{|c|}{ Conceptual Categories } & \multicolumn{2}{|c|}{ Attributive Categories } \\
\hline & $\begin{array}{l}\text { SEX WITH } \\
\text { ADULT }\end{array}$ & $\begin{array}{l}\text { SEX WITH } \\
\text { CHILD }\end{array}$ & Good & Bad \\
\hline $\begin{array}{l}1 . \\
2 . \\
3 . \\
4 . \\
5 .\end{array}$ & $\begin{array}{c}\text { MAN } \\
\text { WOMAN } \\
\text { MARRIAGE } \\
\text { WIFE } \\
\text { HUSBAND }\end{array}$ & $\begin{array}{c}\text { UNDERAGE } \\
\text { UNDEVELOPED } \\
\text { CHILD } \\
\text { ILLEGAL } \\
\text { MOLEST }\end{array}$ & $\begin{array}{l}\text { smile } \\
\text { sunshine } \\
\text { paradise } \\
\text { peace } \\
\text { happy }\end{array}$ & $\begin{array}{l}\text { poison } \\
\text { sickness } \\
\text { cancer } \\
\text { pollution } \\
\text { poor }\end{array}$ \\
\hline
\end{tabular}


stimulus words to one of the four categories (sex with adult, sex with child, good, and bad). Prior to beginning the Attitudes toward CSA IAT, participants were instructed to position their left index finger on the $d$ key and their right index finger on the $k$ key. One concept and one attribute were indicated by one key, whereas the other concept and attribute were indicated by another key. Participants assigned the stimulus words to their respective category by pressing the $d$ key to direct them to the left, and by pressing the $k$ key to direct them to the right.

During the combined task, sex with adult and good were indicated by the $d$ key, whereas sex with child and bad were indicated by the $k$ key. During the reversedcombined task, the conceptual categories' positions were reversed, whereas the attributive categories' positions remained unchanged. This resulted in two new combinations: sex with child and good were now indicated by the $d$ key, and sex with $a d u l t$ and bad were now indicated by the $k$ key. Response speed during the combined and reversed-combined tasks is expected to depend upon the extent to which a concept and an attribute that share one key are associated in participants' memory. A participant with a positive view of child molestation should therefore experience greater ease in assigning stimulus words to their respective category when sex with child and good share the same response key (see Figure 2b), as compared to when sex with child and bad share the same response key (see Figure 2a). Conversely, someone with a negative view of child molestation should experience greater interference in the former condition, and lesser interference in the latter. Participants' performance on the Attitudes toward CSA IAT was subsequently converted to $D$ measures for statistical purposes (see Results section). Developing the Attitudes toward CSA IAT. A group of child molesters and non-sex 

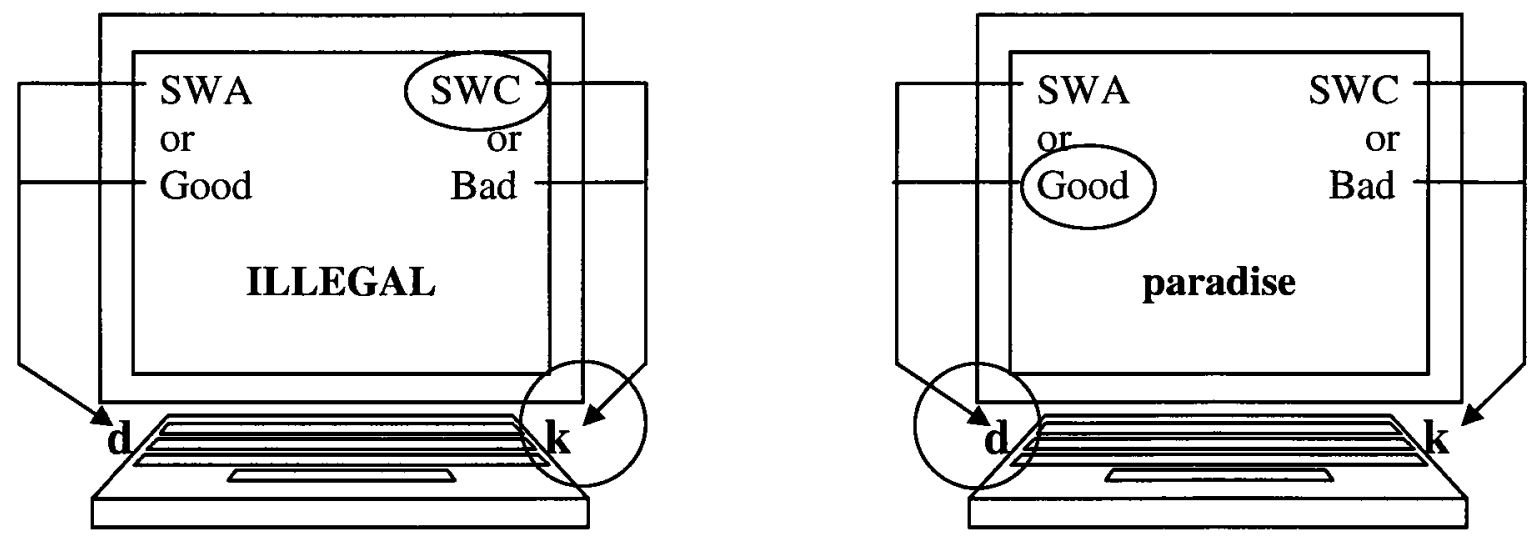

Figure 2a. Example of a combined trial from the Attitudes toward CSA IAT. In these trials, SEX WITH ADULT and "Good" are both indicated by the same key $(d)$ and SEX WITH CHILD and "Bad" are both indicated by the same key $(k)$
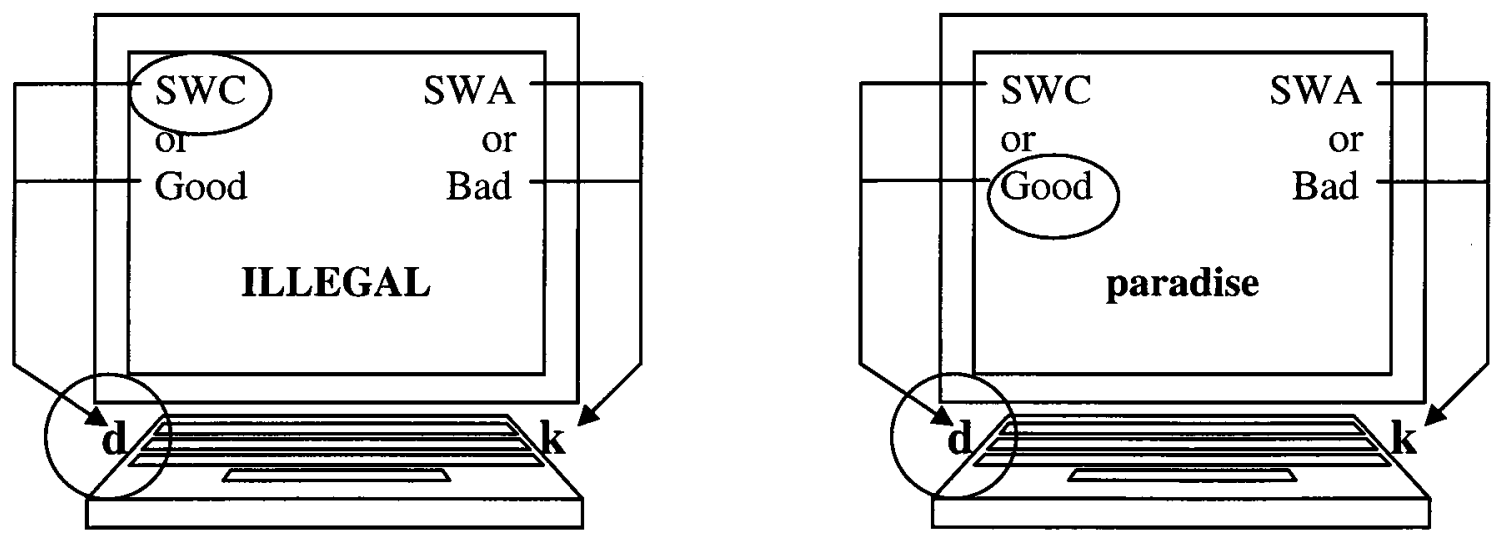

Figure $2 b$. Example of a reversed-combined trial from the Attitudes toward CSA IAT. In these trials, SEX WITH CHILD and "Good" are both indicated by the same key $(d)$ and SEX WITH ADULT and "Bad" are both indicated by the same key $(k)$ 
offenders were surveyed to help develop the novel IAT. The selection of appropriate stimulus words was of chief concern. After all, participants' "primary task in the IAT is to identify the category membership of stimulus items as quickly as possible" (Nosek et al., 2007, p. 269), and so each stimulus item should clearly belong to its respective category. In keeping with this criterion, preliminary semi-structured interviews were conducted with 13 child molesters and three non-sex offenders to determine which words best represented the categories of sex with adult, sex with child, good, and bad (see Appendixes A and B for consent form and interview questions). A second group of 45 sex offenders against children and/or adults was subsequently presented with the words generated during the preliminary interviews. Additional words were conceived through brainstorming and borrowed from the literature (e.g., Gray et al., 2005; Nunes et al., 2007). Participants were asked to rate the words according to their category membership (see Appendixes $\mathrm{C}$ and $\mathrm{D}$ for consent form and rating scales). The words that were most consistently rated as belonging to their respective category were selected as the stimulus words (see Tables 5 and 6). Given that the number of stimulus words presented does not appear to have an impact on IAT effects (Study 2; Nosek, Greenwald \& Banaji, 2005), a total of 10 conceptual words and 10 attributive words were retained for usage in the actual procedure. Once the program was written, the Attitudes toward CSA IAT was pilot tested amongst a third group of two child molesters and three non-sex offenders (see Appendix E for consent form). Problems that mired the administration of the measure were remedied in preparation for the study proper.

The Sex with Children scale. The Sex with Children (SWCH) scale (Mann et al., 2007) is a self-report measure designed to assess beliefs that justify sexual contact 
Table 5

Frequencies of Stimulus Words Selected as Representing the Categories of: Sex with Adult and Sex with Child

\begin{tabular}{clcc}
\hline Item \# & \multicolumn{1}{c}{ Words } & SEX WITH ADULT & SEX WITH CHILD \\
\hline 1. & MAN & $100 \%$ & $0 \%$ \\
2. & WOMAN & $100 \%$ & $0 \%$ \\
3. & MARRIAGE & $100 \%$ & $0 \%$ \\
4. & WIFE & $100 \%$ & $0 \%$ \\
5. & HUSBAND & $100 \%$ & $0 \%$ \\
6. & UNDERAGE & $2.8 \%$ & $97.2 \%$ \\
7. & UNDEVELOPED & $0 \%$ & $100 \%$ \\
8. & CHILD & $2.9 \%$ & $97.1 \%$ \\
9. & ILLEGAL & $2.8 \%$ & $97.2 \%$ \\
10. & MOLEST & $3 \%$ & $97 \%$ \\
\hline
\end{tabular}

Table 6

Frequencies of Stimulus Words Selected as Representing the Categories of: Good and Bad

\begin{tabular}{clcc}
\hline Item \# & \multicolumn{1}{c}{ Words } & Good & Bad \\
\hline 1. & smile & $100 \%$ & $0 \%$ \\
2. & sunshine & $100 \%$ & $0 \%$ \\
3. & paradise & $100 \%$ & $0 \%$ \\
4. & peace & $100 \%$ & $0 \%$ \\
5. & happy & $100 \%$ & $0 \%$ \\
6. & poison & $2.2 \%$ & $97.8 \%$ \\
7. & sickness & $2.2 \%$ & $97.8 \%$ \\
8. & cancer & $2.2 \%$ & $97.8 \%$ \\
9. & pollution & $2.2 \%$ & $97.8 \%$ \\
10. & poor & $0 \%$ & $100 \%$ \\
\hline
\end{tabular}


between adults and children (see Appendix F). The SWCH scale contains 18 items (e.g., Nowadays it is not so bad to have a sexual relationship with someone who is underage because kids know so much more about sex than they used to). Respondents must rate each item on a 4-point scale, from strongly disagree (0) to strongly agree (4). Scores range from 0 to 72 ; the higher a respondent's score, the more he endorses beliefs that justify sexual contact between adults and children. In a study by Mann et al., the scale was found to be structured around two factors, which the researchers dubbed Harmless Sex with Children and Provocative Sexual Children. To elaborate, the SWCH scale appears to tap into the construct of sex with children as harmless, and that of children as catalysts in their own abuse. Each of the two factors boasted strong ${ }^{3}$ internal consistency $(\alpha=.93$ and .87 , respectively). The entire scale boasted strong test-retest reliability ( $r=$ .93), and moderate concurrent validity with another self-report measure of cognitive distortions (Children and Sex Scale; $r=.63$ ). In addition, the entire SWCH scale boasted strong criterion validity, not only discriminating between child molesters and rapists, but between different groups of child molesters as well. To elaborate, child molesters endorsed more CSA supportive beliefs than rapists; in addition, extra-familial child molesters with male victims endorsed more CSA supportive beliefs than extra-familial child molesters with female victims and intra-familial child molesters. Testifying to the SWCH scale's predictive validity, child molesters at higher risk of molesting children again endorsed more CSA supportive beliefs than child molesters at lower risk of doing so.

The Balanced Inventory of Desirable Responding. The Balanced Inventory of

\footnotetext{
${ }^{3}$ Robinson, Shaver and Wrightsman's (1991) rating criteria will henceforth be used to evaluate measures' psychometric properties.
} 
Desirable Responding (BIDR; Paulhus, 1984) is a self-report measure designed to assess whether participants are prone to socially desirable responding (see Appendix G). The BIDR was selected to determine whether performance on the Attitudes toward CSA IAT and the SWCH scale was correlated with socially desirable responding. The BIDR includes 20 items measuring impression management (e.g., when I hear people talking privately, I avoid listening), and 20 items measuring self-deceptive enhancement (e.g., I always know why I like things). Respondents must rate each item on a 7-point scale, from not true (1) to very true (7). The higher a respondent's score, the more he tends to answer in a socially desirable fashion. Administering the BIDR to a sample of violent and sexual offenders, Kroner and Weeks (1996) found that the impression management scale and a modified version of the self-deceptive enhancement scale demonstrated strong ( $\alpha=$ $.84)$ to weak $(\alpha=.58)$ internal consistency, respectively.

Language proficiency and background information. To ensure that participants understood the instructions given to them, as well as the Attitudes toward CSA IAT categories and stimulus words, the Clarke Vocabulary Test (CVT) was selected (Paitich, 1977; see Appendix H). The CVT assesses reading comprehension, and includes 40 items. Participants are presented with a word, and must select from a list which word is most synonymous with it. The data of participants who scored less than 14 on the CVT were excluded from the analyses. A Background Questionnaire was also designed for this study to enquire about self-reported language proficiency, offence history and treatment completion (see Appendix I). Participants who answered yes to one of the questions regarding past non-consensual sexual encounters with adults and past sexual encounters with children were excluded from the non-sex offender group. 
Ancillary measures. It should be noted that the Attitudes toward CSA IAT, the SWCH scale, the BIDR, the CVT and the Background Questionnaire were administered within the context of a larger study. In addition to the aforementioned measures, the study also included the following measures of sexual interest: a Sexual Attraction to Children IAT, the Sexual Interest Profiling System (SIPS; Laws, Hanson, Osborn, \& Greenbaum, 2000) and a viewing time measure designed for the study.

Coding manual. The experimenter reviewed and coded participants' criminal files to collect information on their index sex offences, prior sex offences, and treatment history, among other factors (see Appendix J). The coding manual was specifically designed for this study, and modeled partly after a Correctional Service of Canada File Review Manual (Motiuk \& Porporino, 1993). Child molesters' scores on the following two measures of risk of sexual recidivism were also recorded.

The Static-99. The Static-99 (Hanson \& Thornton, 2000) is a file-review based actuarial risk assessment instrument designed to assess static risk factors for sexual recidivism (see Appendix $\mathrm{M}$ ). Static factors are historical in nature, and do not change over time. The Static-99 gathers information on the following risk factors: prior sex offences, prior sentencing dates, convictions for non-contact sex offences, prior and current instances of non-sexual violence, unrelated and stranger victims, male victims, age, and marital status. The total score is obtained by adding up the scores from the individual risk factors. Individuals with a score of 0 or 1 are considered at low risk for sexual recidivism; individuals with a score of 2 or 3 are considered at medium-low risk; individuals with a score of 4 or 5 are considered at medium-high risk; finally, individuals with a score of 6 and above are considered at high risk. In a meta-analysis by Hanson and 
Morton-Bourgon (2007), the Static-99 moderately predicted sexual recidivism (Mean $d .=$ .70). In a study by Langton, Barbaree, Hanson, Harkins, and Peacock (2007), the Static99 also demonstrated strong test-retest reliability $(r=.88)$. Both the Static-99 scores obtained during the intake assessment at the reception unit and during the most recent assessment at the home institution were recorded. Dates of assessment ranged from January 2003 to June 2008.

The Stable-2007. The Stable-2007 (Hanson, Harris, Scott, \& Helmus, 2007) is an interview and file-review based actuarial risk assessment instrument designed to assess stable dynamic risk factors for sexual recidivism (see Appendix M). Dynamic factors change over time, and can be altered through treatment. Dynamic factors that are stable change only slowly (as opposed to acute dynamic factors, which can change rapidly). The Stable-2007 gathers information on the following stable dynamic factors: significant social influences, capacity for relationship stability, emotional identification with children, hostility toward women, general social rejection, lack of concerns for others, impulsivity, poor problem solving skills, negative emotionality, preoccupation with sex, resorting to sex as a coping strategy, deviant sexual preference and interests, and cooperation with supervision. The total score is obtained by adding up the scores from the individual risk factors. Individuals with a score between 0 and 3 are considered at low risk for sexual recidivism; individuals with a score between 4 and 11 are considered at moderate risk; finally, individuals with a score between 12 and 26 are considered at high risk. In a study by Hanson et al., the Stable- 2007 moderately predicted sexual recidivism (area under the curve $(A U C)$ of the receiver operating characteristic $(R O C)=.67)$, and its previous version, the Stable-2000, boasted strong test-retest reliability (intra-class 
correlation $(I C C)=.89)$. Both the Stable-2007 scores obtained during the intake assessment at the reception unit and during the most recent assessment at the home institution were recorded. If a participant's risk of sexual recidivism was assessed using both the Stable-2007 and its 2000 predecessor, both scores were recorded. If a participant's risk of sexual recidivism was only assessed using the Stable-2000, only its scores were recorded. Assessment dates for the Stable-2000 ranged from January 2003 to July 2007; assessment dates for the Stable-2007 ranged from January 2008 to June 2008.

\section{Procedure}

Once the participant presented himself, the experimenter broadly explained to him the purpose of the experiment and described how the study would proceed. The participant was verbally informed of his rights, and asked to read and sign a consent form if he wished to participate (Appendix E). The experimenter subsequently positioned the laptop computer in front of the participant, and sat opposite him as he completed all of the measures. Prior to initiating the first sequence of measures, the experimenter instructed the participant to inform him/her once he was finished, so that he/she may initiate the second sequence of measures.

All measures were administered on a DELL laptop computer using E-Prime (Psychology Software Tools, 2008). The measures were presented in one sequence of three blocks, and a second sequence of two blocks (see Figure 3). Given that these two sequences were composed of two different software files, the first sequence was followed by a short interruption, during which the experimenter initiated the second sequence. Although evidence suggests that the order in which implicit and explicit measures are completed does not affect performance on these measures (Hofmann et al., 2005), those 


\begin{tabular}{|c|c|c|c|c|}
\hline Sequences & Blocks & Measures & $\begin{array}{l}\text { Within-Block } \\
\text { Order }\end{array}$ & $\begin{array}{l}\text { Within-Sequence } \\
\text { Order }\end{array}$ \\
\hline \multirow[t]{10}{*}{1} & Block 1 & $\begin{array}{l}\text { - Atritudes } \\
\text { toward Child } \\
\text { Sexual Abuse } \\
\text { IAT }\end{array}$ & \multirow[t]{2}{*}{ Counterbalanced } & \multirow[t]{6}{*}{ Counterbalanced } \\
\hline & & $\begin{array}{l}\text { - Sexual } \\
\text { Attraction to } \\
\text { Children IAT }\end{array}$ & & \\
\hline & Block 2 & $\begin{array}{l}\text { Evaluation of } \\
\text { Child Sexual } \\
\text { Abuse Scale }\end{array}$ & \multirow[t]{4}{*}{ Counterbalanced } & \\
\hline & & - Hanson Sex & & \\
\hline & & $\begin{array}{l}\text { Attitudes } \\
\text { Questionnaire }\end{array}$ & & \\
\hline & & $\begin{array}{l}\text { - Sex with } \\
\text { Children Scale }\end{array}$ & & \\
\hline & Block 3 & $\begin{array}{l}\text { - Balanced } \\
\text { Inventory of } \\
\text { Desirable } \\
\text { Responding } \\
\end{array}$ & \multirow[t]{4}{*}{ Counterbalanced } & \multirow[t]{4}{*}{ Sequential } \\
\hline & & - Sexual & & \\
\hline & & $\begin{array}{l}\text { Experiences } \\
\text { Survey }\end{array}$ & & \\
\hline & & $\begin{array}{l}\text { - Background } \\
\text { Questionnaire }\end{array}$ & & \\
\hline \multirow[t]{5}{*}{2} & Block 4 & - Clarke & Sequential & \multirow[t]{5}{*}{ Sequential } \\
\hline & & Vocabulary Test & & \\
\hline & Block 5 & - Sexual Interest & \multirow[t]{3}{*}{ Counterbalanced } & \\
\hline & & Profiling System & & \\
\hline & & - Viewing Time & & \\
\hline
\end{tabular}

Figure 3. Complete study of which the current project was a part. Measures specifically relevant to the present project are shaded 
measures considered (at least intuitively) likely to succumb to the influence of practice and/or carry-over effects were counterbalanced.

Once the participant had completed the second sequence of measures, a series of debriefing statements appeared on screen. The participant was finally thanked for his participation and duly dismissed. Generally, participation lasted approximately one to one hour and a half. The experimenter subsequently retrieved the participant's criminal file from the institution's records department, and proceeded to reviewing and coding the file according to the guidelines outlined in the Coding Manual (Appendix J). 


\section{Results}

Hypotheses. Four main hypotheses were proposed. First, child molesters were expected to display more positive attitudes toward CSA than non-sex offenders on the Attitudes toward CSA IAT (Hypothesis 1). Second, child molesters were expected to report more deviant attitudes toward CSA than non-sex offenders on the SWCH scale (Hypothesis 2). Third, child molesters' and non-sex offenders' performance on the Attitudes toward CSA IAT was expected to be positively correlated with their performance on the SWCH scale (Hypothesis 3). Finally, child molesters' performance on both the Attitudes toward CSA IAT and the SWCH scale was expected to be positively correlated with their risk of sexual recidivism (Hypothesis 4).

Diagnostics. The first two hypotheses were evaluated via analyses of variance, whereas the last two hypotheses were evaluated via correlational analyses. To review, analyses of variance entail two testable assumptions (homogeneous variances and normally distributed data), whereas correlational analyses entail three testable assumptions (normally distributed data, linearity and homoscedasticity). Homogeneity of variances was assessed using Levene's Test of Equality of Error Variances. Concerning normality, any detected outliers were brought within normal range by reducing or increasing them to the next highest or lowest value, respectively; this, while maintaining rank order. In addition, appropriate transformations were attempted to normalize the data if skewness and/or kurtosis were deemed non-normal. For purposes of parsimony, only violations of these assumptions and the statistical remedies implemented will henceforth be described.

Offender and offence characteristics. Amongst the child molesters and the non-sex 
offenders, four offender characteristics were recorded: age, ethnicity, education, and marital status. The child molesters proved significantly older than the non-sex offenders, $\mathrm{F}(1,53)=8.05, p=.01$, Partial $\eta^{2}=.13$; moreover, both the Attitudes toward CSA IAT and the SWCH scale were significantly correlated with age (see Table 7). Based upon the percentages obtained, most participants from both groups were of Caucasian descent, had completed a grade between 7 and 13 at the time of testing, and were single at the time of the offence (see Table 3). Amongst the child molesters, four offence characteristics were recorded: the number of victims in the index sex offence, the time since the most recent sex offence, the gender of the victims in the index sex offence, and the relation of the offender to the victims in the index sex offence. Of the two continuous offence characteristics, the Attitudes toward CSA IAT was only significantly correlated with the number of victims in the index sex offence (see Table 7).

Internal consistency. In order to assess whether the different components (i.e., blocks or items) comprising each of the selected measures produced similar scores when administered to the current sample, correlations between these components were examined. To establish the internal consistency of the Attitudes toward CSA IAT, the difference between participants' average Block 3 and 6 scores and the difference between their average Block 7 and 4 scores was first computed; subsequently, each of the two difference scores were divided by their respective pooled standard deviation. The resulting quotients were found to be significantly correlated with each other $(r=.65, p=$ .00 ). Likewise, the internal consistencies for the CVT (Cronbach's $\alpha=.81$ ), the BIDR (Cronbach's $\alpha=.84$ ), the Impression Management Subscale (Cronbach's $\alpha=.82$ ), the Self-Deception subscale (Cronbach's $\alpha=.64$ ), the SWCH (Cronbach's $\alpha=.98$ ), the 
Table 7

Correlations between Offender and Offence Characteristics and the Two Measures of Attitudes toward CSA

\section{CSA IAT SWCH Factor 1 SWCH Factor 2 SWCH Total}

\begin{tabular}{lcccc}
\hline Age & $\begin{array}{c}-.28^{*} \\
(\mathrm{p}=.04)\end{array}$ & $\begin{array}{c}.36^{*} \\
(\mathrm{p}=.01)\end{array}$ & $\begin{array}{c}.42^{*} \\
(\mathrm{p}=.00)\end{array}$ & $\begin{array}{c}.40^{*} \\
(\mathrm{p}=.00)\end{array}$ \\
$\begin{array}{l}\text { Number of } \\
\text { victims in index } \\
\text { offence }\end{array}$ & $\begin{array}{c}-.47^{*} \\
(p=.00)\end{array}$ & $\begin{array}{c}-.24 \\
(p=.17)\end{array}$ & $\begin{array}{c}-.27 \\
(p=.12)\end{array}$ & $\begin{array}{c}-.28 \\
(p=.12)\end{array}$ \\
$\begin{array}{l}\text { Time since most } \\
\text { recent sex (in } \\
\text { years })\end{array}$ & $\begin{array}{c}-.21 \\
(\mathrm{p}=.23)\end{array}$ & $\begin{array}{c}-.20 \\
(\mathrm{p}=.26)\end{array}$ & $\begin{array}{c}-.02 \\
(\mathrm{p}=.93)\end{array}$ & $\begin{array}{c}-.12 \\
(\mathrm{p}=.51)\end{array}$ \\
\hline
\end{tabular}

Note. The first variable applies to both child molesters and non-sex offenders $(N=55)$, whereas the last two variables only apply to child molesters $(n=34)$ 
Factor 1 subscale (Cronbach's $\alpha=.93$ ), and the Factor 2 subscale (Cronbach's $\alpha=0.96$ ) proved satisfactory. ${ }^{4}$

Language proficiency. The CVT was administered to ensure that participants understood the Attitudes toward CSA IAT categories and stimulus words, as well as the SWCH items. Child molesters' and non-sex offenders' CVT scores were not significantly different in their language proficiency, $F(1,53)=.00, p=.97$, Partial $\eta^{2}=.00$ (see Table 8). However, participants' scores on the CVT were significantly correlated with their scores on the Attitudes toward CSA IAT (see Table 9), suggesting that language proficiency might have affected performance on the implicit measure. Conversely, participants' scores on the CVT were not significantly correlated with their scores on the SWCH scale, indicating that language proficiency did not affect performance on the explicit measure.

Socially desirable responding. The BIDR was used to determine whether performance on the Attitudes toward CSA IAT and the SWCH scale were affected by socially desirable responding. Child molesters' and non-sex offenders' BIDR' scores were not significantly different, BIDR Total: $F(1,53)=.11, p=.75$, Partial $\eta^{2}=.00$, Impression Management: $F(1,53)=.75, p=.39$, Partial $\eta^{2}=.01$, Self-Deception: $F(1,53)=4.04, p=.05$, Partial $\eta^{2}=.07$ (see Table 8). In addition, participants' scores on the BIDR were not significantly correlated with their scores on the Attitudes toward CSA IAT and the SWCH scale (see Table 9), suggesting that performance on these measures was not swayed by the potentially confounding influence of inter- and intra-personal processes, such as impression management and self-deception.

Implicit attitudes toward CSA. According to the first hypothesis, child molesters were

\footnotetext{
${ }^{4}$ Robinson, Shaver, and Wrightsman (1991) describe coefficient $\alpha$ 's of .80 or higher as exemplary.
} 
Table 8

Child Molesters' and Non-Sex Offenders' Scores on the CVT and the BIDR

\begin{tabular}{|c|c|c|c|c|c|c|c|}
\hline & \multicolumn{2}{|c|}{$\begin{array}{c}\text { Child molesters } \\
\text { (34) }\end{array}$} & \multicolumn{2}{|c|}{$\begin{array}{c}\text { NS Offenders } \\
(21)\end{array}$} & \multirow[t]{2}{*}{$\begin{array}{c}\text { Cohen's } \\
\quad d\end{array}$} & \multirow[t]{2}{*}{$\begin{array}{c}\text { Lower } \\
\text { CI }\end{array}$} & \multirow[t]{2}{*}{$\begin{array}{c}\text { Upper } \\
\text { CI }\end{array}$} \\
\hline & $M$ & $S D$ & $\bar{M}$ & $S D$ & & & \\
\hline CVT & 29.53 & 5.31 & 29.48 & 4.94 & .01 & -.53 & .55 \\
\hline $\begin{array}{l}\text { BIDR } \\
\text { Impression } \\
\text { Management }\end{array}$ & 7.03 & 3.97 & 6.00 & 4.74 & .24 & -.31 & .78 \\
\hline $\begin{array}{l}\text { BIDR } \\
\text { Self- } \\
\text { Deception }\end{array}$ & 6.38 & 2.75 & 8.10 & 3.53 & .56 & .01 & 1.11 \\
\hline BIDR Total & 13.41 & 5.83 & 14.00 & 7.41 & .09 & -.45 & .64 \\
\hline
\end{tabular}

Note. A confidence level of $95 \%$ was selected for all confidence intervals 
Table 9

Correlations between the CVT, the BIDR and the Two Measures of Attitudes toward CSA

\begin{tabular}{lcccc}
\hline & CSA IAT & SWCH Factor 1 & SWCH Factor 2 & SWCH Total \\
\hline CVT & $-.29^{*}$ & -.01 & -.06 & -.04 \\
& $(\mathrm{p}=.03)$ & $(\mathrm{p}=.94)$ & $(\mathrm{p}=.64)$ & $(\mathrm{p}=.76)$ \\
BIDR & .01 & .01 & .09 & .04 \\
Impression & $(p=.94)$ & $(p=.97)$ & $(p=.52)$ & $(p=.78)$ \\
Management & & & -.16 & -.12 \\
BIDR & .19 & $(p=.56)$ & $(p=.24)$ & $(p=.39)$ \\
Self-Deception & $(p=.16)$ & -.04 & -.02 & -.03 \\
BIDR Total & .10 & $(p=.79)$ & $(p=.89)$ & $(p=.81)$ \\
& $(p=.48)$ & & & \\
\hline
\end{tabular}

$N=55$ 
expected to display more positive attitudes toward CSA than non-sex offenders on the Attitudes toward CSA IAT. To evaluate this hypothesis, participants' reaction times on the Attitudes toward CSA IAT were converted to $D$ measures. $D$ measures are obtained by computing the difference between the mean response times during the combined (sex with adult and good) and reversed-combined (sex with child and good) tasks, and by dividing this difference by the standard deviation of all the individual response times during the two tasks. To reiterate, higher $D$ measures indicate a more positive attitude toward sex with children, whereas lower $D$ measures indicate a more negative attitude toward sex with children. The $D$ measure has been found to outperform other IAT scoring algorithms (Greenwald et al., 2003).

Prior to running the main analysis, the potentially confounding effect of presentation order (i.e., whether participants got the sex with child and good or sex with adult and good blocks first) on participants' performance was examined. To this end, a 2 (Group: child molesters, non-sex offenders) x 2 (Order: sex with child and good first, sex with adult and good first) Factorial ANOVA was conducted. Neither the order main effect, $F(1,51)=1.14, p=.29$, Partial $\eta^{2}=.02$, or the group by order interaction, $F(1,51)=.52$, $p=.47$, Partial $\eta^{2}=.01$, were significant. ${ }^{5}$ Given that performance on the Attitudes toward CSA IAT was unaffected by presentation order, the group main effect was subsequently examined. Contrary to expectations, child molesters' $D$ measures were not significantly different from those of non-sex offenders, $F(1,51)=.26, p=.61$, Partial $\eta^{2}$ $=.01$, signifying that the Attitudes toward CSA IAT did not detect any attitudinal differences between child molesters and non-sex offenders (see Table 10).

\footnotetext{
${ }^{5}$ Cohen (1988) defined effect sizes approximating $.2, .5$ and .8 as small, medium and large, respectively.
} 
Table 10

Child Molesters' and Non-Sex Offenders' Scores on the Attitudes toward CSA IAT and the SWCH Scale

\begin{tabular}{|c|c|c|c|c|c|c|c|}
\hline & \multicolumn{2}{|c|}{$\begin{array}{c}\text { Child molesters } \\
\text { (34) }\end{array}$} & \multicolumn{2}{|c|}{$\begin{array}{c}\text { NS Offenders } \\
(21)\end{array}$} & \multirow[t]{2}{*}{$\begin{array}{c}\text { Cohen's } \\
d\end{array}$} & \multirow[t]{2}{*}{$\begin{array}{c}\text { Lower } \\
\text { CI }\end{array}$} & \multirow[t]{2}{*}{$\begin{array}{c}\text { Upper } \\
\text { CI }\end{array}$} \\
\hline & $\bar{M}$ & $S D$ & $M$ & $S D$ & & & \\
\hline CSA IAT & -.76 & .32 & -.73 & .42 & .08 & -.46 & .63 \\
\hline $\begin{array}{l}\text { SCWH F1: } \\
\text { Sex with } \\
\text { children } \\
\text { harmless }\end{array}$ & 3.91 & 5.76 & .43 & .98 & .76 & -.20 & 1.32 \\
\hline $\begin{array}{l}\text { SCWH F2: } \\
\text { Children } \\
\text { responsible } \\
\text { for abuse }\end{array}$ & 2.76 & 3.43 & .24 & .62 & .92 & -.35 & 1.49 \\
\hline SWCH Total & 6.65 & 8.87 & .48 & 1.12 & .88 & -.31 & 1.45 \\
\hline
\end{tabular}


In an attempt to shed light on this rather unexpected finding, potential confounding variables were identified. Amongst the continuous offender and offence characteristics and the administered measures, three potential confounding variables were identified: age, the number of victims in the index offence, and CVT scores. Each of the three variables significantly correlated with the dependent variable (see Table 11). Given that age was the only variable that resulted in an actual group difference, and that it significantly correlated with number of victims in the index offence and CVT scores, only it was retained as a covariate. However, no variation in significance or effect size was produced when age was inputted as a single covariate into an ANCOVA comparing child molesters and non-sex offenders, $F(1,52)=.19, p=.67$, Partial $\eta^{2}=.00$. (ANCOVA assumptions were verified and deemed satisfied).

Given that no differences were found between the main and comparison groups, further a posteriori analyses were conducted to determine if differences would arise within the child molester group itself. According to the literature, child molesters who target underage males and unrelated children are considered especially at risk of recommitting sexual offences against children. As such, their attitudes toward CSA should, theoretically, be well-engrained. The gender of victims and the relation of offenders to the victims were recorded during file reviews. Child molesters were first divided into the following two subgroups: those who have ever offended against at least one male victim $(M=-.83, S D=.28, n=20)$ and those who have only offended against female victims in either their index or prior sex offences $(M=-.69, S D=.32, n=14)$. A One-Way ANOVA comparing the two subgroups was run, yet no significant difference was found, $F(1,32)=2.00, p=.17$, Cohen's $d=-.47$ (CI: $-1.16-.22$ ), Partial $\eta^{2}=.06$. 
Table 11

Correlations between Potential Covariates

\begin{tabular}{|c|c|c|c|}
\hline & Age & $\begin{array}{l}\text { Number of victims in } \\
\text { most recent offence }\end{array}$ & CVT \\
\hline $\begin{array}{l}\text { Age } \\
\text { Number of victims in } \\
\text { most recent offence }\end{array}$ & & $\begin{array}{c}.36^{*} \\
(p=.03)\end{array}$ & $\begin{array}{c}.27^{*} \\
(\mathrm{p}=.046) \\
.22 \\
(\mathrm{p}=.21)\end{array}$ \\
\hline CVT & & & \\
\hline
\end{tabular}

Note. The first and third variables apply to both child molesters and non-sex offenders ( $N$ $=55)$, whereas the second variable only applies to child molesters $(n=34)$ 
Second, child molesters were divided into the following two subgroups: those who have ever offended against at least one unrelated victim $(M=-.76, S D=.28, n=27)$, and those who have only offended against related victims $(M=-.75, S D=.40, n=7)$. A One-Way ANOVA comparing the two subgroups was run; likewise, no significant difference was found, $F(1,32)=.01, p=.93$, Cohen's $d=.03\left(\mathrm{CI}:-.80-.86\right.$ ), Partial $\eta^{2}=.00$. Whether participants had received treatment was recorded during file reviews and a One-Way ANOVA comparing child molesters who had received treatment $(M=-.70, S D=.32, n=$ $15)$ and those who had not $(M=-.82, S D=.31, n=19)$ was run; no significant difference was found, $F(1,32)=1.27, p=.27$, Cohen's $d=.38$ (CI: -.30-1.06), Partial $\eta^{2}=.04$, indicating that whether child molesters received treatment or not did not alter the results. Self-reported attitudes toward CSA. According to the second hypothesis, child molesters were expected to report more deviant attitudes toward CSA than non-sex offenders on the SWCH scale. To evaluate this hypothesis, participants' scores on the SWCH scale were examined via a One-Way ANOVA. Outliers were detected and brought within range. Scores were also found to be positively skewed. Although several transformations were attempted, none successfully normalized the data; analyses were thus conducted with the untransformed data. As expected, child molesters reported significantly more deviant attitudes toward CSA than non-sex offenders on the SWCH scale total scores, $F(1,53)=9.99, p=.00$, Partial $\eta^{2}=.16$. Delving deeper into the specific features of those attitudes, child molesters also scored significantly higher on the SWCH scale's two subscales, Factor $1, F(1,53)=7.48, p=.01$, Partial $\eta^{2}=.12$, and Factor 2, $F(1,53)=11.09, p=.00$, Partial $\eta^{2}=.17$, implying that child molesters believe sex with children to be a harmless act and/or that children are responsible for their own 
abuse to a greater extent than their non-sex offender counterparts (see Table 9). Given that child molesters and non-sex offenders significantly differed in terms of age and that scores on the SWCH scale were significantly correlated with age, an ANCOVA was run utilizing age as a covariate. Entering age as a covariate did not alter significance or effect size, $F(1,52)=5.09, p=.03$, Partial $\eta^{2}=.09$; although the Factor 2 findings remained significant, $F(1,52)=5.84, p=.02$, Partial $\eta^{2}=.10$, the Factor 1 findings only bordered on significance, $F(1,52)=3.63, p=.06$, Partial $\eta^{2}=.07$. (ANCOVA assumptions were verified and deemed satisfied).

Relation between implicit and explicit attitudes toward CSA. According to the third hypothesis, child molesters' and non-sex offenders' performance on the Attitudes toward CSA IAT was expected to be positively correlated with their performance on the SWCH scale. To evaluate this hypothesis, child molesters' and non-sex offenders' $D$ measures on the Attitudes toward CSA IAT were correlated with their scores on the SWCH scale. Contrary to expectations, participants' performance on the Attitudes toward CSA IAT was not significantly correlated with their scores on the SWCH scale or either of its two factors, indicating that implicit and explicit attitudes toward CSA do not, at least necessarily, simply mirror themselves at different levels of cognition (see Table 12).

Relation between attitudes toward CSA and risk of sexual recidivism. According to the fourth and final hypothesis, child molesters' performance on the Attitudes toward CSA IAT and their scores on the SWCH scale were expected to be positively correlated with their estimated risk of sexual recidivism (Hypothesis 4). To evaluate this hypothesis, child molesters' $D$ measures on the Attitudes toward CSA IAT, in addition to their scores on the SWCH scale, were correlated with their Static-99 scores and Stable-2007 scores. 
Table 12

Correlations between the Implicit and Explicit Measures of Attitudes toward CSA

CSA IAT SWCH Factor 1 SWCH Factor 2 SWCH Total

CSA IAT

$$
\begin{gathered}
-.16 \\
(p=.25)
\end{gathered}
$$$$
\begin{gathered}
-.12 \\
(p=.40)
\end{gathered}
$$$$
-.15
$$$$
(p=.28)
$$

SWCH Factor 1

$\begin{array}{cc}.87^{*} & .98^{*} \\ (p=.00) & (p=.00)\end{array}$

SWCH Factor 2

$$
\begin{gathered}
.94^{*} \\
(p=.00)
\end{gathered}
$$

\section{SWCH Total}

$N=55$ 
For purposes of parsimony, participants' total scores on the Static-99 and the Stable-2007 were combined into one risk score (according to rules outlined by Hanson et al., 2007). If a participant's risk of sexual recidivism was only assessed using the Stable-2000, then its score was factored into the final combined total recidivism score in place of the Stable2007 score. It was found that the majority of child molesters in the sample were considered to be at moderate-low risk of recidivism (see Table 13). Despite the fair range in risk scores, child molesters' performance on the Attitudes toward CSA IAT and their scores on the SWCH scale were not significantly correlated with their risk scores (see Table 14), suggesting that attitudes toward CSA are not necessarily related to risk of sexual recidivism. Further a posteriori analyses were conducted to determine if either measure significantly correlated with the attitudes supportive of CSA item of the Stable2000 (if the most recent scores were not available, initial assessment scores were used instead); only the SWCH scale's Factor 2 subscale was correlated with the item, providing further support for the explicit measure's construct validity (see Table 14). 
Table 13

Child Molesters' Combined Static/Stable Ratings

\begin{tabular}{lc}
\hline Combined Static/Stable & Child Molesters \\
Rating & $(23)$ \\
\hline Low & $13 \%$ \\
& $(3)$ \\
Moderate-Low & $30.4 \%$ \\
& $(7)$ \\
Moderate-High & $17.4 \%$ \\
& $(4)$ \\
High & $21.7 \%$ \\
& $(5)$ \\
Very High & $17.4 \%$ \\
\end{tabular}

Note. Recidivism risk data were not available for some child molesters 
Table 14

Correlations between the Combined Static/Stable Ratings, the Attitudes Supportive of CSA Item of the Stable-2000 and the Measures of Attitudes toward CSA

\section{CSA IAT SWCH Factor 1 SWCH Factor 2 SWCH Total}

\begin{tabular}{lcccc}
\hline $\begin{array}{l}\text { Combined } \\
\text { Static/Stable }\end{array}$ & $\begin{array}{l}.09 \\
\text { Rating }\end{array}$ & .10 & .17 & .12 \\
$\begin{array}{l}\text { Attitudes } \\
\text { Supportive of } \\
\text { CSA item of the } \\
\text { Stable-2000 }\end{array}$ & $(p=.70)$ & $(p=.67)$ & $(p=.45)$ & $. .58)$ \\
\hline
\end{tabular}

$n=23$ (for first variable)

$n=18$ (for second variable)

Note. Recidivism risk data were not available for some child molesters 


\section{Discussion}

Studies utilizing the IAT to assess cognitions in child molesters have to date focused on attitudes toward sex in general (i.e., sex as uncontrollable and entitled) as well as those toward children specifically (i.e., children as pleasant, attractive or sexual). However, no study has yet sought to investigate child molesters' attitudes toward the problematic act itself. Essentially, do child molesters consider sex with children to be good or bad? In an effort to determine whether child molesters view CSA from a positive or negative standpoint, the current study assessed a group of child molesters' implicit attitudes toward CSA using an adapted version of the IAT specially designed to measure these attitudes. Four main hypotheses were proposed. First, child molesters were expected to display more positive attitudes toward CSA than non-sex offenders on the Attitudes toward CSA IAT (Hypothesis 1). Contrary to expectations, no attitudinal differences between child molesters and non-sex offenders were detected. Second, child molesters were expected to report more deviant attitudes toward CSA than non-sex offenders on an explicit measure of attitudes toward CSA, the SWCH scale (Hypothesis 2). As expected, child molesters did report more pro-CSA attitudes than non-sex offenders. Delving deeper into the nature of these attitudes, it appeared that child molesters believed sex with children to be a harmless act and children to be responsible for their own abuse; this, to a greater extent than their non-sex offender counterparts. Third, child molesters' and nonsex offenders' performance on the Attitudes toward CSA IAT was expected to be positively correlated with their performance on the SWCH scale (Hypothesis 3). Contrary to expectations, the two measures of attitudes toward CSA were not related. Finally, child molesters' performance on both the Attitudes toward CSA IAT and the SWCH scale was 
expected to be positively correlated with their estimated risk of sexual recidivism (Hypothesis 4). Contrary to expectations, the two measures of attitudes toward CSA were not related to risk of sexual recidivism.

Regarding the first hypothesis, child molesters did not ultimately display more positive attitudes toward CSA than non-sex offenders on the Attitudes toward CSA IAT. As mentioned earlier, previous studies have attempted to evaluate child molesters' implicit attitudes toward a variety of domains, including children as sexual objects, entitlement, uncontrollability and dangerous world (Gray et al., 2005; Mihailides et al., 2004; Nunes, et al., 2007). However, no other study has yet to appraise child molesters' evaluation of child molestation itself. As such, there exist no empirical precedents against which to compare the present findings. Although no other study quite resembles the current one, other similar scientific ventures may help shed some light upon child molesters' evaluative tendencies. Prior research has successfully demonstrated that nondeviant sexual behaviors are viewed positively by those who engage in them, and negatively by those who do not. For example, Jellison et al. (2004) found that participants of different sexual orientations expressed more positive attitudes toward their own sexual orientation in-group, relative to that of the out-group. It is worth noting, however, that Jellison et al. only considered self-reported sexual orientation when forming its groups, whereas the present study considered actual behavior when assigning its participants. Still, it is within empirical bounds to expect that, similarly to non-deviant sexual behaviors, those who engage in deviant sexual behaviors should view them more positively than those who do not.

Alternatively, it remains possible that differences in attitudes toward deviant sexual 
activities are not as clear-cut as differences in attitudes toward non-deviant sexual activities amongst individuals who partake in said activities and those who do not. In their evaluation of the Abel and Becker Cognitions Scale and the Child Molester Scale, Tierney and McCabe (2001) reported that although differences between child molesters and non-sex offending controls were found, none were actually clinically significant. That is, differences, when found, only related to extent of agreement or disagreement, rather than actual direction. To elaborate, child molesters and controls both expressed negative attitudes toward CSA; however, child molesters simply expressed less negative attitudes than control participants. It is possible that Tierney and McCabe's findings regarding the Abel and Becker Cognitions Scale and the Child Molester Scale extend to the Attitudes toward CSA IAT as well. Indeed, child molesters and non-sex offenders both scored in the negative range on the implicit measure, suggesting that they both view (at least at an implicit level of cognition) child molestation in a negative light. If that is in fact the case, perhaps then the Attitudes toward CSA IAT was simply not able to capture the subtle, albeit very real attitudinal difference that might actually differentiate child molesters from non-sex offenders.

Regarding the second hypothesis, child molesters did ultimately report more deviant attitudes toward CSA than non-sex offenders on the SWCH scale. This finding corroborates that from Mann et al.'s (2007) original validation study, further substantiating the relatively novel measure. This result also stands in agreement with previous studies' conclusions on explicit measures of attitudes toward CSA. Evaluating a variety of self-report scales specifically designed to assess explicit attitudes toward CSA (the Abel and Becker Cognitions Scale, the Child Molester Scale, and the MOLEST 
scale), Bumby (1996), Hayashino et al. (1995), and Tierney and McCabe (2001) found that child molesters indeed possess more cognitive distortions than control groups, and that different types of child molesters possess different amounts of cognitive distortions. (It should be noted that, in some instances, although these findings were statistically significant, they may not have shown clinical significance). As such, the available literature appears to provide the hypothesis that child molesters entertain more deviant explicit attitudes toward CSA than individuals who have never sexually abused children with more support than its null counterpart. The findings from the original SWCH scale validation study, coupled with those from the current study, further support this hypothesis.

Regarding the third hypothesis, child molesters' and non-sex offenders' performance on the Attitudes toward CSA IAT was not ultimately positively correlated with their performance on the SWCH scale. Contrary to expectations, implicit and explicit attitudes toward CSA did not mirror each other. Although child molesters expressed more positive explicit attitudes toward CSA, their implicit evaluations of the act proved similar to those of non-sex offenders. In their examination of attitudes toward non-deviant sexual activities amongst participants of different sexual orientations, Jellison et al. (2004) observed that implicit and explicit measures of attitudes toward sexual orientation were in fact related. To elaborate, positive implicit attitudes toward the sexual orientation ingroup were associated with positive explicit attitudes toward the same group, and with negative explicit attitudes toward the sexual orientation out-group. As such, it would seem that, similarly to non-deviant sexual behaviors, those who partake in deviant sexual activities should express more positive implicit and explicit attitudes toward deviant 
sexual activities, and more negative explicit attitudes toward non-deviant sexual activities, relative to individuals who do not partake in deviant activities.

Regarding the fourth and final hypothesis, child molesters' performance on both the Attitudes toward CSA IAT and the SWCH scale was not ultimately positively correlated with their estimated risk of sexual recidivism. That is, neither level of attitude appeared to be related to participants' likelihood of reoffending. This finding stands at odds with that of Mann et al. (2007), who found that attitudes (at least explicit ones) toward CSA were related to risk of sexual recidivism. To elaborate, child molesters considered at higher risk of molesting children endorsed more CSA-supportive beliefs than child molesters at lower risk of doing so. In stark contrast to the present project, however, this particular study boasted a large sample size and greater variability in risk scores. Concerning implicit cognitions, Nunes et al. (2007) found a relation between implicit attitudes toward children and a measure of sexual recidivism risk. Whereas general antisocial attitudes and general recidivism are clearly correlated (Andrews \& Bonta, 2006), the relation between specific child molester attitudes and sexual recidivism remains to be substantiated. This ambiguous relation was, to some extent, reflected by the removal of the attitudes supportive of CSA item from the most recent revision of the Stable, an actuarial risk assessment instrument designed to measure dynamic risk factors for sexual recidivism (Hanson \& Morton-Bourgon, 2004; Hanson et al., 2007).

Although the current study treads new scientific grounds, its conclusions nevertheless bear some limitations. Some of these pertain to characteristics of the obtained sample. To elaborate, only $51 \%$ of all offenders who were approached to participate in the study ultimately consented to do so, rendering the final sample representative of only half of 
the population of interest. Complying with the experimenter's request, the end sample might have been a particularly pro-social one; however, the fact that child molesters demonstrated a fair range of risk scores on the recidivism scales serves to partially refute this possibility. Also, offenders who participated in the present study were mainly of Caucasian descent, were not engaged in a relationship at the time of the crime, and had only limited education at the time of testing. As a result, the two groups may have been too similar, which resulted in the Attitudes toward CSA IAT not being sensitive enough to detect a difference between them. As for the child molester group specifically, it was mainly composed of moderate-to-low risk individuals who had received treatment, and who had offended against at least one male and/or one unrelated victim; also, several years had passed since they committed their index offence. Perhaps a sample of high-risk, untreated child molesters who had only recently been incarcerated would have produced a more pronounced difference. Past or present treatment participation, however, did not seem to have any bearing on IAT scores in the present study. Another possibility is that the non-sex offender group was not a suitable control; evidence, however, suggests otherwise as these participants scored low on the SWCH scale. In addition, participants' language proficiency arose as a potential issue, as demonstrated by the correlation between the CVT and the Attitudes toward CSA IAT. This finding was particularly worrisome, as the IAT constitutes a vocabulary-based test; however, all participants made the CVT cut-off, confirming that all participants had at the very least a working knowledge of English. Although characteristics of the obtained sample may explain the current findings, it remains possible that group composition was simply not an issue at all. 
If external factors such as group composition cannot account for the findings, perhaps internal factors such as measurement issues are responsible. (1) First, the Attitudes toward CSA IAT was, as previously mentioned, specially designed for this study; as such, it is not a validated measure. It may be that the conceptual categories sex with child and sex with adult proved themselves too broad or generic, and that the conceptual stimulus words did not clearly belong to them. Nosek et al. (2007) observed that participants' "primary task in the IAT is to identify the category membership of stimulus items as quickly as possible" (p. 269), and so each stimulus item should clearly belong to its respective category. Perhaps the present study did not comply with this basic tenet of IAT construction. However, much attention was dedicated to the selection of appropriate stimulus words prior to the study proper. Still, participants may perceive words to clearly belong to their respective categories when filling out a questionnaire, but not when they have limited time to think. Yet, Jellison et al. (2004) successfully detected attitudinal differences amongst participants of different sexual orientations using the conceptual categories gay and straight and attributive categories positive and negative. (2) Second, to tap into the entire construct of attitudes toward CSA at all levels of cognition, the SWCH scale was selected as an explicit variant of the Attitudes toward CSA IAT to assess explicit attitudes toward CSA. However, both measures remain qualitatively different; the SWCH scale measures excuses and justifications, whereas the Attitudes toward CSA IAT measures evaluations. It may be that the tendency to make excuses and justifications is a relevant construct in the commission of CSA, whereas specific evaluations are not. (3) Third, perhaps the Attitudes toward CSA IAT is actually measuring a non-intended construct, or perhaps the construct that it is measuring (be it the intended one or another 
one) simply does not matter; that is, it may be that attitudes toward CSA do not distinguish between offenders who partake in CSA and those who do not.

Taking the aforementioned limitations into account, a number of interpretations of the current study's findings are possible. As stated previously, the world of attitude assessment is commonly divided into two realms: that of explicit and implicit measures. Explicit measures are adequate for measuring explicit attitudes. To measure implicit attitudes, however, implicit measures are required. Both means of assessment are complementary, in that both can provide unique information about individual's attitudes, ultimately producing a more comprehensive assessment of attitudes. As such it was assumed that both types of attitude should mirror each other. However, this hypothesis was not supported. Thus, it may be that everyone endorses negative explicit and implicit attitudes toward CSA. However, after one commits a crime, explicit (but not implicit) attitudes change; in other words, individuals who engage in CSA may justify the crime by changing their explicit attitudes to support CSA (Abel, Gore, Holland, Camp, Becker, \& Rathner, 1989; Gannon, Ward, \& Collie, 2007). This change may, however, occur only at a superficial level; thus, their implicit attitudes remain untouched, causing them to continue harboring negative implicit feelings toward CSA. If this argument is correct, one would find a positive relation between explicit and implicit attitudes toward CSA prior to a sexual assault against a child, and a negative one after the assault has already occurred. In an attempt to substantiate this proposition, correlations between the Attitudes toward CSA IAT and the SWCH scale within the child molester and non-sex offender groups were examined. If the latter claim is true, there should be a positive correlation between the explicit and implicit measures in the non-sex offender group (given that they have 
never sexual assaulted children) and a negative correlation within the child molester group. Contrary to what would have been predicted by this line of reasoning, no significant correlations were found within either group.

Although the current study did not ultimately support the existence of positive implicit attitudes toward CSA in child molesters, the IAT has proven successful at detecting attitudinal differences amongst different groups in the past, and as such holds promise as a means of examining child molester cognitions. In fact, the line of study that this particular project is a part of entails many empirical and practical implications. Further research is required to further substantiate and refine the IAT when used with forensic populations. Although this outcome lies in the very distant future and may even never come to fruition at all, the implicit measure may possibly be of use as a forensic assessment tool; that is, provided that it may be fine-tuned, and is one day deemed reliable and valid as an accurate indicator of offence-related cognitions. The potential utility of the IAT in forensic contexts might involve assessing associations that underlie theories commonly held by offenders charged with particular crimes at the beginning of a treatment specifically structured to target and reduce deviant attitudes. This initial assessment would serve to establish an attitudinal baseline. Progress would subsequently be monitored by measuring the current status of associations at different intervals during the treatment, in the hopes that the ties that bind certain categories together are eventually loosened. Should the IAT ever be adapted for such clinical usage, it could very well one day integrate forensic assessment batteries and stand side-by-side with today's most popular assessment methods. 


\section{References}

Abel, G. G., Gore, D. K., Holland, C. L., Camp, N., Becker, J. V., \& Rathner, J. (1989). The measurement of the cognitive distortions of child molesters. Annals of Sex Research, 2, 135-153.

American Psychiatric Association (2000). Diagnostic and Statistical Manual for Mental Disorders (4th ed., text revision). Washington, DC: American Psychiatric Association.

Andrews, D. A., \& Bonta, J. (2006). The psychology of criminal conduct $\left(4^{\text {th }} \mathrm{ed}.\right)$, Cincinnati, OH: Anderson.

Araki, G. (Director). (2004). Mysterious skin [Motion picture]. United States: Desperate Pictures.

Aronson, E. (2000). Cognitive Dissonance. In Encyclopedia of Psychology (Vol. 2, pp. 141-142). Washington, DC: American Psychological Association.

Atkinson, R. C., \& Shiffrin, R. M. (1968). Human memory: A proposed system and its control processes. In K. W. Spence \& J. T. Spence (Eds.), The psychology of learning and motivation (Vol. 2, pp. 89-195). Orlando, FL: Academic Press.

Brendl, C. M., Markman, A. B., \& Messner, C. (2001). How do indirect measures of evaluation work? Evaluating the inference of prejudice in the Implicit Association Test. Journal of Personality and Social Psychology, 81, 760-773.

Bumby, K. M. (1996). Assessing the cognitive distortions of child molesters and rapists: Development and validation of the MOLEST and RAPE scales. Sexual Abuse: A Journal of Research and Treatment, 8, 37-53.

Canadian Centre for Justice Statistics (2001). Family violence in Canada: A statistical 
profile (Catalogue number: 85-224-XIE). Ottawa, ON: National Clearinghouse on Family Violence.

Canadian Press, 2006. Whitmore had long list of victims in Ontario. Retrieved April, 25, 2008, from http://www.ctv.ca/servlet/ArticleNews/story/CTVNews/ 20060802/whitmore_profile_060802/20060802/.

Cohen, J. (1988). Statistical power analysis for the behavioral sciences (2nd ed.). Hillsdale, NJ: Lawrence Earlbaum Associates.

Collins, A. M., \& Loftus, E. F. (1975). A spreading activation theory of semantic processing. Psychological Review, 82, 85-88.

Czyzewska, M., \& Ginsburg, H. J. (2007). Explicit and implicit effects of anti-marijuana and anti-tobacco TV advertisements. Addictive Behaviors, 32, 114-127.

De Houwer, J. (2001). A structural and process analysis of the Implicit Association Test. Journal of Experimental Social Psychology, 37, 443-451.

De Houwer, J., Crombez, G., Koster, E. H. W., \& De Beul (2004). Implicit alcoholrelated cognitions in a clinical sample of heavy drinkers. Journal of Behavior Therapy and Experimental Psychiatry, 35, 275-286.

Department of Justice Canada. Criminal Code of Canada (R.S., 1985, c. C-46). Retrieved August 24, 2009, from http://laws.justice.gc.ca/en/C-46/.

Faul, F., Erdfelder, E., Lang, A.-G., \& Buchner, A. (2007). G*Power 3: A flexible statistical power analysis program for the social, behavioral, and biomedical sciences. Behavior Research Methods, 39, 175-191.

Fazio, R. H. (2001). On the automatic activation of associated evaluations: An overview. Cognition and Emotion, 15, 115-141. 
Fazio, R. H., \& Olson, M. A. (2003). Implicit measures in social cognition: Their meaning and use. Annual Review of Psychology, 54, 297-327.

Finkelhor, D., \& Araji, S. (1986). Explanations of pedophilia: A four factor model. The Journal of Sex Research, 22, 145-161.

Freud, S. (1990). The ego and the id (J. Strachey, Ed. \& Trans.). New York, NY: W. W. Norton \& Company. (Original work published 1923)

Gannon, T. A., Ward, T. \& Collie, R. (2007). Cognitive distortions in child molesters: Theoretical and research developments over the past two decades. Aggression and Violent Behavior, 12, 402-416.

Goldman, J. D. G., \& Padayashi, U. K. (2000). Some methodological problems in estimating incidence and prevalence in child sexual abuse research. The Journal of Sex Research, 37, 305-314.

Gray, N. S., Brown, A. S., MacCulloch, M. J., Smith, J., \& Snowden, R. J. (2005). An implicit test of associations between children and sex in pedophiles. Journal of Abnormal Psychology, 114, 304-308.

Greenwald, A. G., \& Banaji, M. R. (1995). Implicit social cognition: attitudes, selfesteem and stereotypes. Psychological Review, 102, 4-27.

Greenwald, A. G., \& Farnham, S. D. (2000). Using the Implicit Association Test to measure self-esteem and self-concept. Journal of Personality and Social Psychology, 79, 1022-1038.

Greenwald, A. G., McGhee, D. E., \& Schwartz, J. L. K. (1998). Measuring individual differences in implicit cognition: The Implicit Association Test. Journal of Personality and Social Psychology, 74, 1464-1480. 
Greenwald, A. G., Nosek, B. A., \& Banaji, M. R. (2003). Understanding and using the Implicit Association Test: I. An improved scoring algorithm. Journal of Personality and Social Psychology, 85, 197-216.

Groth, A. N., \& Burgess, A. W. (1977). Motivational intent in the sexual assault of children. Criminal Justice and Behavior, 4, 253-263.

Groth, A. N., Hobson, W. F., \& Gary, T. S. (1982). The child molester: Clinical observations. Journal of Social Work and Human Sexuality, 1, 129-144.

Grumm, M., \& Gollani, G. V. (2007). Measuring big-five personality dimensions with the implicit association test -- Implicit personality traits or self-esteem? Personality and Individual Differences, 43, 2205-2217.

Hall, G. C. N., \& Hirschman, R. (1991). Toward a theory of sexual aggression: A quadripartite model. Journal of Consulting and Clinical Psychology, 59, 662669.

Hall, G. C. N., \& Hirschman, R. (1992). Sexual aggression against children: A conceptual perspective of etiology. Criminal Justice and Behavior, 19, 8-23.

Hanson, K. R., Gizzarelli, R., \& Scott, H. (1994). The attitudes of incest offenders: Sexual entitlement and acceptance of sex with children. Criminal Justice and Behavior, 21, 187-202.

Hanson, K. R., Harris, A. J. R., Scott, T.-L., \& Helmus, L. (2007). Assessing the risk of sexual offenders on community supervision: The Dynamic Supervision Project. Ottawa, Ontario, Canada: Ministry of Public Safety and Emergency Preparedness Canada.

Hanson, K. R., \& Morton-Bourgon, K. (2004). Predictors of sexual recidivism: An 
updated meta-analysis. Ottawa, Ontario, Canada: Ministry of Public Safety and Emergency Preparedness Canada.

Hanson, R. K., \& Morton-Bourgon, K. (2007). The accuracy of recidivism risk assessments for sexual offenders: A meta-analysis. Ottawa: Public Safety and Emergency Preparedness Canada.

Hanson, K. R., \& Thornton, D. (2000). Improving risk assessments for sex offenders: A comparison of three actuarial scales. Law and Human Behavior, 24, 119-136.

Hayashino, D. S., Wurtele, S. K., \& Klebe, K. J. (1995). Child Molesters: An examination of cognitive factors. Journal of Interpersonal Violence, 10, 106-116.

Hofmann, W., Gawronski, B., Gschwendner, T., Le, H., \& Schmitt, M. (2005). A meta analysis on the correlation between the Implicit Association Test explicit selfreport measures. Personality and Social Psychology Bulletin, 31, 1369-1385.

Humphreys, A., Hanes, A., Brean, J., Rook, K., Vallis, M., \& Blackwell, T. (2007, October 20). Predators among us. National Post. Retrieved October 20, 2007, from http://network.nationalpost.com/np/blogs.

Jarecki, A. (Director). (2004). Capturing the Friedmans [Motion picture]. United States: HBO Documentary.

Jellison, W. A., McConnell, A. R., \& Gabriel S. (2004). Implicit and explicit measures of sexual orientation attitudes: Ingroup preferences and related behaviors and beliefs among gay and straight men. Personality and Social Psychology Bulletin, 30, $629-642$.

Kalmus, E., \& Beech, A. R. (2003). Forensic assessment of sexual interest. Aggression and Violent Behavior, 10, 193-217. 
Keller, L. (Producer). (2004) Dateline's To Catch a Predator [Television Broadcast]. United States: National Broadcasting Company.

Koss, M.P. \& Gidycz, C.A. (1985). Sexual Experiences Survey: Reliability and validity. Journal of Consulting and Clinical Psychology, 53, 422-423.

Koss, M.P. \& Oros, C.J. (1982). Sexual Experiences Survey: A research instrument investigating sexual aggression and victimization. Journal of Consulting and Clinical Psychology, 50, 455-457.

Langton, C. M., Barbaree, H. E., Hanson, K. T., Harkins, L., \& Peacock, E. J. (2007). Reliability and validity of the Static-2002 among adult sexual offenders with reference to treatment status. Criminal Justice and Behavior, 34, 616-640.

Laws, D. R., Hanson, R. K., Osborn, C. A., \& Greenbaum, P. E. (2000). Classification of child molesters by plethysmographic assessment of sexual arousal and a selfreport measure of sexual preference. Journal of Interpersonal Violence, 15, 12971312.

Lerner, A.J., \& Loewe, F. (1996). Gigi [CD]. United States: Rhino Records.

MacFarlane, S. (Creator). (1999). Family guy [Television series]. United States: $20^{\text {th }}$ Century Fox Television.

Maison, D., Greenwald, A. G., \& Bruin, R. H. (2004). Predictive validity of the Implicit Association Test in studies of brands, consumer attitudes and behavior. Journal of Consumer Psychology, 14, 405-415.

Mann, R., Webster, S., Wakeling, H., \& Marshall, W. (2007). The measurement and influence of child sexual abuse supportive beliefs. Psychology, Crime and Law, $13,443-458$. 
Marshall, W. L., \& Barbaree, H. E. (1990). An integrated theory of the etiology of sexual offending. In W. L.Marshall, D. R. Laws, \& H. E Barbaree (Eds.), Handbook of sexual assault: Issues, theories, and treatment of the offender (pp. 257-275). New York, NY: Plenum Press.

Marziano, V., Ward, T., Beech A. R., \& Pattison P. (2006). Identification of five implicit theories underlying cognitive distortions in child abusers: A preliminary study. Psychology, Crime and Law, 12, 97-105.

Milhailides, S., Devilly, G. J., \& Ward, T. (2004). Implicit cognitive distortions and sexual offending. Sexual Abuse: A Journal of Research and Treatment, 6 , 333-350.

Motiuk, L. L., \& Porporino, F. J., (1993). An examination of sex offender case histories in federal corrections. Ottawa, Ontario, Canada: Correctional Service Canada, Research and Statistics Branch.

Nickoletti, P., \& Taussig, H. N. (2006). Outcome expectancies and risk behaviors in maltreated adolescents. Journal of Research on Adolescence, 16, 217-228.

Nosek, B. A., Banaji, M. R., \& Greenwald, A. G. (2002). Harvesting implicit group attitudes and beliefs from a demonstration web site. Group Dynamics: Theory, Research, and Practice, 6, 101-115.

Nosek, B. A., Greenwald, A. G., \& Banaji, M. R. (2005). Understanding and using the Implicit Association Test: II. Method Variables and Construct Validity. Personality and Social Psychology Bulletin, 31, 166-180.

Nosek, B. A., Greenwald, A. G., \& Banaji, M. R. (2007). The Implicit Association Test at age 7: A methodological and conceptual review. In J. A. Bargh (Ed.), 
Automatic processes in social thinking and behavior (pp. 265-292).

Psychology Press, New York, NY.

Nosek, B. A., Smyth, F. L. (2007). A multitrait-multimethod validation of the Implicit Association Test: Implicit and explicit attitudes are related but distinct constructs. Experimental Psychology, 54, 14-29.

Nunes, K. L., Firestone, P., \& Baldwin, M. W. (2007). Indirect assessment of cognitions of child sexual abusers with the Implicit Association Test. Criminal Justice and Behavior, 34, 454-475.

Olson, J. M., \& Zanna, M. P. (1993). Attitudes and attitude change. Annual Review of Psychology, 44, 117-154.

Paitich, D. (1977). The Clarke Vocabulary Scale: A Multiple-Choice Estimate of WAIS Vocabulary Level. Clarke Institute of Psychiatry: Toronto, Ontario.

Parker, T., \& Stone, M. (Creators). (1997). South park [Television series]. Comedy Central. United States.

Paulhus, D. L. (1984). Two-component models of socially desirable responding. Journal of Personality and Social Psychology, 46, 598-609.

Psychology Software Tools. E-Prime (Version 1.0) [Computer software] (2008). Pittsburg, PA: Psychology Software Tools.

Robinson J. P., Shaver P. R., \& Wrightsman L. S. (1991). Measures of personality and social psychological attitudes. San Diego: Academic Pr.

Rothermund, K., \& Wentura, D. (2001). Figure-ground asymmetries in the Implicit Association Test. Zeitschrift fur Experimentelle Psychologie, 48(2), 94-106.

Schlenker, B.R., \& Pontari, B.A. (2000). The strategic control of information: Impression 
management and self-presentation in daily life. In A. Tesser, R. Felson, \& J. Suls (Eds.), Perspectives on self and identity, (pp. 199-232). Washington, D.C.: American Psychological Association.

Seto, M. C. (2004). Pedophilia and sexual offences against children. Annual Review of Sex Research, 15, 321-361.

Snowden, R. J., Gray, N. S., Smith, J., Morris, M., \& MacCulloch, M. J. (2004). Implicit affective associations to violence in psychopathic murderers. The Journal of Forensic Psychiatric \& Psychology, 15, 620-641.

Tabachnick, B. G., \& Fidell, L. S. (2007). Experimental design using ANOVA. Belmont, CA: Thomson Brooks/Cole.

Teachman, B. A., Gregg, A. P., \& Woody, S. R. (2001). Implicit associations for fearrelevant stimuli among individuals with snake and spider fears. Journal of Abnormal Psychology, 110, 226-235.

Tierney, D. W., \& McCabe, M. P. (2001). An evaluation of self-report measures of cognitive distortions and empathy among Australian sex offenders. Archives of Sexual Behavior, 30, 495-519.

Ward, T., \& Beech, A. (2006). An integrated theory of sexual offending. Aggression and violent behavior, 11, 44-63

Ward, T., Hudson, S. M., Johnston, L., \& Marshall, W. L. (1997). Cognitive distortions in sex offenders: An integrative review. Clinical Psychology Review, 17, 479-507.

Ward, T., \& Keenan, T. (1999). Child molesters' implicit theories. Journal of Interpersonal Violence, 14, 821-838.

Ward, T., \& Siegert, R. J. (2002). Toward a comprehensive theory of child sexual abuse: 
A theory knitting perspective. Psychology, Crime \& Law, 8, 319-351.

Wolf, D. (Creator). (1990). Law and order [Television series]. United States: Wolf Films. 
Under the Radar 80

Appendix A

Interview Consent Form 


\section{Interview Consent Form}

An informed consent form outlines the procedure, identifies any potential negative consequences, and provides contact information should you have any questions or concerns about the research that cannot be addressed by the experimenter. The main purpose of a consent form is to INFORM you of what you will be required to do so that you have adequate information to decide whether or not you wish to participate.

This research is being conducted by Kelly Babchishin and Nicolas Kessous under the supervision of Dr. Kevin Nunes (Assistant Professor, Department of Psychology, Carleton University, 613-520-2600, ext 1545; kevin nunes@carleton.ca). For questions or concerns about this study please contact Kevin Nunes. Should you have any ethical or any other concerns about this study, please contact Dr. Avi Parush, Chair of the Carleton University Ethics Committee for Psychological Research (613-520-2600, ext. 6026;

avi parush@carleton.ca) or Dr. Anne Bowker, Chair of the Psychology Department (613-520-2600, ext. 2648; psychchair@carleton.ca).

The purpose of this research is to make a list of words related to things like children, adults, asexual attractiveness, and sexual offending. The words provided by you will be put together with words from other participants to create measures for use in later research. Other more general questions will be asked about your opinion of child sexual abuse and other topics. Your participation will involve speaking with the researcher for about one hour.

Information obtained will NOT be shared with Correctional Service Canada (CSC) staff and will NOT be put on any institutional file. You will not be identified as a participant in the publication or presentation of the results. Your name and other identifying details will not be written on information you provide.

Because some of the activities deal with sensitive material, such as reading descriptions of sexual acts and viewing pictures of naked people, they may be embarrassing or offensive. You are free to withdraw from the project at any time, refuse to participate, and refuse to answer questions. Refusal to participate will NOT affect your treatment by CSC in any way. Participation in this study will NOT affect any administrative decisions concerning you, such as your institutional placement or parole.

The data collected will be kept in a secure manner at Carleton University for a period of 10 years in a locked filing cabinet and password-protected computer, with any identifying information removed, and will be accessible only to the researchers working on this research.

I have read and understood the information above. My signature indicates that I agree to participate in this study. There are two copies of the consent form, one of which I may keep.

Participant Signature: Date:

Witness Signature: Date: 
Under the Radar 82

Appendix B

\section{Interview Questions}


PRELIMINARY INTERVIEW WITH INMATES TO INFORM THE CONSTRUCTION OF TWO IMPLICIT ASSOCIATION TESTS ASSESSING SEXUAL ATTRACTION TO CHILDREN AND ATTITUDES TOWARD CHILD SEXUAL ABUSE

- Date of interview (yyyy/mm/dd): 20

- Location of interview: Bath $\square \quad$ Pittsburg $\square \quad$ RTC $\square \quad$ Warkworth $\square$

- Interviewer: Kelly B. $\square \quad$ Nicolas K. $\square \quad$ Kevin N. $\square$

- Interviewee category: CM $\square$ NS

- Age of interviewee: ___ yrs

\section{QUESTIONS}

Recommended prompts: "Does anything else come to mind?" or "Can you elaborate on that?"

\section{D) Words}

1. What does the word "sexy" make you think of?

2. What do the words "not sexy" make you think of?

3. What are some words you would use that mean the same thing as "sexually attractive"?

4. What are some words you would use that mean the same thing as "not sexually attractive"?

5. What are some words you would use that mean the same thing as "sexually arousing"?

6. What are some words you would use that mean the same thing as "not sexually arousing"?

7. What words come to mind when you think of an adult having sexual contact with a child?

8. What words come to mind when you think of an adult having sexual contact with another adult? 
9. What kind of activities does the phrase "sex with a child" make you think of?

10. What kind of activities does the phrase "sex with an adult" make you think of?

\section{II) Perceived victim and perpetrator outcomes}

11. What are some good things that a child would get from having sex with an adult?

12. What are some good things that an adult would get from having sex with a child?

13. What are some bad things that a child would get from having sex with an adult?

14. What are some bad things that an adult would get from having sex with a child?

15. Do you think that having sex with a child is wrong? Why?

\section{III) Motivations for current offence}

16. Can you describe the offence(s) you are currently in prison for? (For CM, focus on sex offence even if nonsex offences were also committed. If many offences, ask about most serious one. Alternately, if crimes are many but similar, then ask about group of offences)

a. Tell me about the person you were convicted of offending against (i.e., age, gender, relation)

b. How do you feel about the crime you have been convicted of?

c. Can you tell me about your life before the offence? (i.e., life circumstances)

d. Do you remember how you felt right before the offence?

e. Did you think of any consequences before acting?

f. What are some of them?

g. Which one was the most relevant to you?

h. Did you use any drugs or alcohol? If so, do you think they contributed to your offence? 
i. How did you feel after the offence?

j. Do you feel the punishment you got is fair?

k. Can you tell me what life is like in prison?

\section{IV) Relative evaluation of child sexual abuse}

17. How do you feel about (other) people who have sex with children?

\section{V) Victim empathy:}

18. Are there things children do that increase the chances of them getting sexually abused?

19. Do victims deserve sympathy?

\section{VI) General views:}

20. Do you think the things that happen to us are within our control?

21. ONLY ASK CM: Is it comforting to be in the presence of children when things are going wrong? 
Under the Radar 86

Appendix C

Rating Scales Consent Form 


\section{Rating Scale Consent Form}

An informed consent form outlines the procedure, identifies any potential negative consequences, and provides contact information should you have any questions or concerns about the research that cannot be addressed by the experimenter. The main purpose of a consent form is to INFORM you of what you will be required to do so that you have enough information to decide whether or not you wish to participate.

This research is being conducted by Kelly Babchishin (613-520-2600, ext. 2649; kbabchis@connect.carleton.ca) and Nicolas Kessous (613-520-2600, ext. 2649; nkessous@connect.carleton.ca) under the supervision of Dr. Kevin Nunes, Assistant Professor, Department of Psychology, Carleton University, (613-520-2600, ext. 1545; kevin nunes@carleton.ca). For questions or concerns about this study, please contact Kevin Nunes. Should you have any ethical or any other concerns about this study, please contact Dr. Avi Parush, Chair of the Carleton University Ethics Committee for Psychological Research (613-520-2600, ext. 6026; avi_parush@carleton.ca) or Dr. Anne Bowker, Chair of the Psychology Department (613-520-2600, ext. 2648; psychchair@carleton.ca).

The purpose of the research is to see how incarcerated men view words or pictures related to adults, children, sexual attractiveness, and sexual offending. You will be asked to fill out a questionnaire that will take about 15 minutes to complete. You will also be asked to answer a few questions about your conviction(s). Your answers combined with many other people's answers will be used to select words for use in future research.

Your answers are anonymous. That is, nobody will know how you answered because your name will not be written on your questionnaire. Your answers will NOT be shared with Correctional Service Canada (CSC) staff or put on any institutional file. You will NOT be identified as a participant in the publication or presentation of the results. You are free to withdraw from the project at any time, refuse to participate, and refuse to answer questions. Refusal to participate will NOT affect your treatment by CSC in any way. Participation in this study will NOT affect any administrative decisions concerning you, such as your institutional placement or parole.

The data collected will be kept in a secure manner at Carleton University for a period of 10 years in a locked filing cabinet and password-protected computer and will be accessible only to the researchers working on this research.

I have read and understood the information above. My signature indicates that I agree to participate in this study. There are two copies of the consent form, one of which I may keep.

Participant Signature: Date: 
Under the Radar 88

Appendix D

Rating Scales 
INSTRUCTIONS: Please indicate if each word is "good" or "bad" by circling one of the options. For example, if you think "vacation" is good, you would circle "good". If you think "vacation" is bad, you would circle "bad".

\begin{tabular}{|lll|}
\hline 1. VACATION & Good & Bad \\
\hline 2. ROTTEN & Good & Bad \\
\hline 3. SMILE & Good & Bad \\
4. SUNSHINE & Good & Bad \\
\hline 5. BAD & Good & Bad \\
\hline 6. RAINBOW & Good & Bad \\
\hline 7. VOMIT & Good & Bad \\
\hline 8. POISON & Good \\
\hline 9. SICKNESS & Good & Bad \\
\hline 10.PARADISE & Good & Bad \\
\hline 11. CANCER & Good & Bad \\
\hline 12. PEACE & Good & Bad \\
\hline 13. POLLUTION & Good & Bad \\
\hline 14. GOOD & Good & Bad \\
\hline 15. WAR & Good & Bad \\
\hline 16. SUCCESS & Good & Bad \\
\hline 17. LUCKY & Good & Bad \\
\hline 18. HEALTH & Good & Bad \\
\hline 19. DISASTER & Good & Bad \\
\hline 20. POOR & Good & Bad \\
\hline 21. DEATH & Good & Bad \\
\hline 22. HAPPY & Good & Bad \\
\hline
\end{tabular}


INSTRUCTIONS: Please indicate if each word fits better with "sex with an adult" or "sex with a child" by circling one of the options. For example, if you think "young" fits best with "sex with an adult", you would circle "sex with an adult". If you think "young" fits best with "sex with a child", you would circle "sex with a child".
1. YOUNG
Sex with an adult
Sex with a child

Sex with an adult

Sex with an adult

Sex with an adult

Sex with an adult

Sex with an adult

6. KID

7. TALL

8. CHILD

9. ADULT

10. SHORT

11. ABUSE

12. MARRIAGE

13. MOLEST

14. UNDERAGE

15. UNDEVELOPED

16. MATURE

17. IMMATURE

18. PROHIBITED

19. BIG

20. WOMAN

21. WIFE

22. LITTLE

23. LARGE

24. LEGAL
Sex with an adult

Sex with an adult

Sex with an adult

Sex with an adult

Sex with an adult

Sex with an adult

Sex with an adult

Sex with an adult

Sex with an adult

Sex with an adult

Sex with an adult

Sex with an adult

Sex with an adult

Sex with an adult

Sex with an adult

Sex with an adult

Sex with an adult

Sex with an adult
Sex with a child

Sex with a child

Sex with a child

Sex with a child

Sex with a child

Sex with a child

Sex with a child

Sex with a child

Sex with a child

Sex with a child

Sex with a child

Sex with a child

Sex with a child

Sex with a child

Sex with a child

Sex with a child

Sex with a child

Sex with a child

Sex with a child

Sex with a child

Sex with a child

Sex with a child

Sex with a child 


\begin{tabular}{lll}
\hline 25. INFANT & Sex with an adult & Sex with a child \\
26. DEVELOPED & Sex with an adult & Sex with a child \\
\hline 27. ILLEGAL & Sex with an adult & Sex with a child \\
\hline 28. HUSBAND & Sex with an adult & Sex with a child \\
\hline 29. HONEYMOON & Sex with an adult & Sex with a child \\
\hline 30. SMALL & Sex with an adult & Sex with a child \\
\hline 31. PEDOPHILE & Sex with an adult & Sex with a child \\
\hline
\end{tabular}


INSTRUCTION: Please circle your answer.

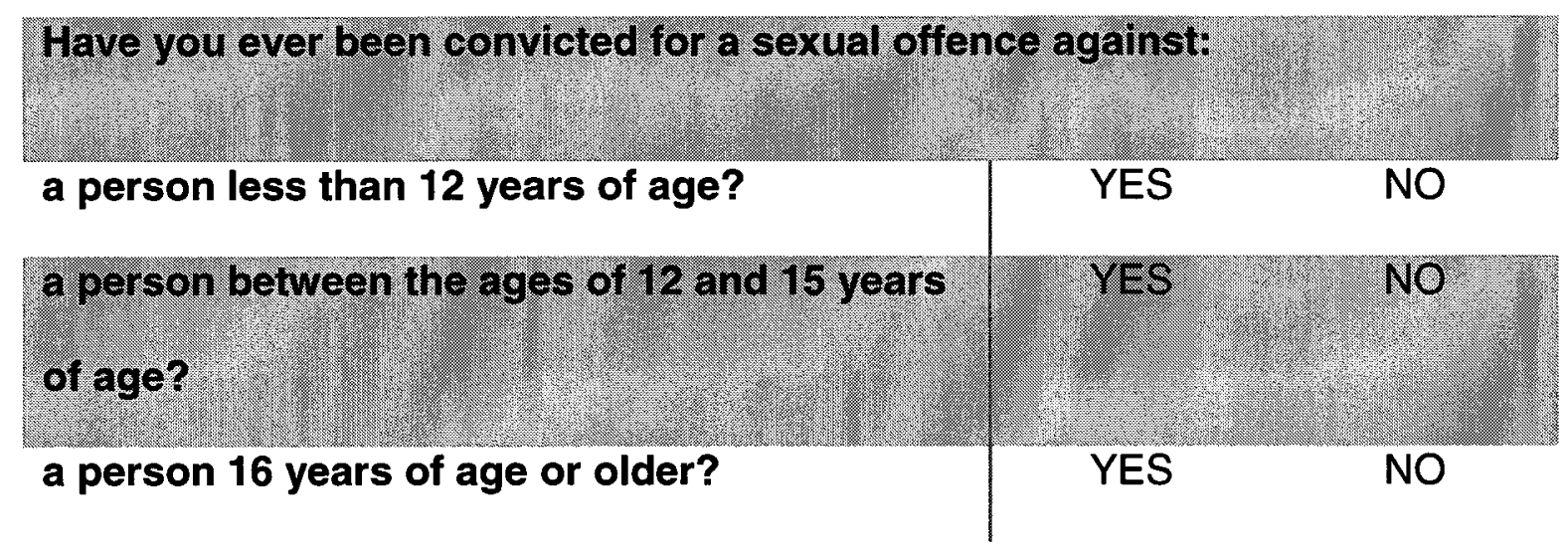


Appendix E

Pilot Study and Study Proper Consent Form 


\section{Pilot Study and Study Proper Consent Form}

An informed consent form outlines the procedure, identifies any potential negative consequences, and provides contact information should you have any questions or concerns about the research that cannot be addressed by the experimenter. The main purpose of a consent form is to INFORM you of what you will be required to do so that you have adequate information to decide whether or not you wish to participate.

This research is being conducted by Kelly Babchishin and Nicolas Kessous under the supervision of Dr. Kevin Nunes (Assistant Professor, Department of Psychology, Carleton University, 613-520-2600, ext 1545; kevin_nunes@carleton.ca). For questions or concerns about this study please contact Kevin Nunes. Should you have any ethical or any other concerns about this study, please contact Dr. Avi Parush, Chair of the Carleton University Ethics Committee for Psychological Research (613-520-2600, ext. 6026;

avi parush@carleton.ca) or Dr. Anne Bowker, Chair of the Psychology Department (613-520-2600, ext. 2648; psychchair@carleton.ca).

The purpose of the research is to see if incarcerated men who have not committed sex offences are different from men who have committed sex offences in the way they think about children and sex offending. The researchers need information from men who have not committed sex offences as well as those who have been arrested for sex offences.

Your participation will consist of one session, lasting approximately 1 hour and 30 minutes. You will be asked to complete some categorization tasks and questionnaires on a computer. For one of these questionnaires you will be asked to rate how attractive you find a wide range of sexual acts, some of them involving children and violence. You will also be asked to view pictures of naked women, men, girls, and boys, and rate the attractiveness of these pictures.

You are asked to consent to the disclosure of specific information from your institutional files, such as your criminal record, intake assessment, and psychological assessment information. This information will be used by the researchers to see if there is a relationship between specific file information and the tasks completed in the present study. Your file information will be accessed for the current study and for follow-up studies up to a maximum of 10 years from now.

The contents of your files will be used only for research purposes and your confidentiality will be respected and protected. The information you provide will NOT be shared with Correctional Service Canada (CSC) staff or put on any institutional file. You will not be identified as a participant in the publication or presentation of the results. Your name, FPS number, and other personal information will NOT be written on the information you provide to protect your confidentiality.

Because some of the activities deal with sensitive material, such as reading descriptions of sexual acts and viewing pictures of naked people, they may be embarrassing or offensive. You are free to withdraw from the project at any time, refuse to participate, and refuse to answer questions. Refusal to participate will NOT affect your treatment by CSC in any way. Participation in this study will NOT affect any administrative decisions concerning you, such as your institutional placement or parole.

The data collected will be kept in a secure manner at Carleton University for a period of 10 years in a locked filing cabinet and password-protected computer, with any identifying information removed, and will be accessible only to the researchers working on this research.

I have read and understood the information above. My signature indicates that I agree to participate in this study. There are two copies of the consent form, one of which I may keep.

Participant Signature:

Witness Signature:
Date:

Date: 
Under the Radar 95

Appendix F

Sex with Children Scale 


\section{Sex with Children Scale}

SWCH scale items

Strongly

Strongly

disagree

agree

1. Children actually enjoy sex with a man if the man is nice to them.

2. Most children actually enjoy sex with an adult so long as the man does not hurt them.

3. Many children are sexually seductive towards adults.

4. Children enjoy sexual attention from adults.

5. Men who have sex with children are usually led into it by the child.

6. Children who do not wear underwear and who sit in a way that is revealing are suggesting sex.

7. Children who are unloved by their parents are actually helped by men who have sex with them.

8. Sex between adults and children is quite natural and healthy and it is only because of the repressive rules of our society that men are punished for doing this.

9. It is far better for young people to have their first sexual experience during childhood with an adult than to risk what is sure to be an unpleasant experience with someone their own age when they are a teenager.

10. A man can't help having sex with a child if the child acts in a provocative manner.

11. Having sex with a child is not really all that bad because it doesn't really harm the child.

12. If an adult has sex with a child who enjoys it and seems to want it, it shouldn't be considered a crime.

13. Children are old enough to decide whether or not they want to have sex with someone.

14. Having sex with a child is a way of expressing your love and affection for that child.

15. Having sex with a child is a good way to teach them about sexuality.

16. Many children benefit from having sex with an adult.

0

$\begin{array}{llll}0 & 1 & 2 & 3\end{array}$

$\begin{array}{llll}\mathbf{0} & 1 & \mathbf{2} & 3\end{array}$

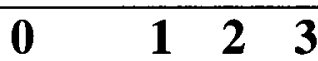

$\begin{array}{llllll}0 & 1 & 2 & 3 & 4\end{array}$

$\begin{array}{lllll}0 & 1 & 2 & 3 & 4\end{array}$

$\begin{array}{lllll}0 & 1 & 2 & 3 & 4\end{array}$

$\begin{array}{lllll}0 & 1 & 2 & 3 & 4\end{array}$

$\begin{array}{lllll}\mathbf{0} & 1 & \mathbf{2} & \mathbf{3} & 4\end{array}$

4

4




\section{Appendix G}

\section{Balanced Inventory of Deceptive Responding}




\section{Balanced Inventory of Deceptive Responding}

Read each statement and circle the number that best describes you, from Not True to Very True about you.

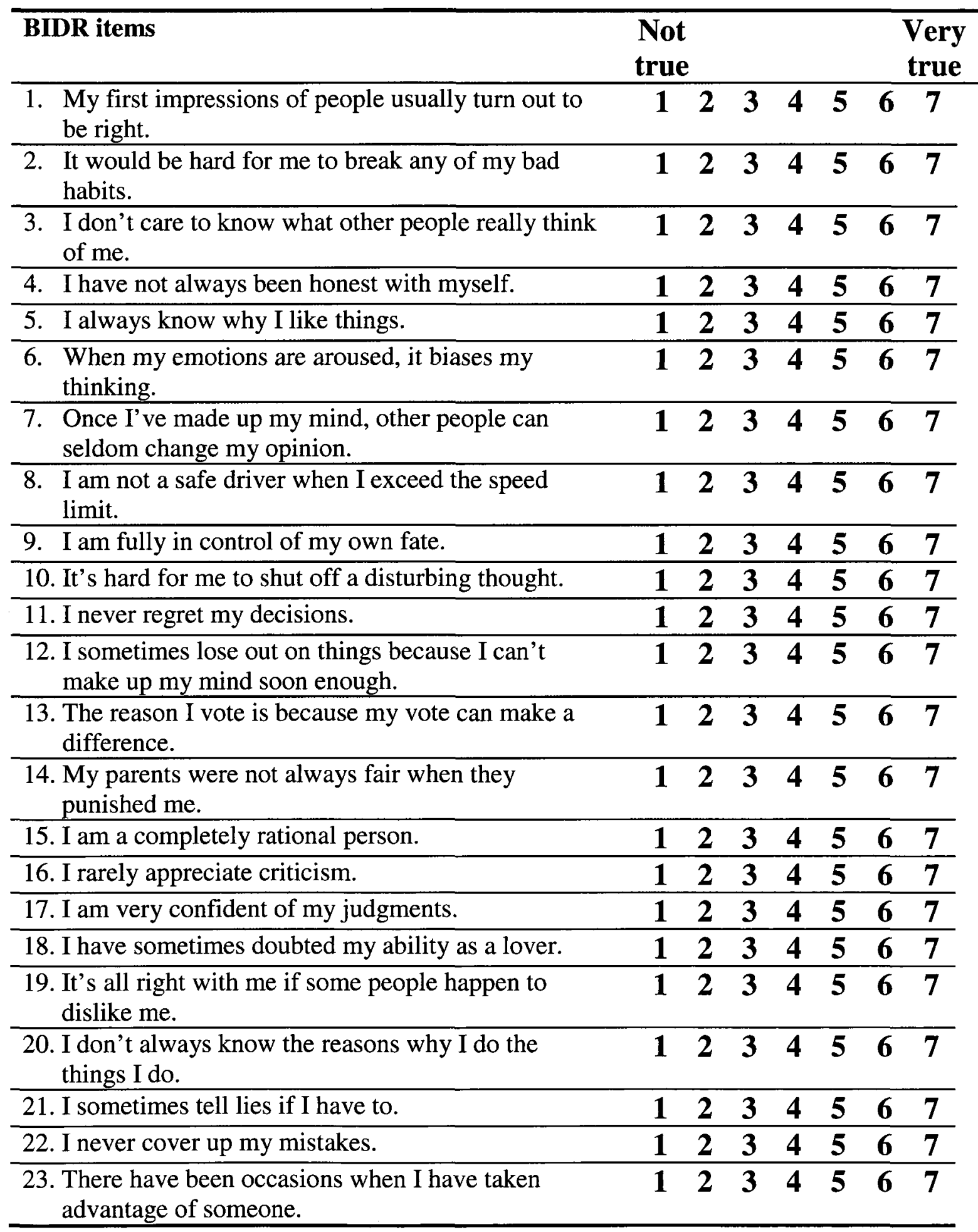




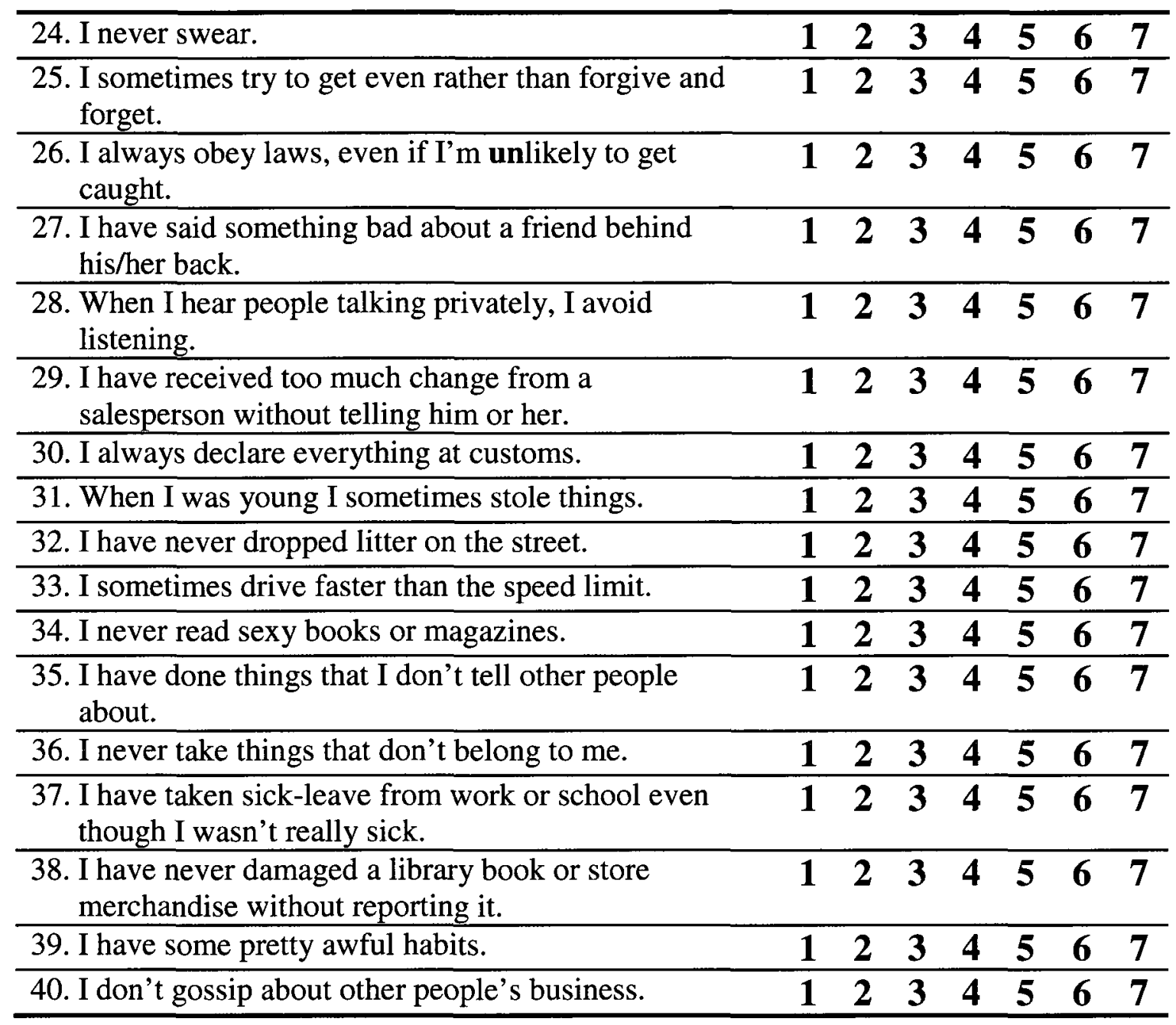




\section{Appendix H}

\section{Clarke Vocabulary Scale}




\section{CLARKE VOCABULARY SCALE}

INSTRUCTIONS: Please circle the response that has the most similar meaning to the underlined word.

\begin{tabular}{|c|c|c|c|c|c|}
\hline 1. & a book & A. is to read & B. is a ball & C. is blue & D. is to run \\
\hline 2. & a car & A. is a dance & B. is to drive & C. is black & D. is to eat \\
\hline 3. & a horse & A. has four legs & B. is small & $\begin{array}{l}\text { C. lives in a } \\
\text { house }\end{array}$ & D. flies \\
\hline 4. & a clock & $\begin{array}{l}\text { A. keeps you } \\
\text { dry }\end{array}$ & B. is deep & C. tells time & D. is for cats \\
\hline 5. & a hammer & $\begin{array}{l}\text { A. grows on a } \\
\text { tree }\end{array}$ & B. is a tool & C. is for you leg & D. has a shell \\
\hline 6. & a pillow & A. is an animal & B. is hard & C. is to open jars & D. is to sleep on \\
\hline 7. & a glove & $\begin{array}{l}\text { A. goes on your } \\
\text { hand }\end{array}$ & $\begin{array}{l}\text { B. goes on your } \\
\text { head }\end{array}$ & $\begin{array}{l}\text { C. is to work } \\
\text { with }\end{array}$ & D. is a tree \\
\hline 8. & a saw & A. is to cut with & B. is to sit on & $\begin{array}{l}\text { C. is to point } \\
\text { with }\end{array}$ & D. is a page \\
\hline 9. & Fur & A. is blue & B. is animal hair & C. is sweet & D. is on birds \\
\hline 10. & Jewel & A. round & B. sky & C. flower & D. diamond \\
\hline 11. & Connect & A. spill & B. part & C. join & D. feel \\
\hline 12. & Shovel & A. farm & B. spade & C. cry & D. ace \\
\hline 13. & Weapon & A. sword & B. correct & C. lip & D. pecan \\
\hline 14. & Nuisance & A. baby & B. help & C. worse & D. bother \\
\hline 15 . & $\underline{\text { ridiculous }}$ & A. silly & B. ruined & C. poor & D. defenceless \\
\hline 16. & $\underline{\text { nimble }}$ & A. fat & B. active & C. brave & D. sick \\
\hline
\end{tabular}




\begin{tabular}{|c|c|c|c|c|c|}
\hline 17. & wager & A. court & B. dice & C. gamble & D. strike \\
\hline 18. & magnify & A. make smaller & B. distant & C. make bigger & D. handle \\
\hline 19. & fable & A. fur & B. watch & C. rhyme & D. story \\
\hline 20. & $\underline{\text { facetious }}$ & A. hungry & B. witty & C. weighty & D. ugly \\
\hline 21. & $\underline{\text { blemish }}$ & A. flaw & B. abuse & C. vaunt & D. clean \\
\hline 22. & $\underline{\text { strife }}$ & A. try & B. verse & C. battle & D. wine \\
\hline 23. & $\underline{\text { seclude }}$ & A. ensure & B. dream & C. isolate & D. obtain \\
\hline 24. & recede & A. withdraw & B. deny & C. repeat & D. dine \\
\hline 25 . & profusion & A. glitter & B. plenty & C. noise & D. glory \\
\hline 26. & adversary & A. opponent & B. explosive & C. light & D. grammar \\
\hline 27. & effrontery & A. bombing & B. boldness & C. triviality & D. belief \\
\hline 28. & impending & A. valuable & B. prominent & C. imminent & D. obese \\
\hline 29. & abyss & A. confusion & B. suicide & C. monastery & D. chasm \\
\hline 30. & diverge & A. asset & B. vacation & C. distress & D. wander \\
\hline 31. & devoid & A. planet & B. vacuum & C. missing & D. insect \\
\hline 32. & arduous & A. laborious & B. shapeless & C. sterile & D. proud \\
\hline 33. & vigilant & A. watchful & B. careful & C. literal & D. winning \\
\hline
\end{tabular}


Under the Radar 103

\begin{tabular}{|l|l|l|l|l|l|}
\hline 34. & relinquish & A. food & B. plague & C. distress & D. surrender \\
\hline 35. & $\underline{\text { catacomb }}$ & A. deep valley & $\begin{array}{l}\text { B. Japanese } \\
\text { garden }\end{array}$ & C. ruined city & $\begin{array}{l}\text { D. underground } \\
\text { cemetery }\end{array}$ \\
\hline 36. & $\underline{\text { indemnity }}$ & A. penalty & B. subsidy & C. amity & D. ordinance \\
\hline 37. & $\underline{\text { reprobation }}$ & A. approval & B. censure & C. slander & D. verification \\
\hline 38. & $\underline{\text { dilatory }}$ & A. slow & B. expanded & C. selfish & D. uncertain \\
\hline 39. & $\underline{\text { requite }}$ & A. admonish & B. love & C. repay & D. commend \\
\hline 40. & $\underline{\text { imprecation }}$ & A. inaccuracy & B. scruple & C. curse & D. rarity \\
\hline
\end{tabular}


Under the Radar 104

Appendix I

\section{Background Questionnaire}




\section{Background Questionnaire}

1) Do you speak English fluently?

$1=$ Yes

$2=$ No

2) Do you understand written English?

$1=$ Yes $2=$ No

3) Do you understand spoken English?

$1=$ Yes $2=$ No

4) Is English your first language?

$1=$ Yes $2=$ No

5) Did you attend an English grade school (grades 1 to 8)?

$1=$ Yes $2=$ No

6) Did you attend an English high school?

$1=$ Yes $2=$ No

7) Who are you most sexually attracted to?

$1=$ Women $2=$ Men

$3=$ Both men and women

8) Have you ever used physical force or threats to make an adult have sexual contact with you when he or she didn't want to?

$1=$ Yes $2=$ No

9) Have you ever had sexual contact with a child under the age of 16 when you were at least 4 years older than the child?

$1=$ Yes $2=$ No

10) Have you ever had sexual contact with a child under the age of 14 when you were at least 4 years older than the child?

$1=$ Yes $2=$ No

11) Have you ever had sexual contact with a child under the age of 12 when you were at least 4 years older than the child?

$1=$ Yes $2=$ No

12) Have you ever had sexual contact with an animal?

$1=$ Yes $2=$ No

13) Have you ever been charged for a sex offence against someone under the age of 12 ?

$1=$ Yes $2=$ No 
14) Have you ever been charged for a sex offence against someone between the ages of 12 and 15 ?

$1=$ Yes

$$
2=\text { No }
$$

15) Have you ever been charged for a sex offence against someone aged 16 or older? $1=$ Yes $2=$ No

16) Have you ever received any treatment for sex offending?

$$
1=\text { Yes } 2=\mathrm{No}
$$


Appendix J

Coding Manual 


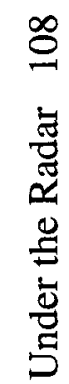

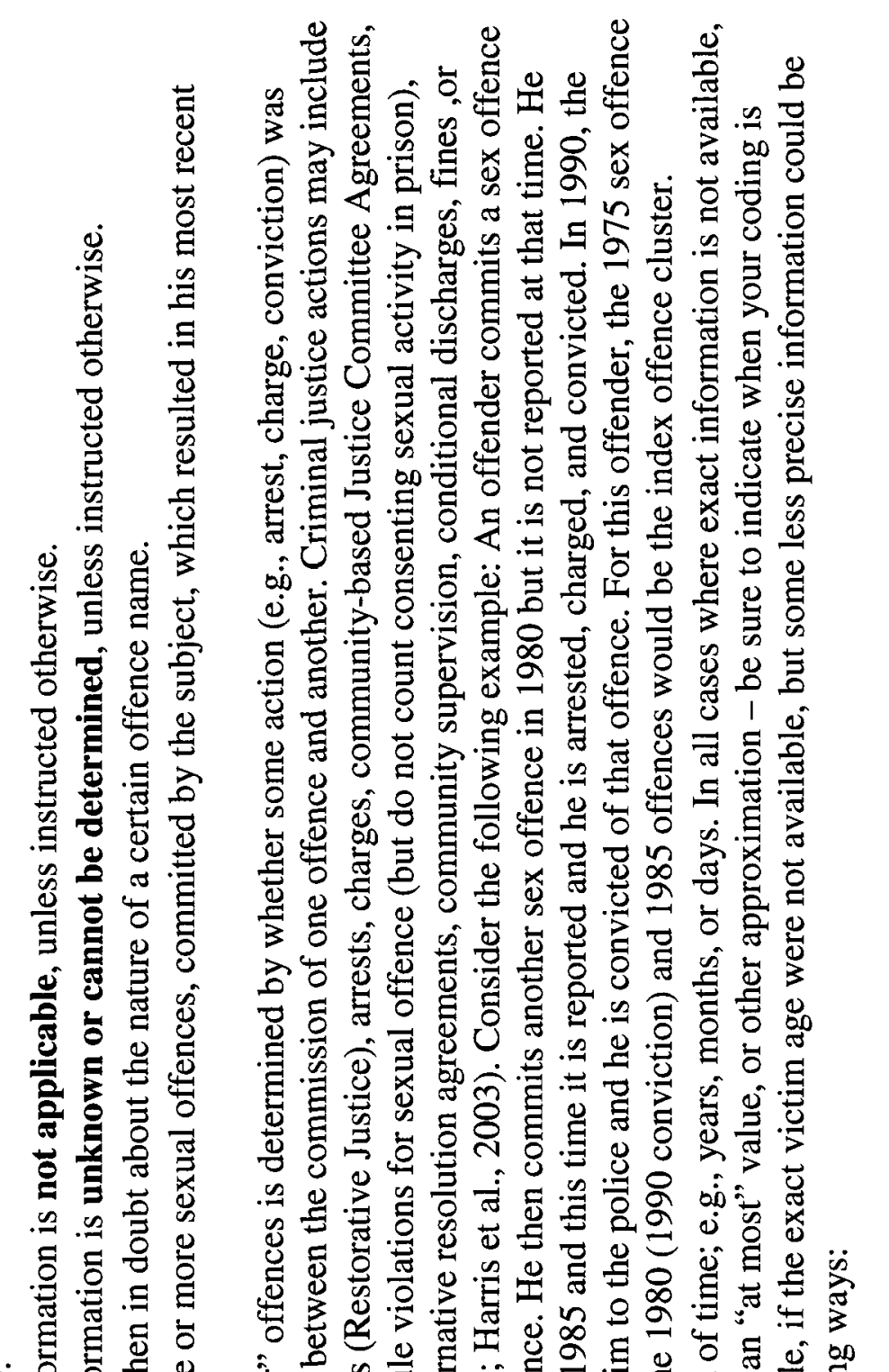

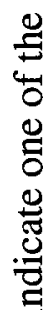

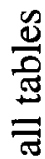

클

离

จ

ช్ํㅋ

冚

$\stackrel{\square}{\square}$

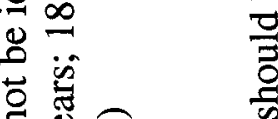

离密

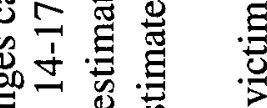

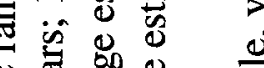

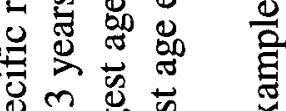

光

긍

G is

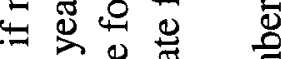

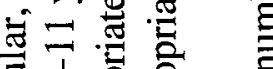

링ㅎㅇㅇ은

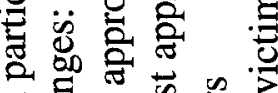

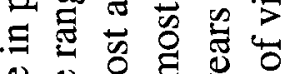

คิ

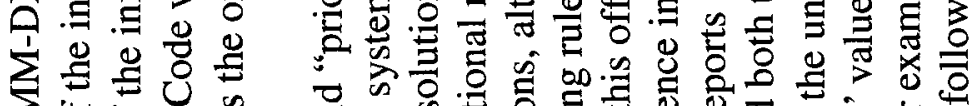

○ $\Xi \gtrsim$

$\pi \mathbb{\sigma}_{\infty} \infty$

苛 $\sum_{1}=\frac{\pi}{8}$

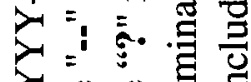

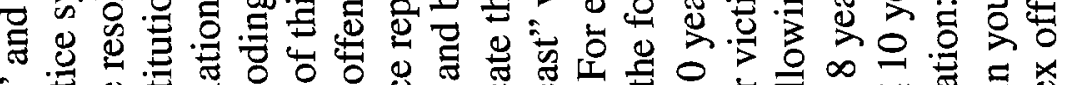

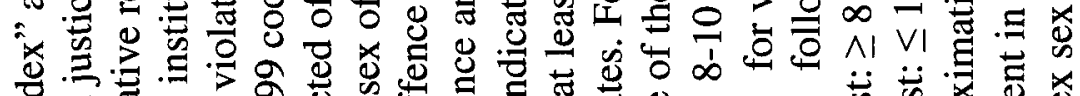

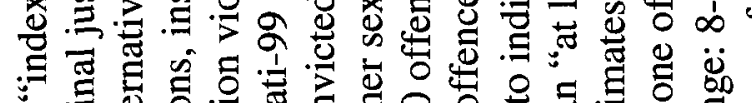

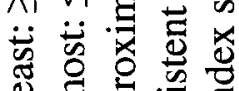

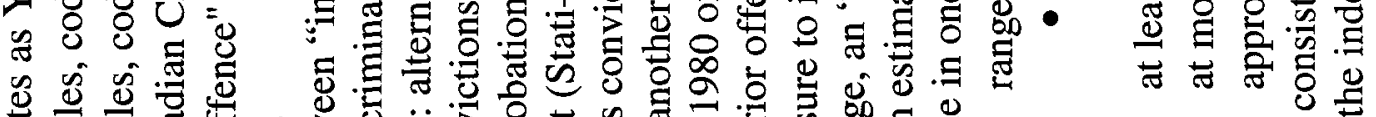

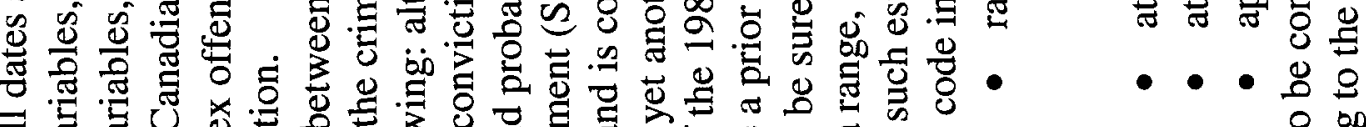

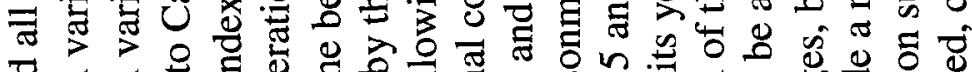

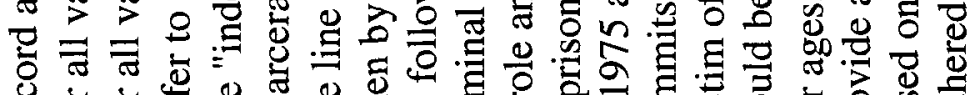

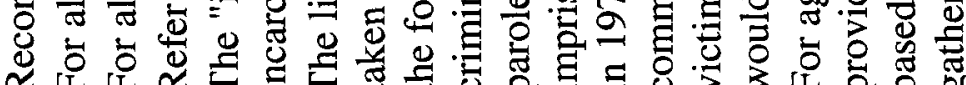
용 党 ๓ 


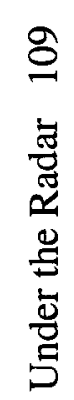
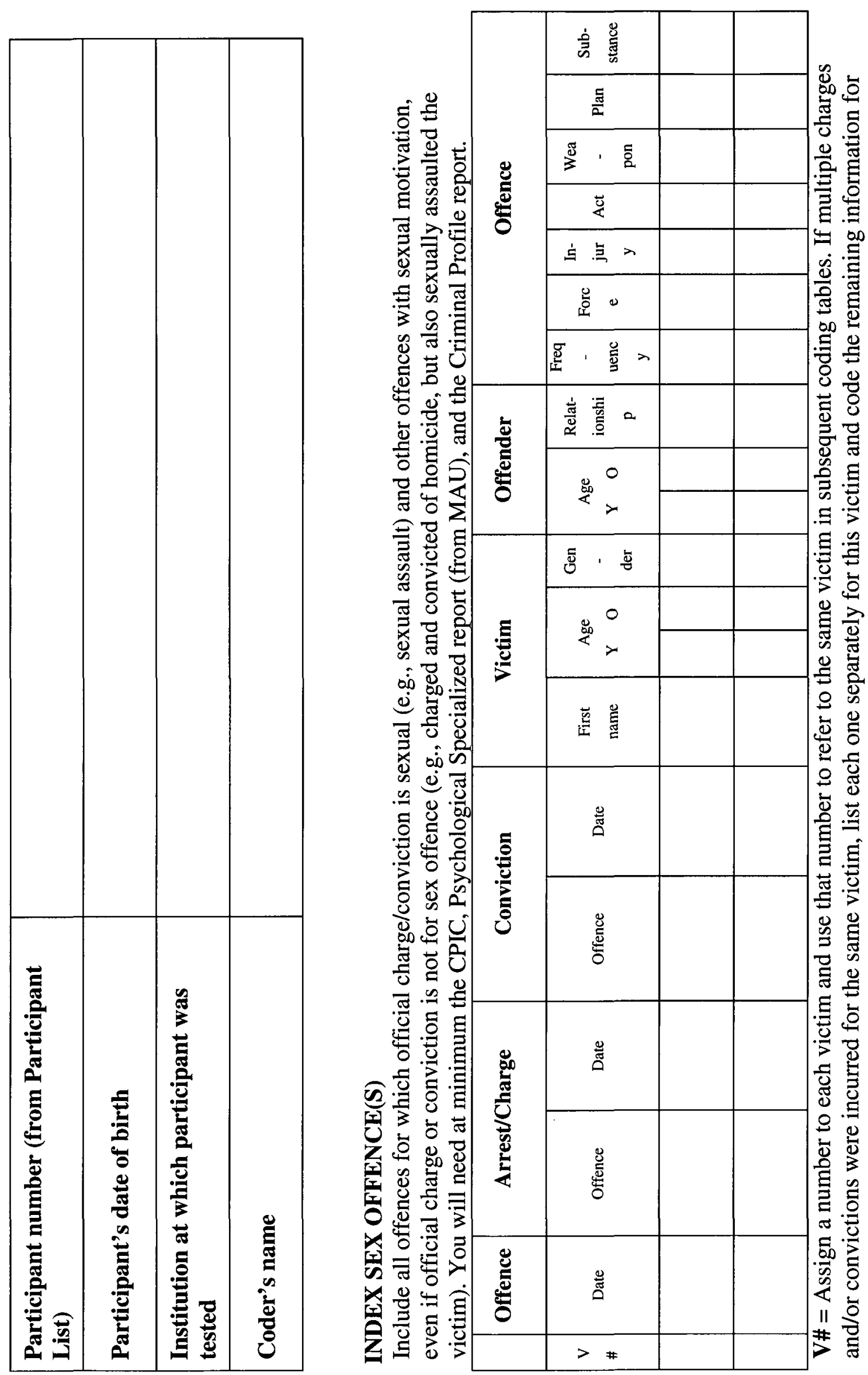


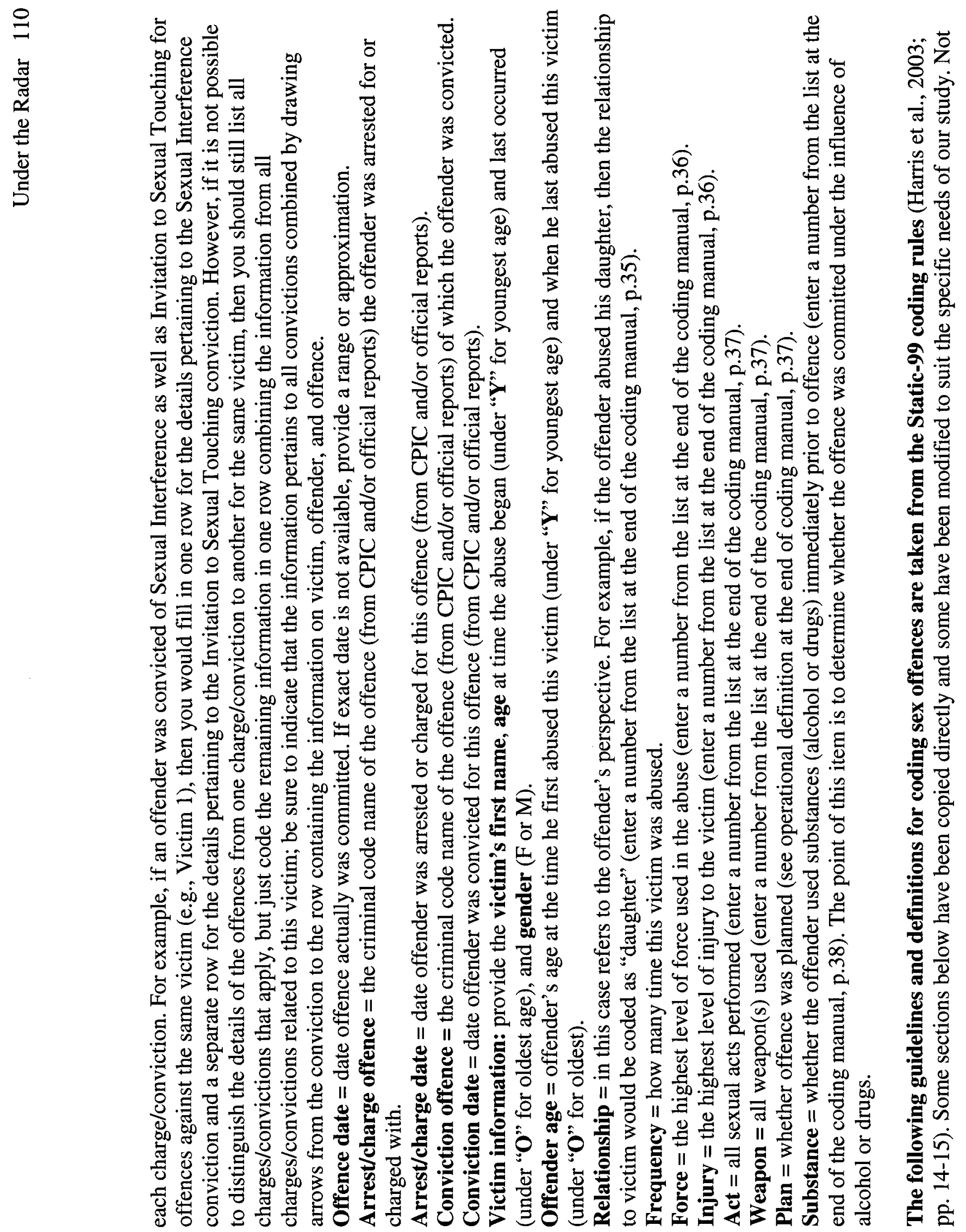




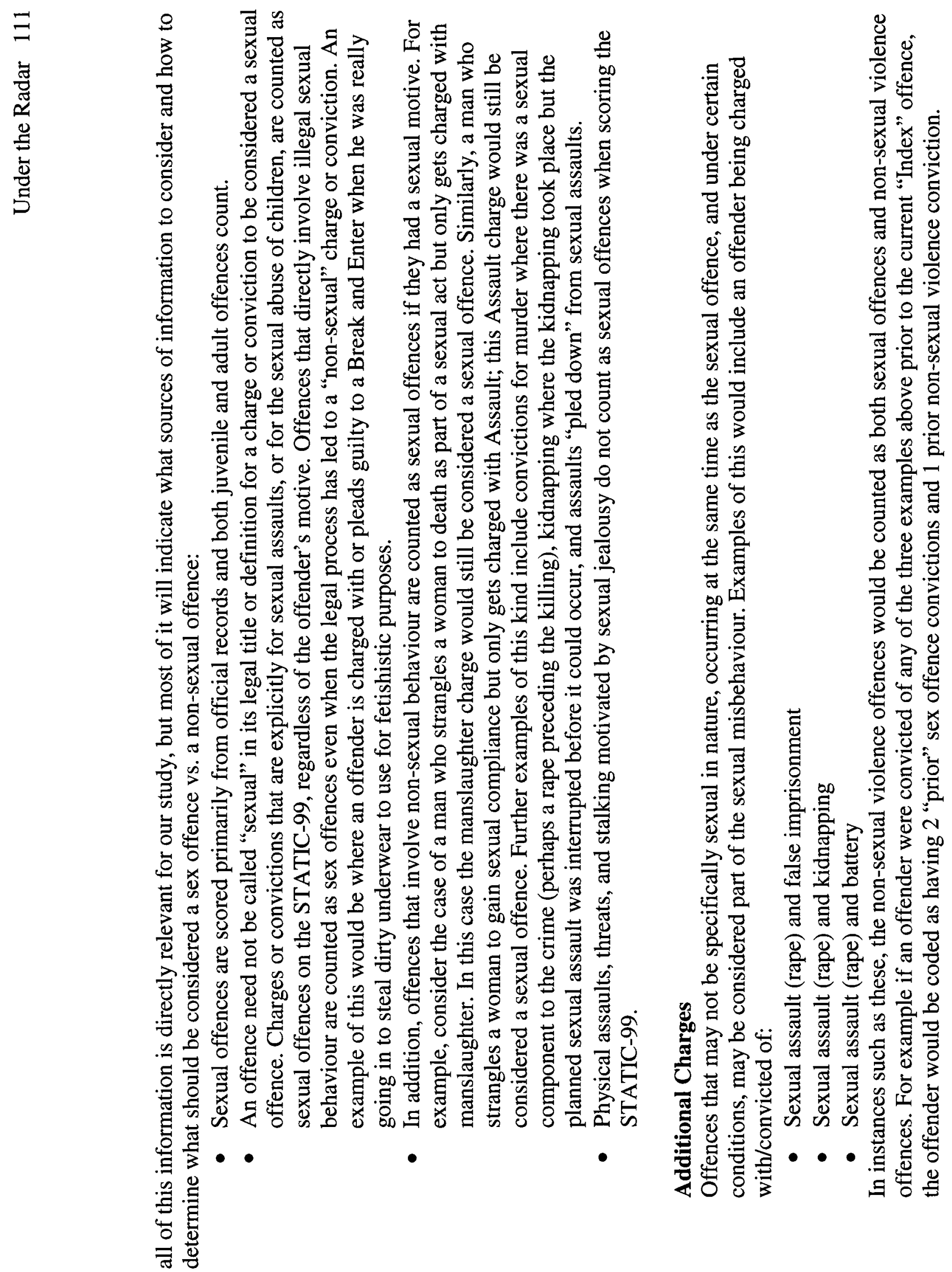




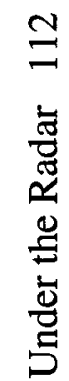

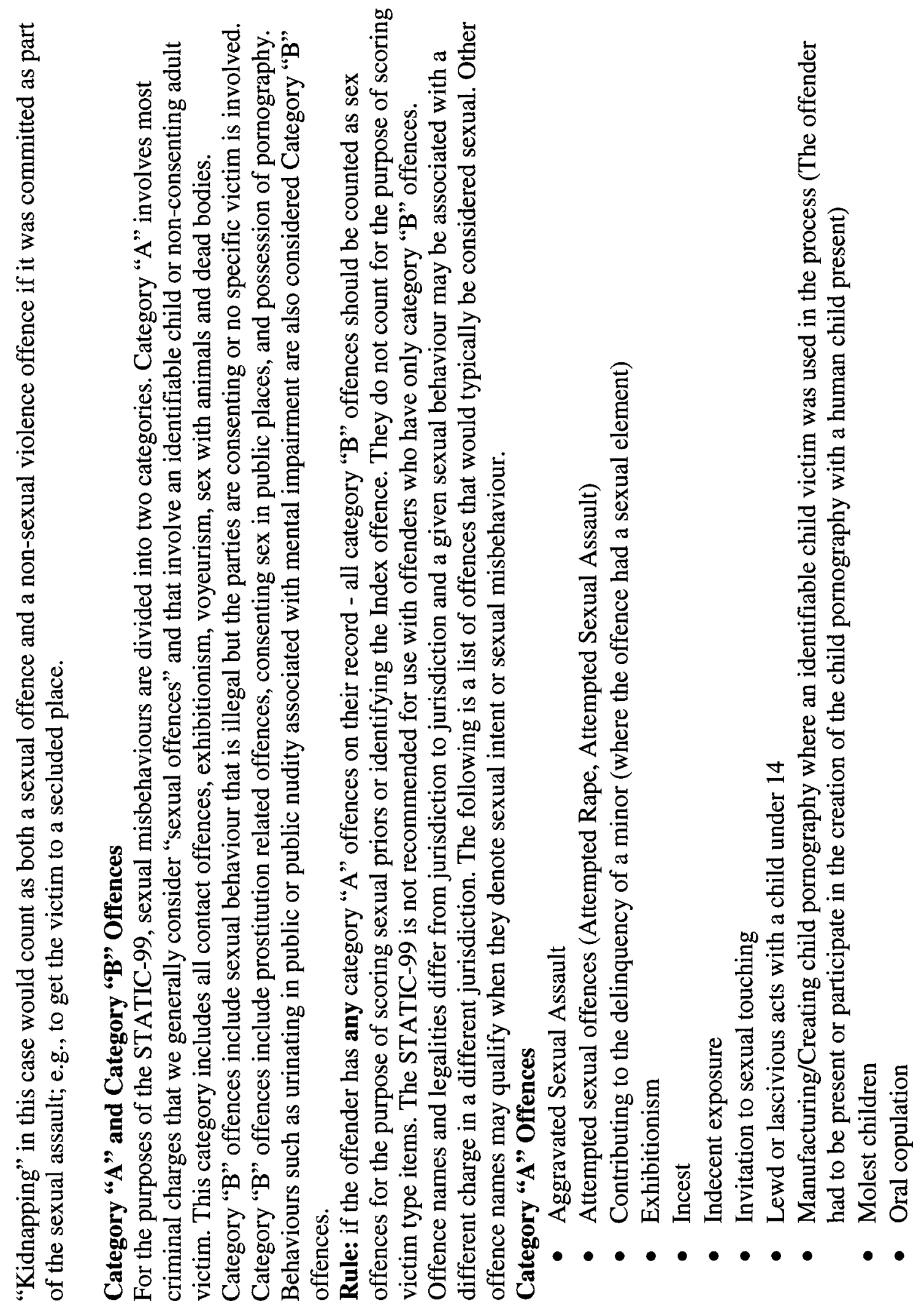




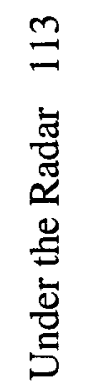

글

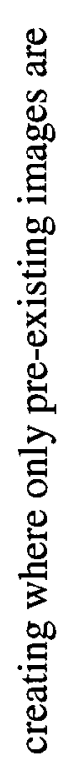

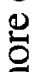

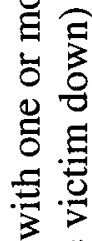

$\dddot{8}$

훈흥

$\therefore$

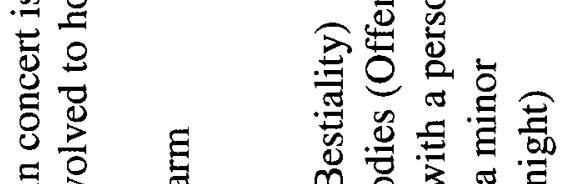

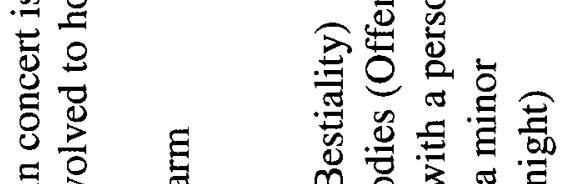

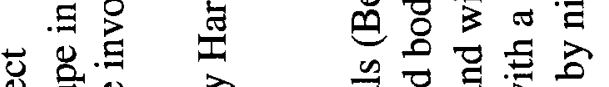

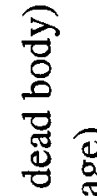

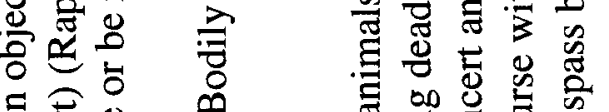

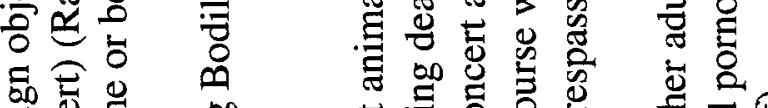

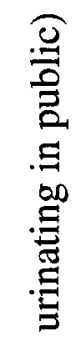

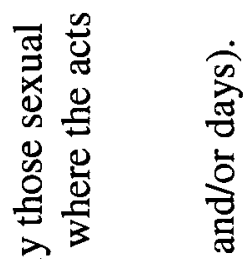

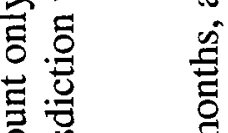

吾串

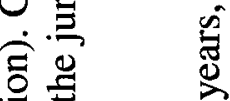

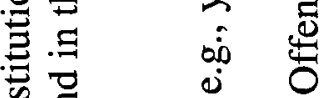

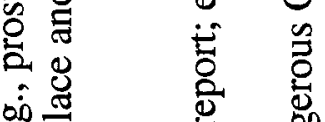

i்

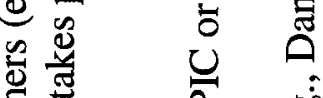

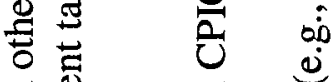

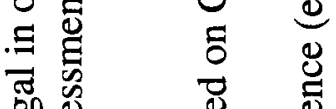

잉

莺

鄫

코 윰

is

造

总苍

$\stackrel{0}{0}$

్ㅗㅇ

:

苛

을

$\Xi \quad \stackrel{0}{0} \quad$

曾 运

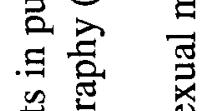

苛芯芯

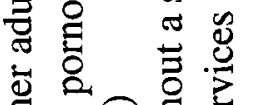

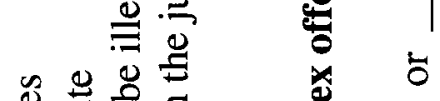

芳

สำ

롱

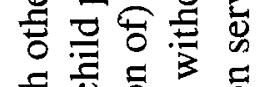

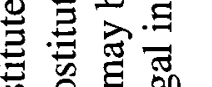

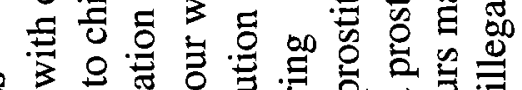

$x$ on

㔄焉

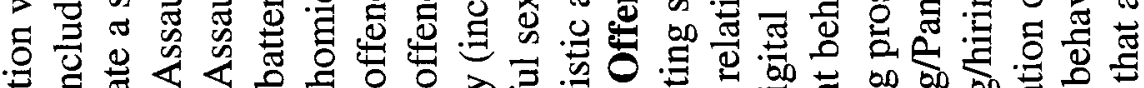

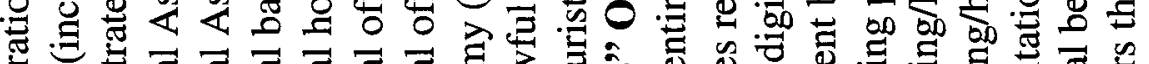

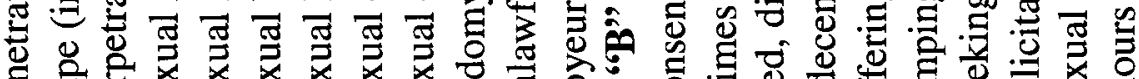

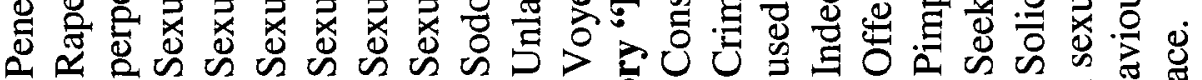




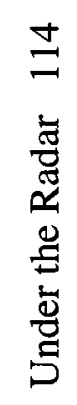

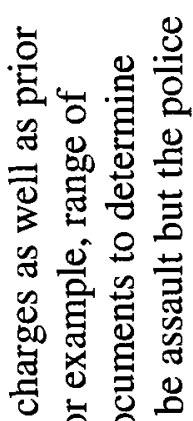

可象

解

당

.

O응

政

는

$\times$

o

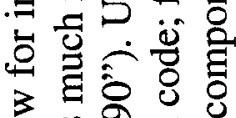

영 产

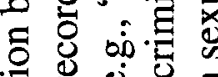

政

응을

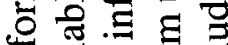

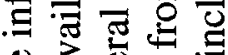

의 웧

응

记

可

政

讨

年

동

这

政

政

$\sim \overline{0} 8 \stackrel{0}{\circ}$

䨔

늘 응 영

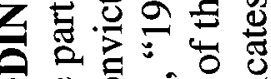

8 옹 of oj

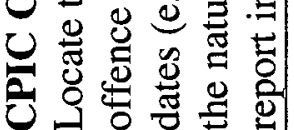

ن웡

过

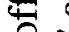

을

s.

30

용

品

g.

을

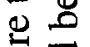

楁

용

送

하

는

Uి

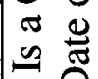

II

政 II

:

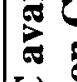

II

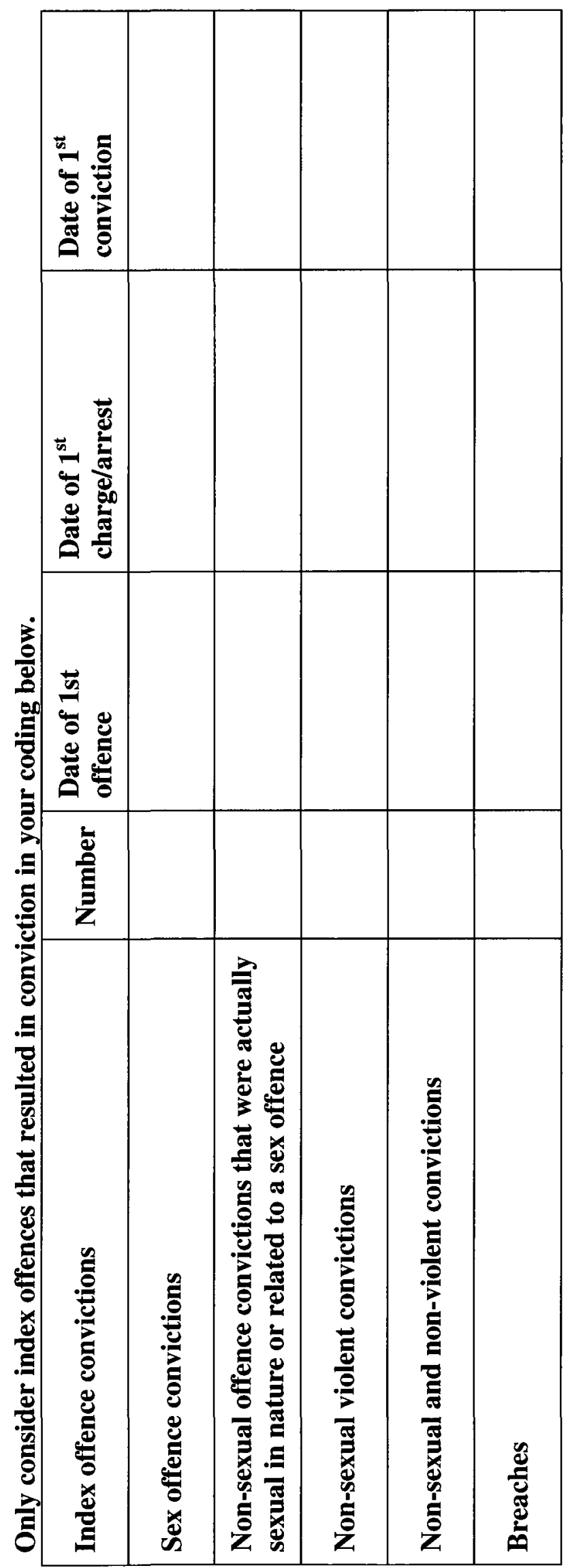




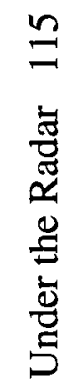

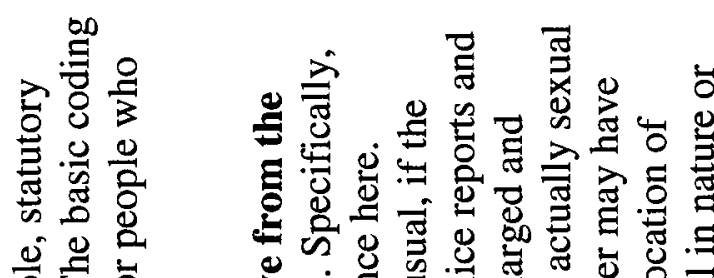

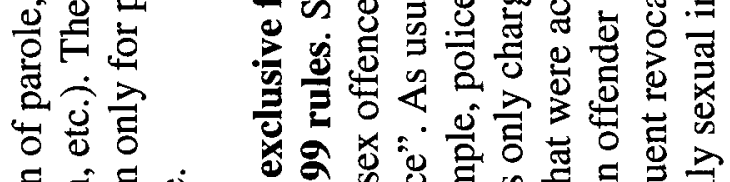

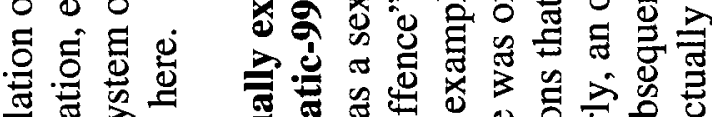

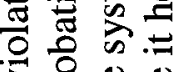

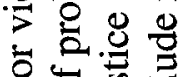

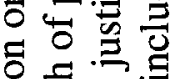

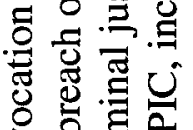

क्ष

$\because$ o 04

$\stackrel{0}{0}$ 츠

()

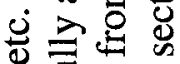

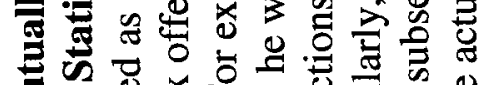

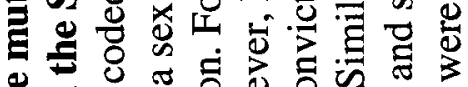

\&

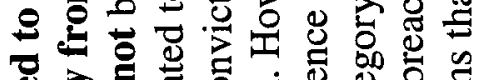

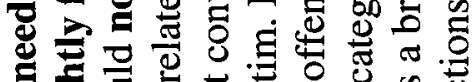

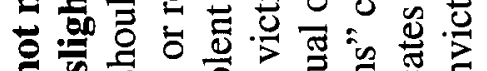

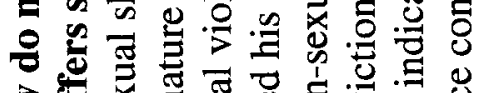

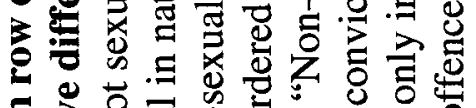

รี

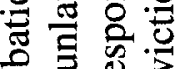

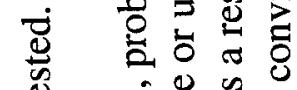

령영

ब

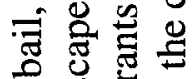

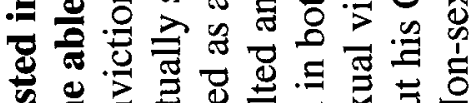

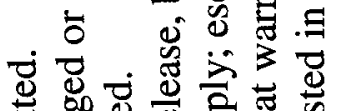

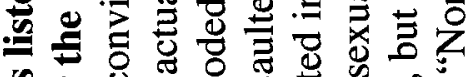

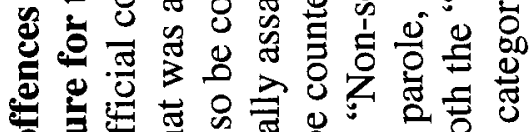

:

要

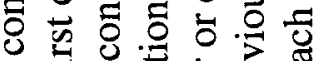

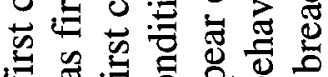

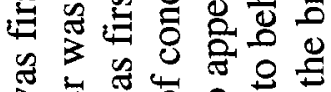

उั

\&

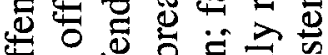

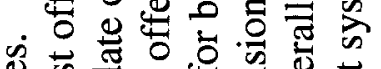

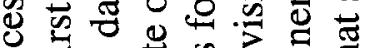

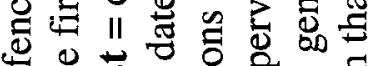

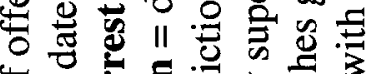

苂 II

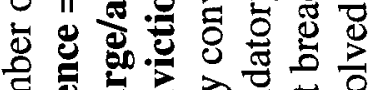

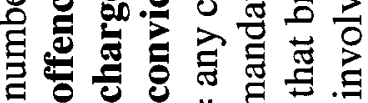

II के के

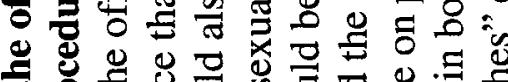

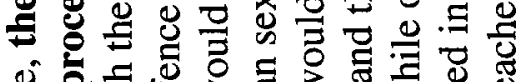

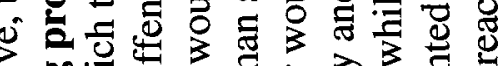

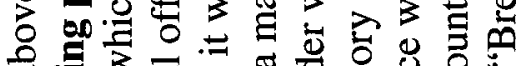

ส

ڤ

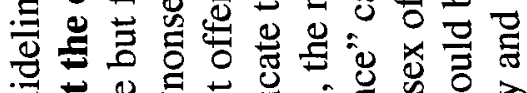

븐 a

웜

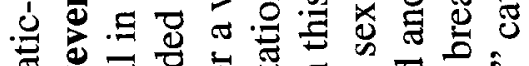

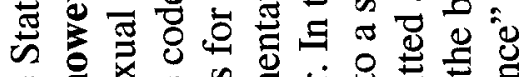

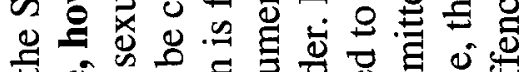

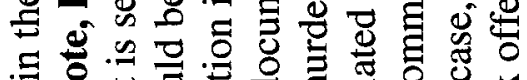

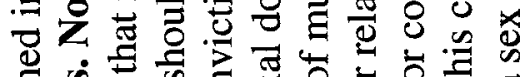

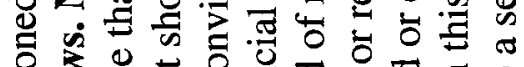

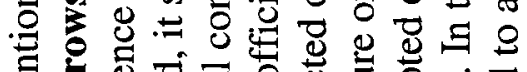

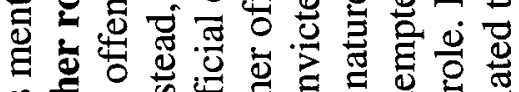

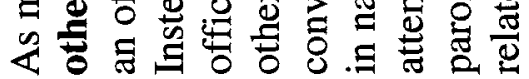

遂总

电照

ठ류

बิ

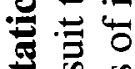

क 08

吾总

롤

戈 总

I

풍

迅

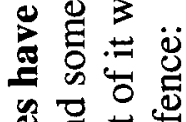

过焉荌

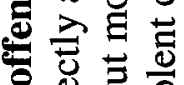

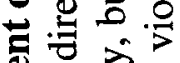

을 뀰

웡 范

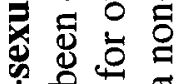

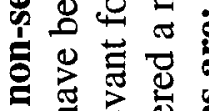

$0 \frac{2}{3}$ 焉

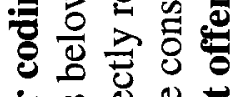

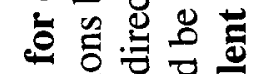

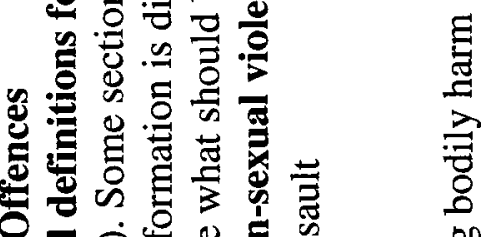

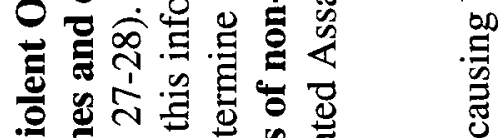

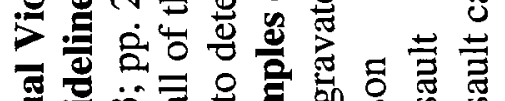

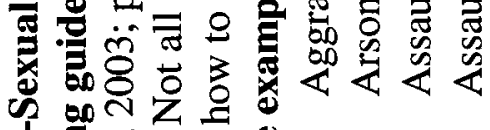

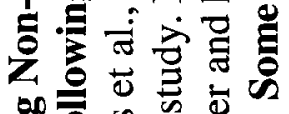

을

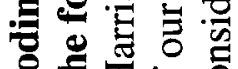

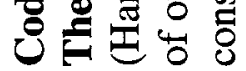




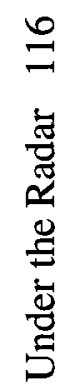

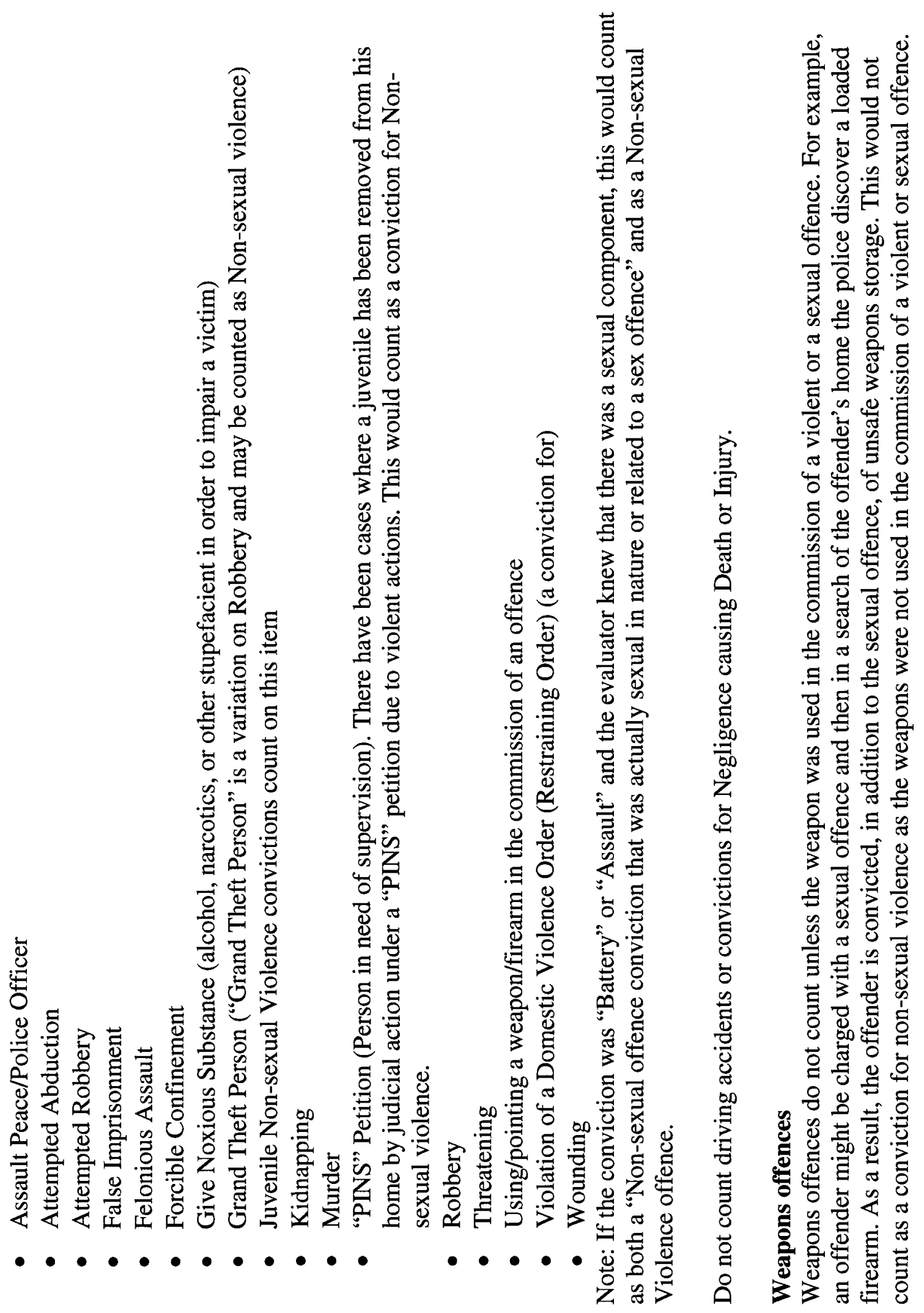




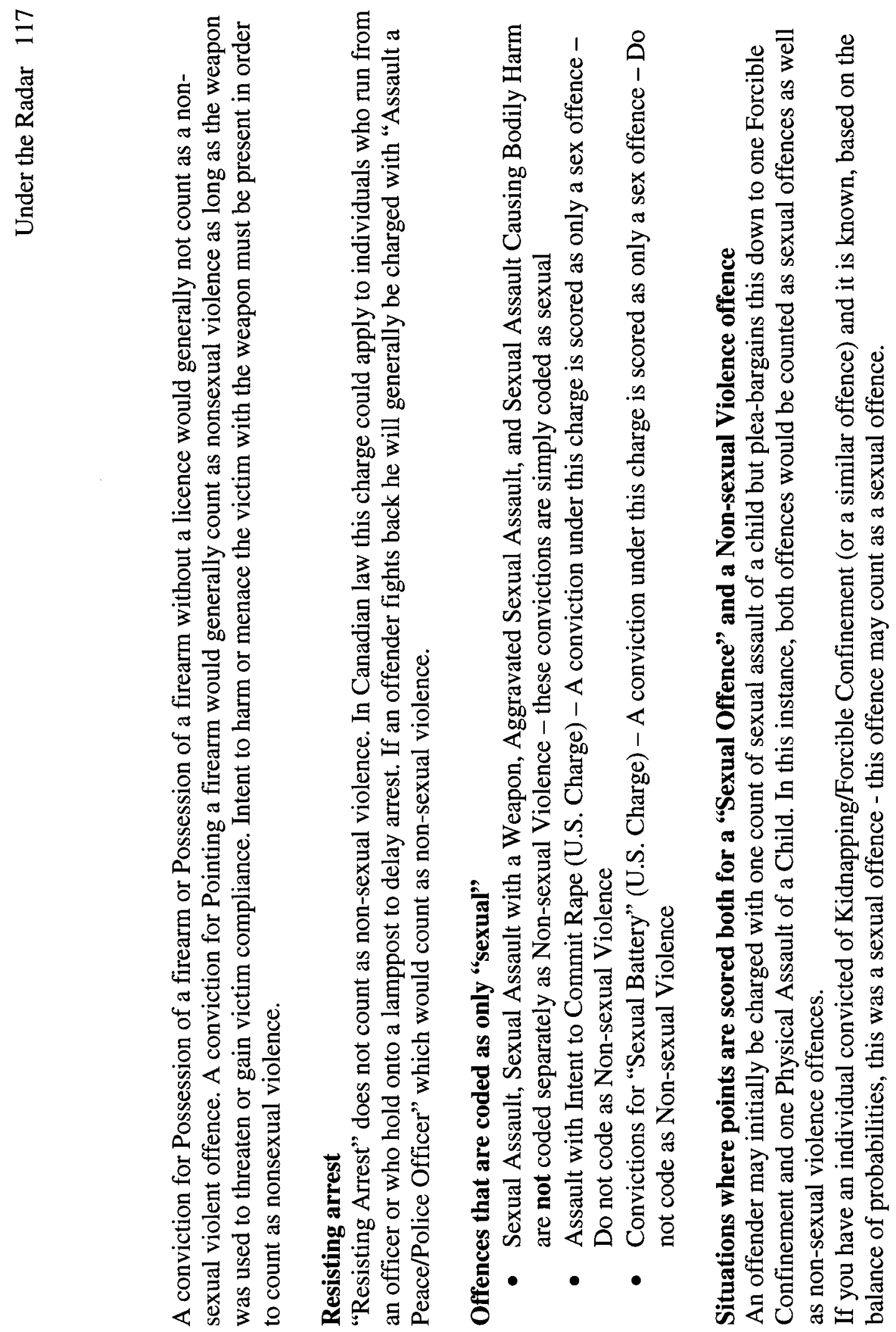




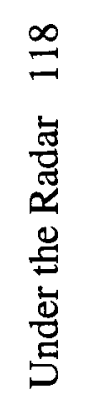
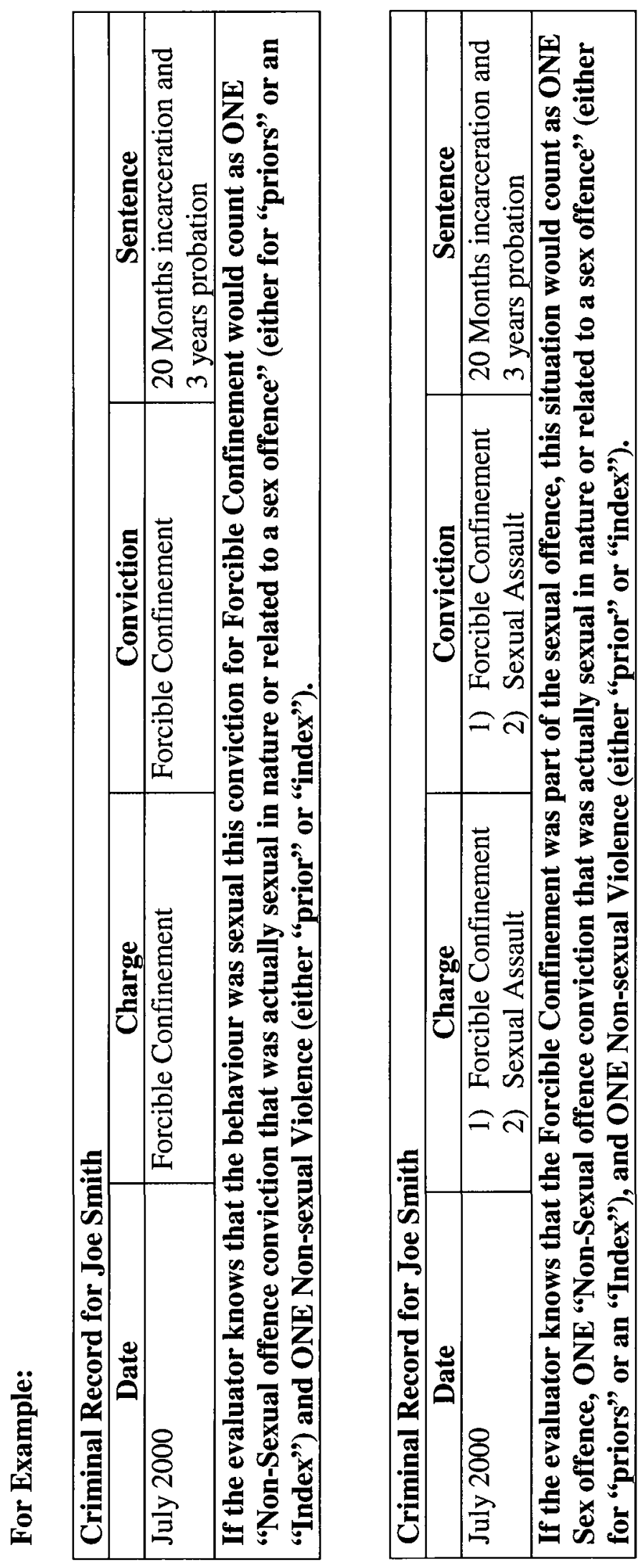

ᄒ믈

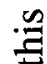

农

츌ㅊ

일 엉

호 올

苟 5

$8 \frac{1}{3} \tilde{\sigma}$

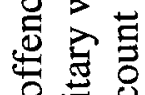

芯寻

을 을

๘屯

它

ङ

苟 0

.

년

ส

깅

를 음

롱묘

월

넝 0

¿

है웡

品?

ฮ

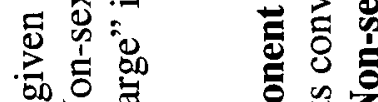

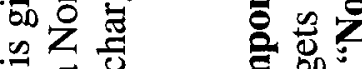

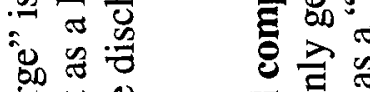

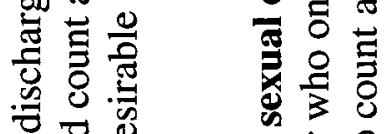

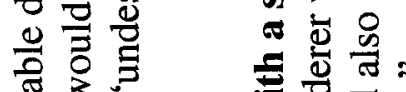

휸

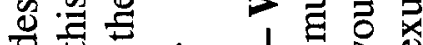

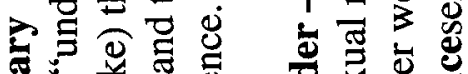

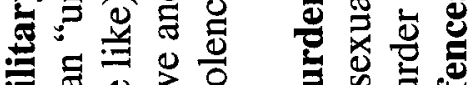

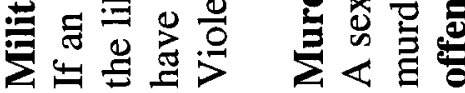




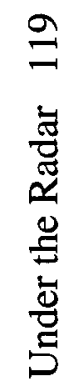

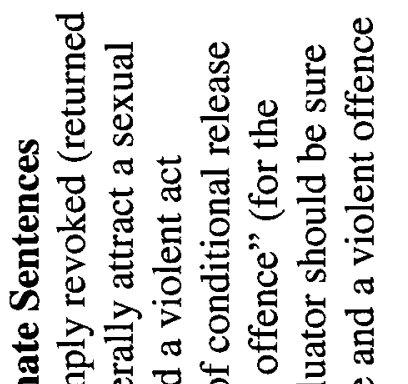

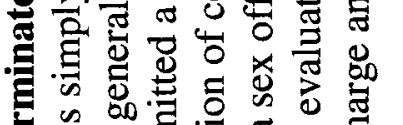
는

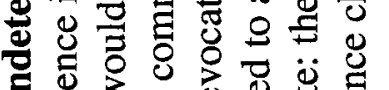

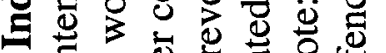

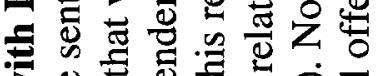
1늘 는. 政

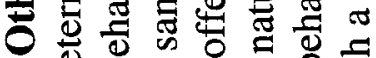
물.

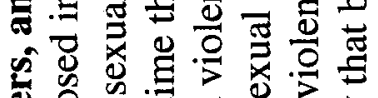

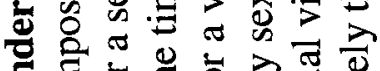

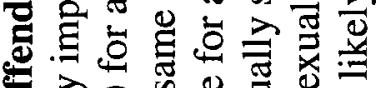

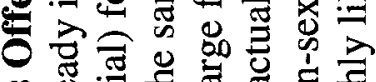

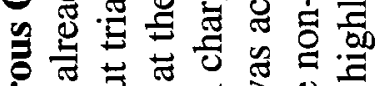

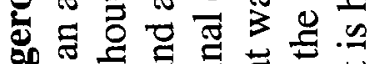
政 so

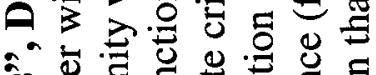

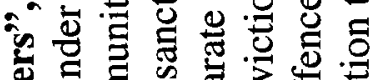

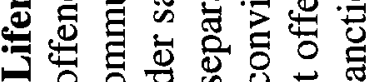

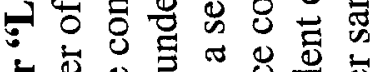

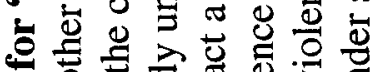

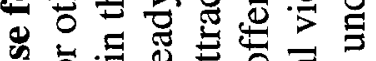
墨5 5 은

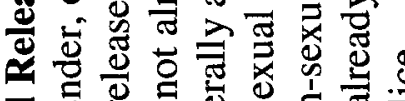

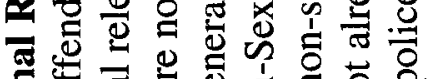

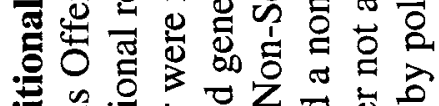

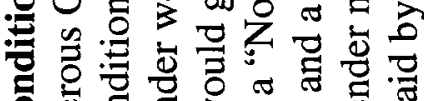
8) 을

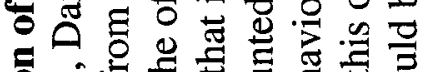
5. 는 (5)

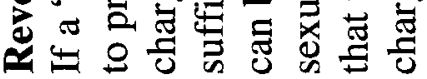




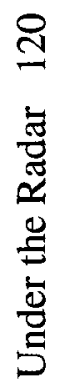

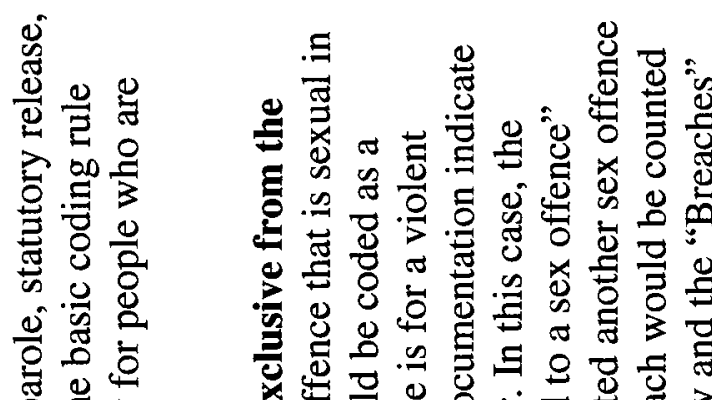

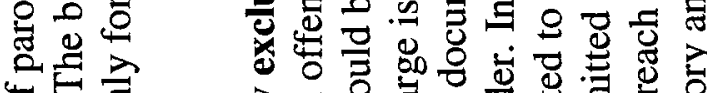

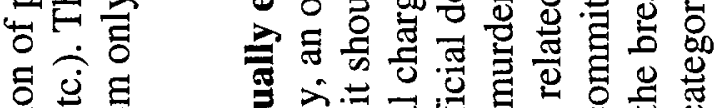
语焉

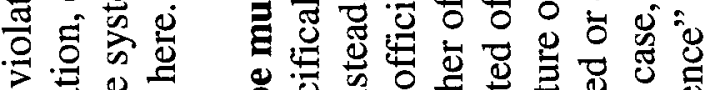
ᄒ。

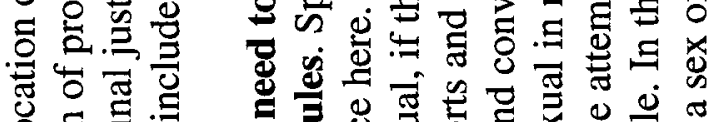

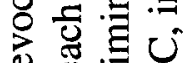
ల

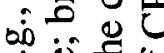
(i) ن సี छี

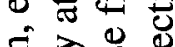

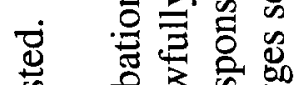
\& 히하

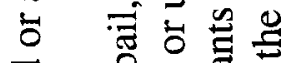

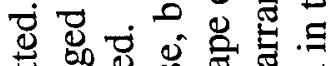
正

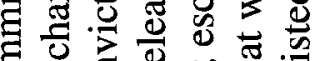

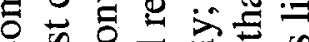

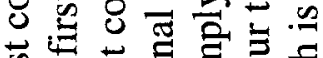
幽的

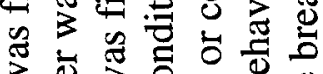
3 क 308

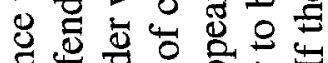

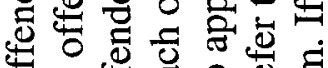

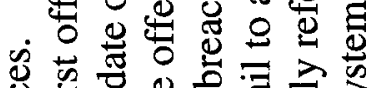

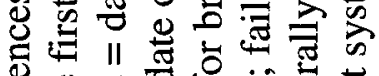
矛起泀 t ষ

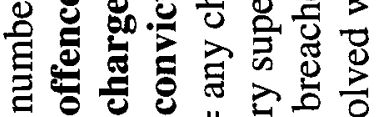
II $\vec{\omega}$ के II के

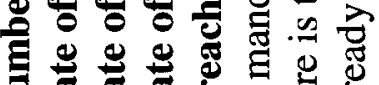

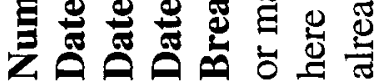

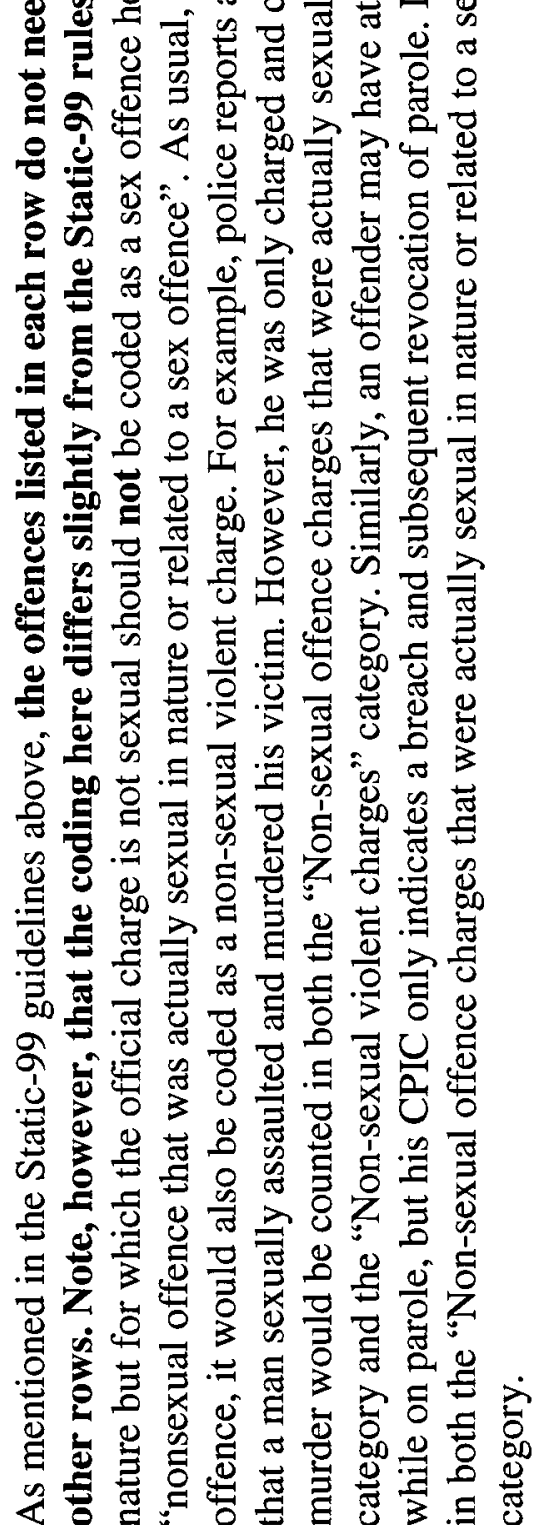




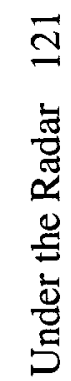

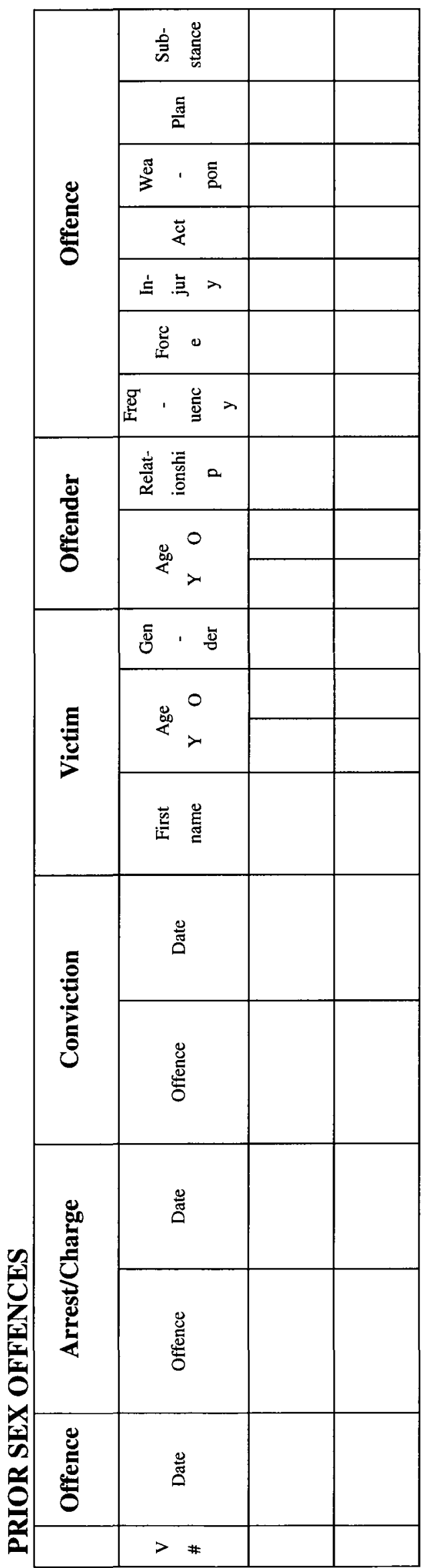

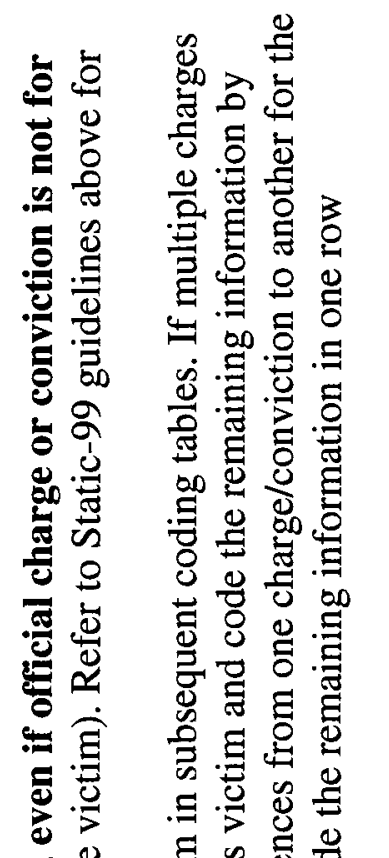

ध

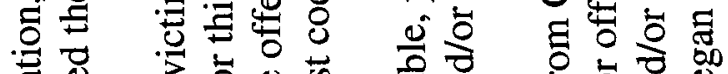

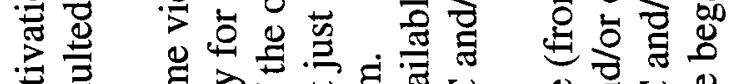

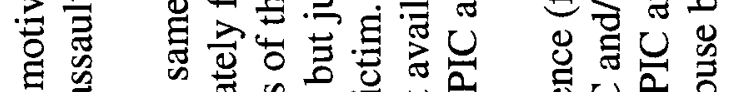

ह

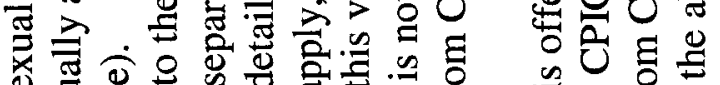

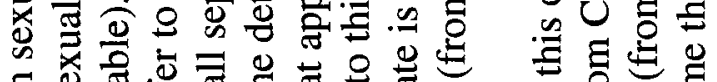

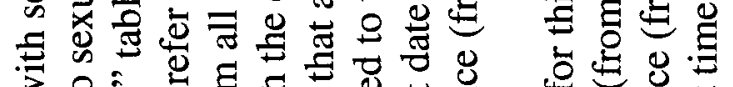

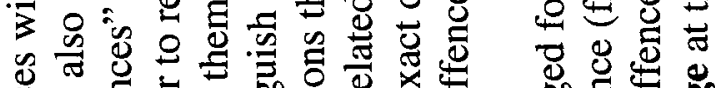

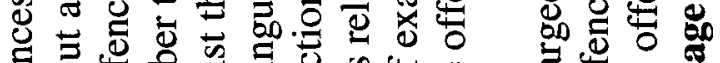

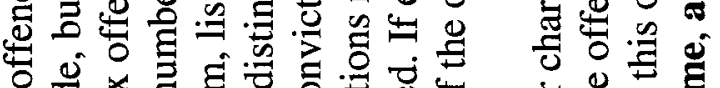

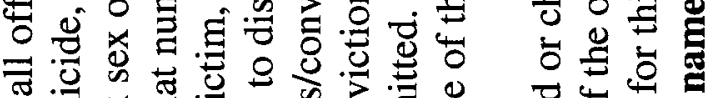

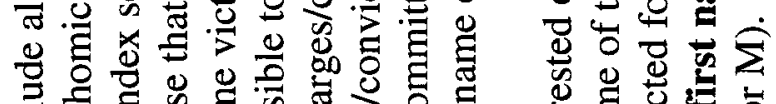

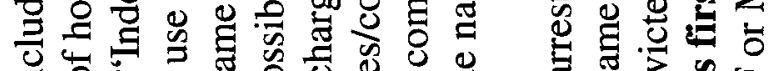

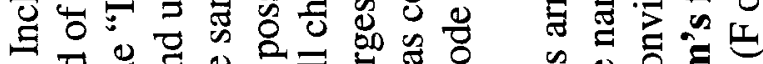

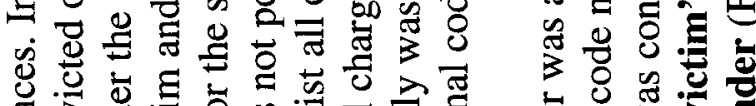

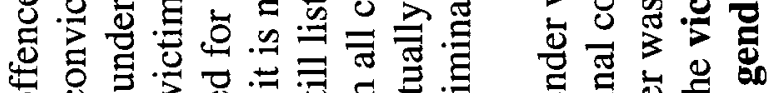

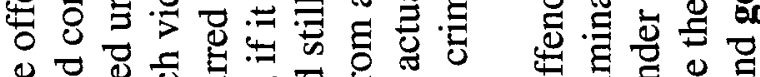

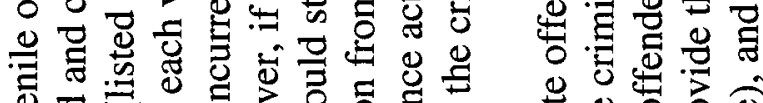

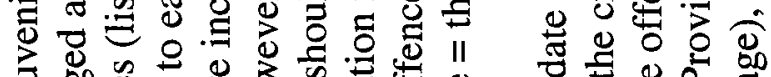

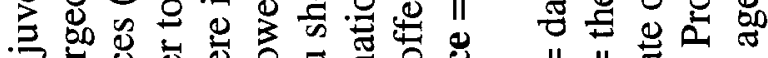

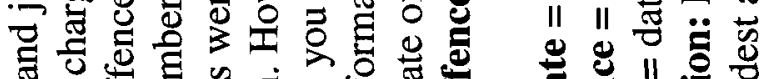

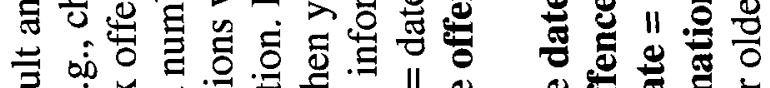
寻

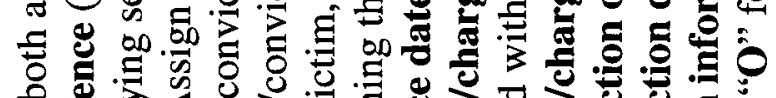

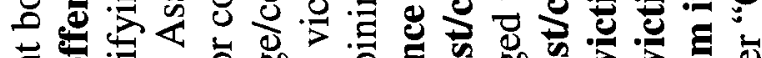

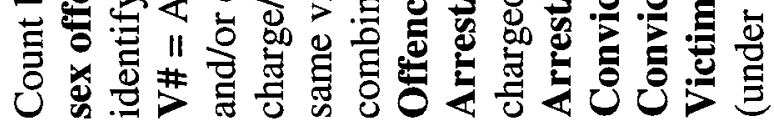




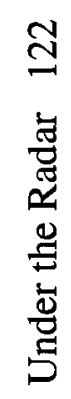

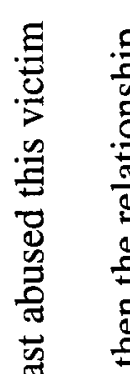

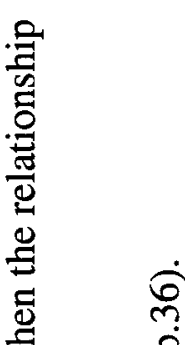

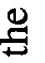

ㄸํㅇ

-

政

हีํㄹ

㝋

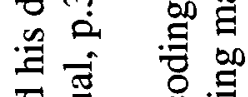

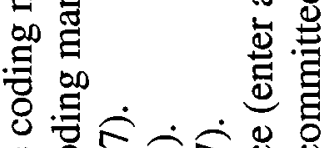

鹃 它官官导

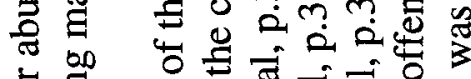

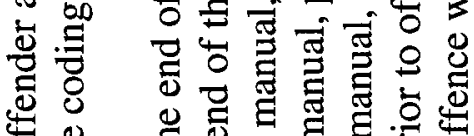

巳

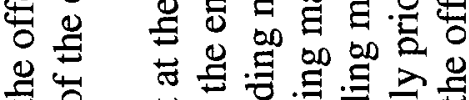

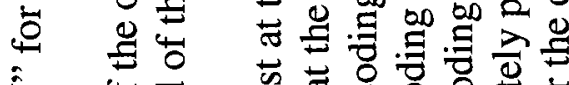

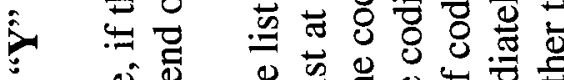

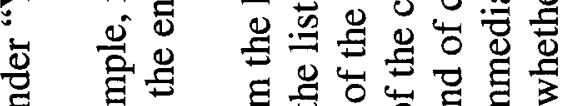

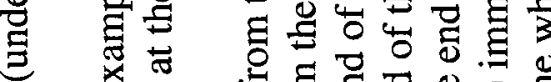

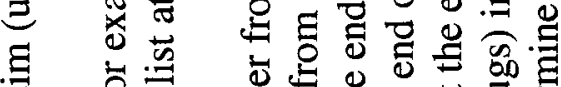

.

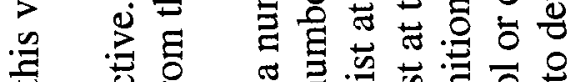

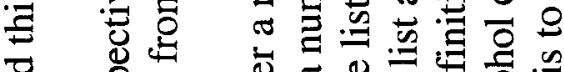

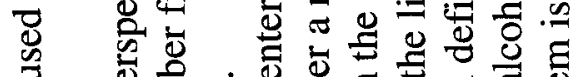

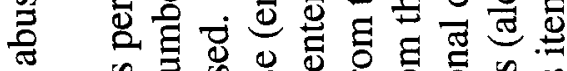

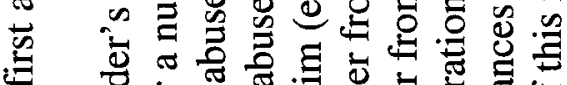

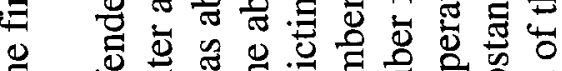

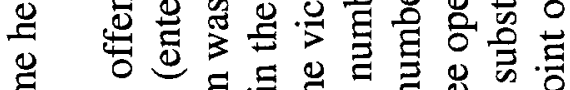

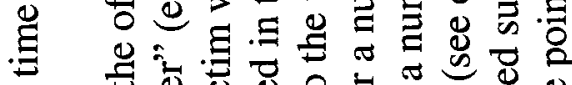

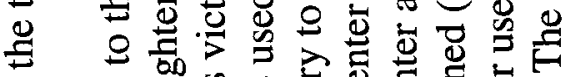

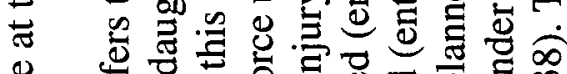

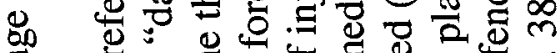

क

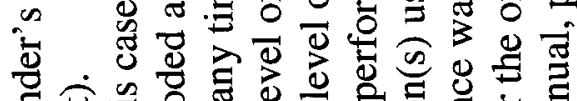

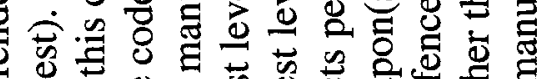

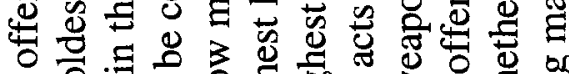

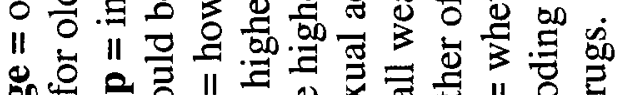

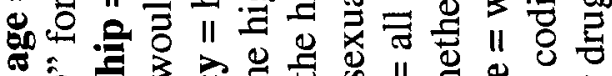
"人

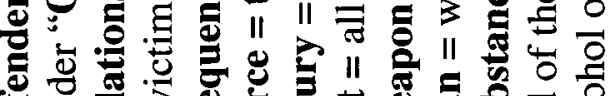

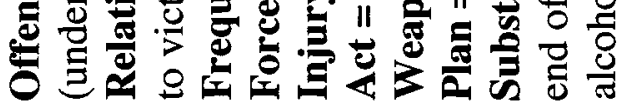

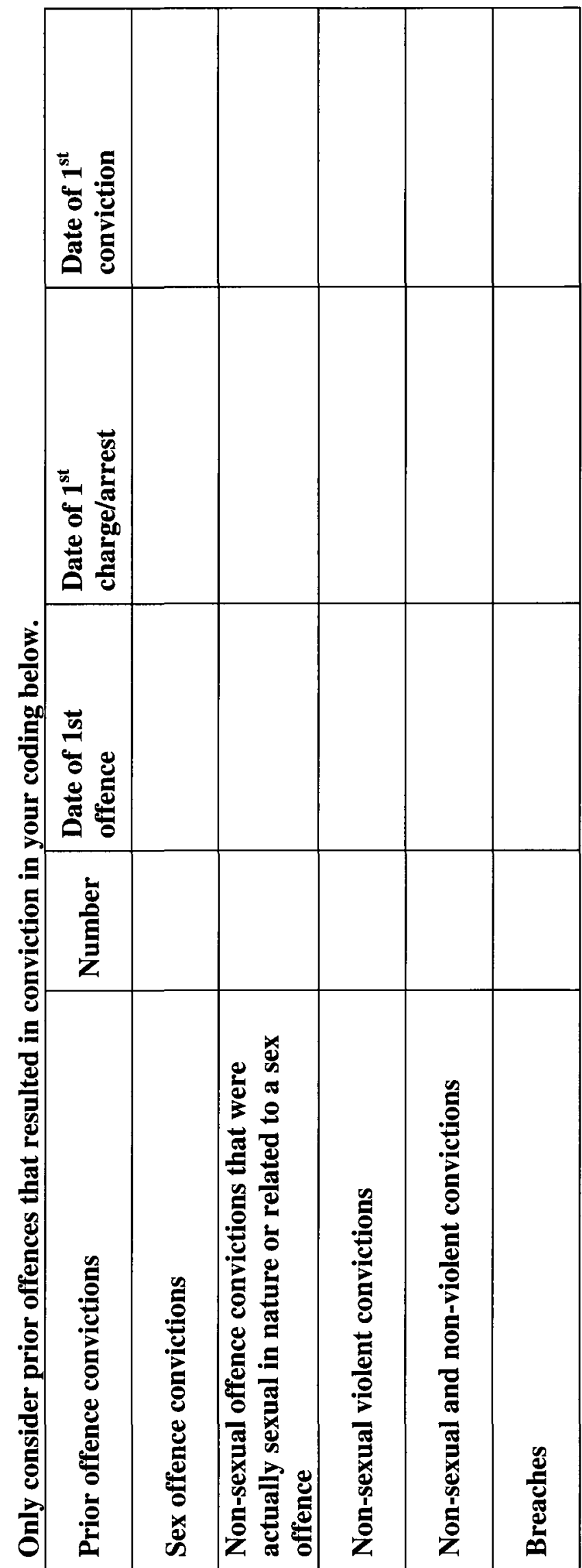




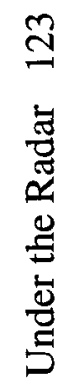

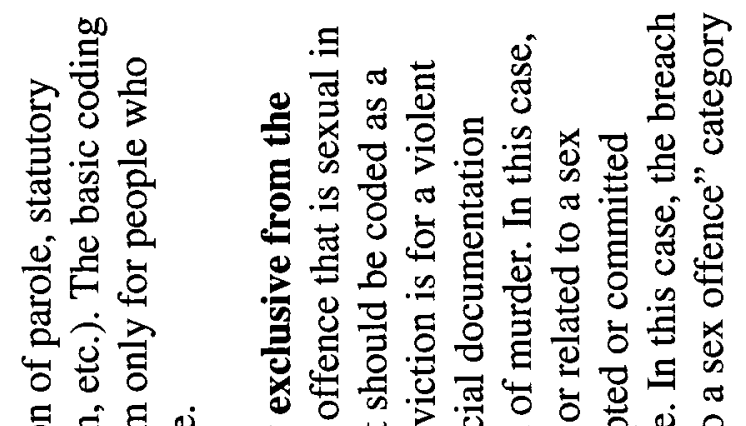

혀영

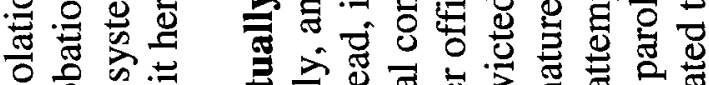

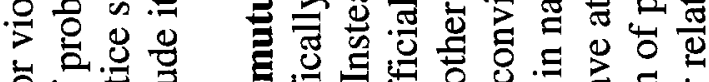

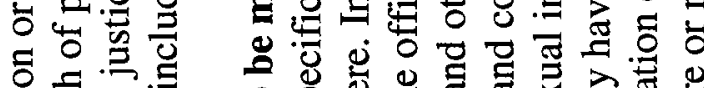

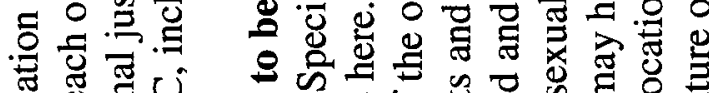

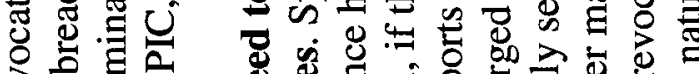

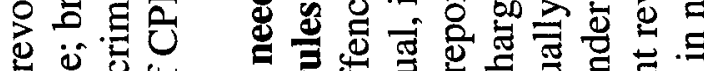

$\therefore$ 品

क

(i)

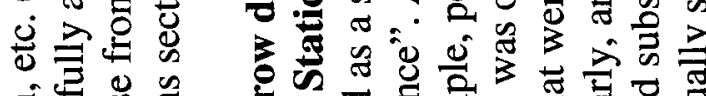

응

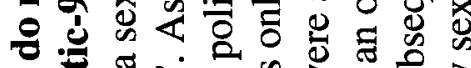

疍

昰

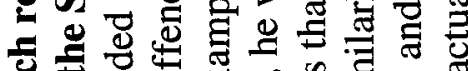
ษ

ఫ્屯

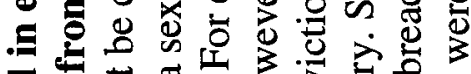

吕

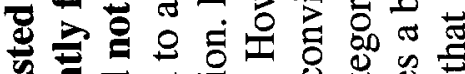

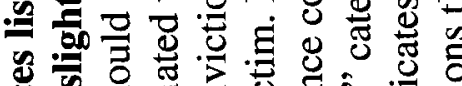

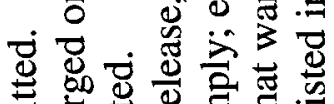

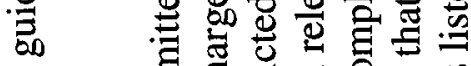

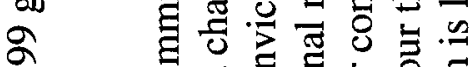

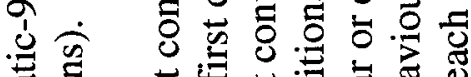

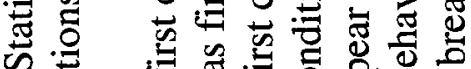

ه.

๙

过

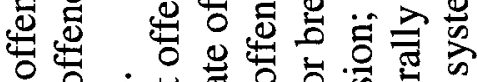

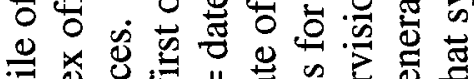

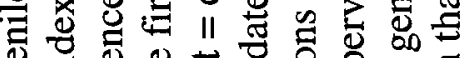
刍㔛莺

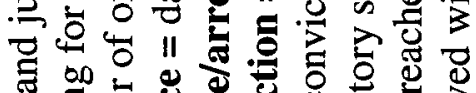

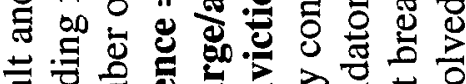

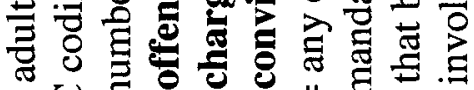

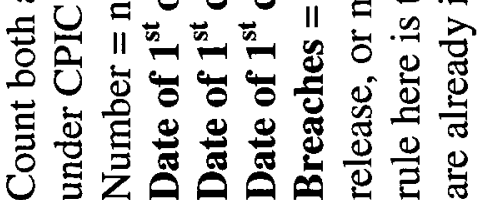

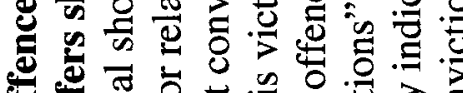
힝 莺 ฐ

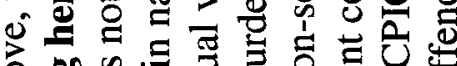
○

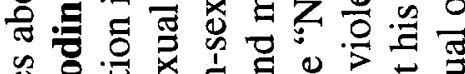

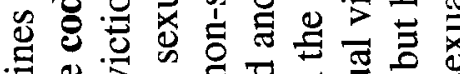

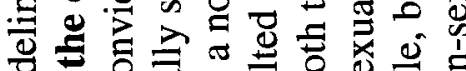

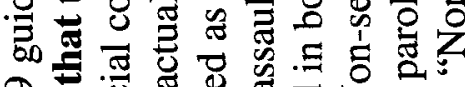
જे

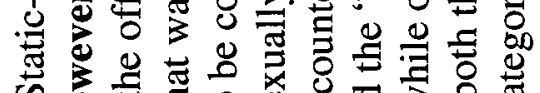

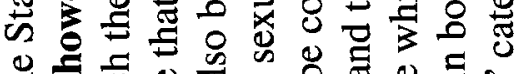
을 氜 . ఫृ

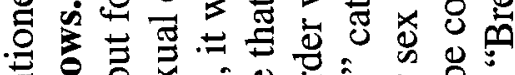

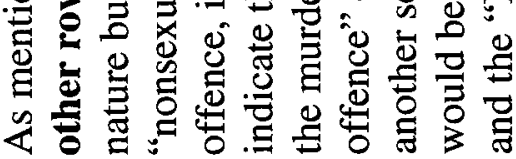




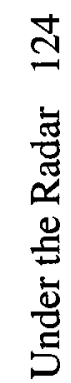

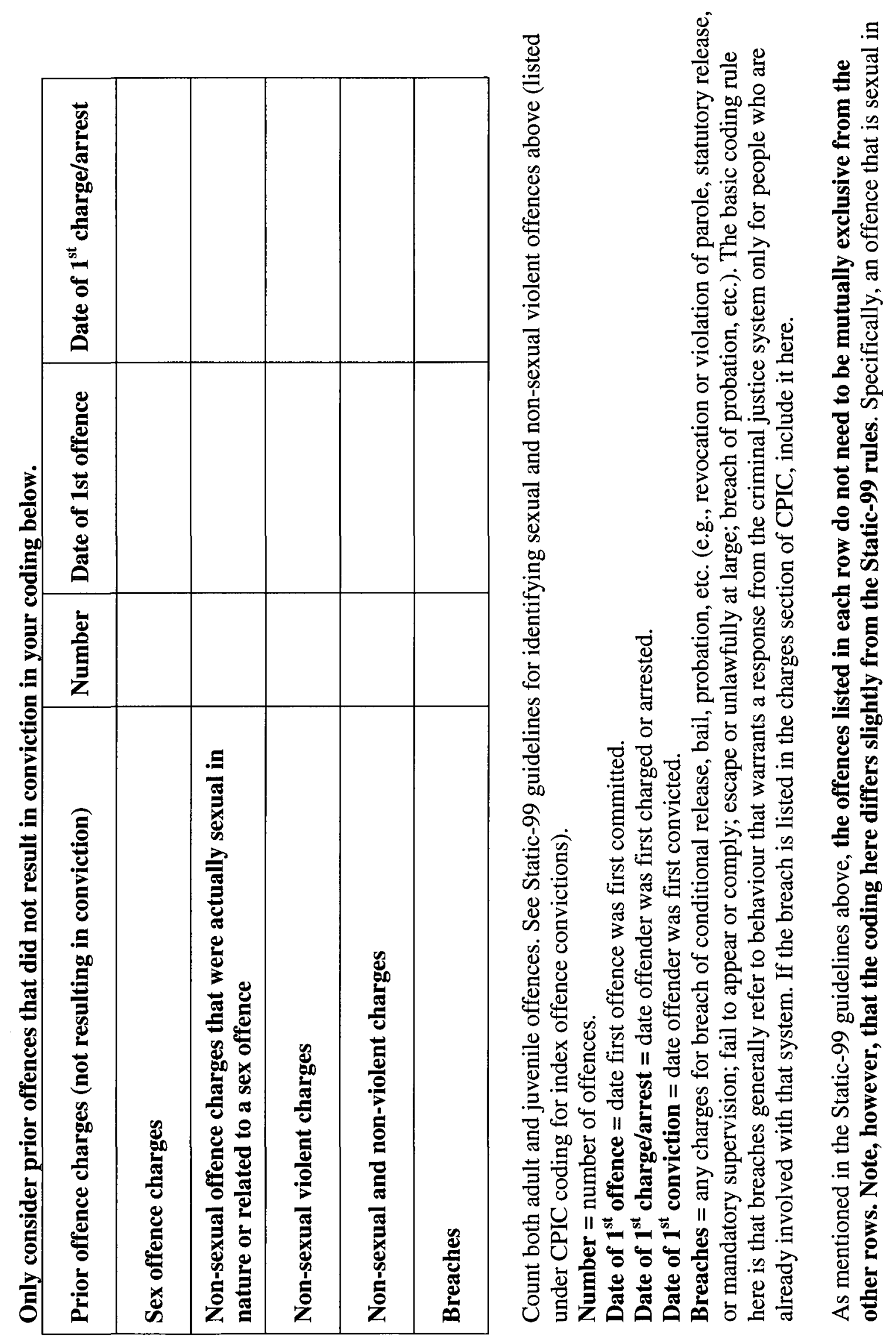




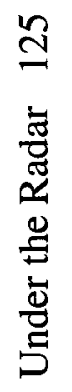

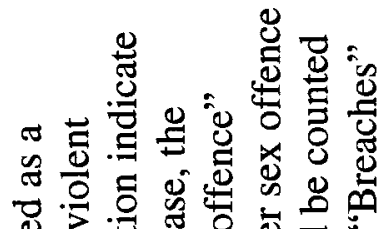

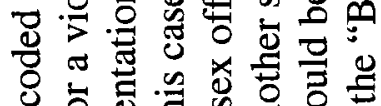

o

응

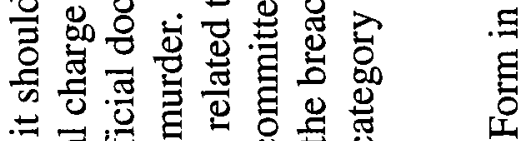

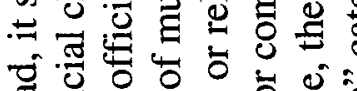

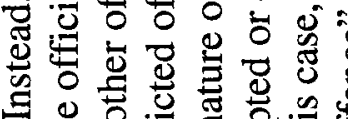

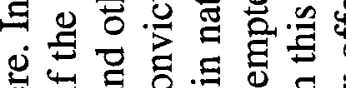

政:

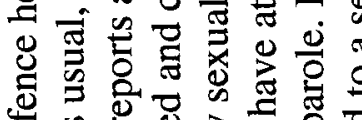

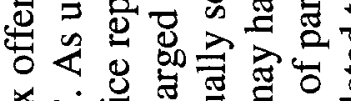

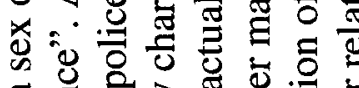

o

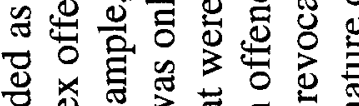

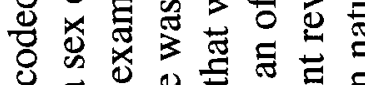

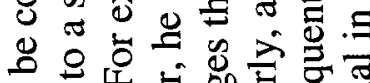

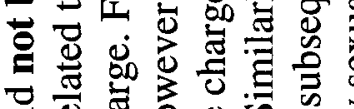

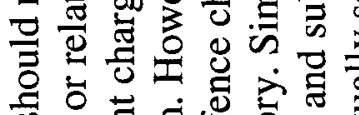

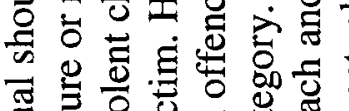

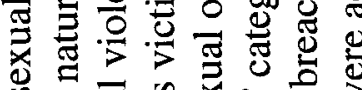

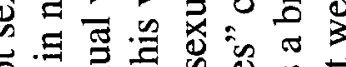

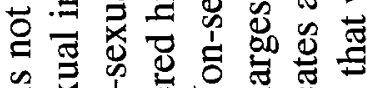

政

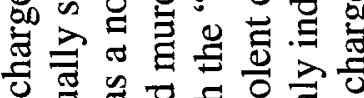

을

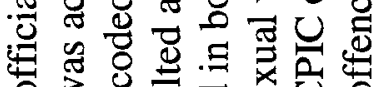

3 을

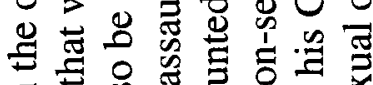

궁

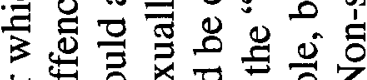

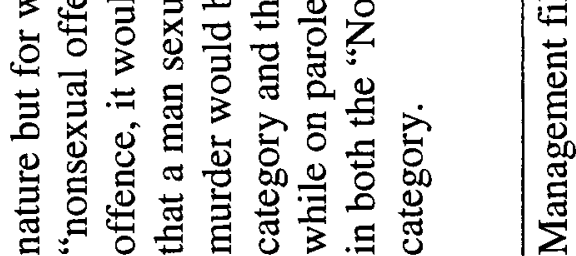

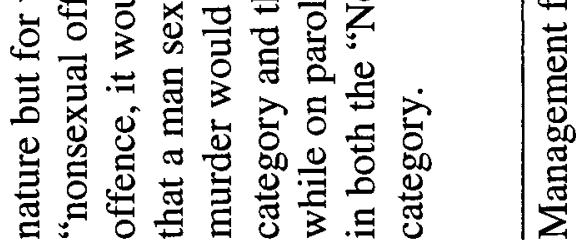

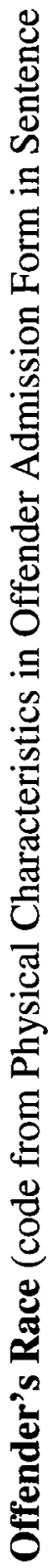

酠

离

개요

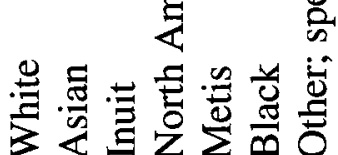

II II II II II II
巡

ชั

.

\&

8

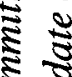

8

\&

S

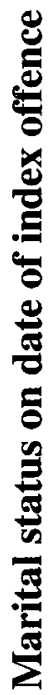

รั ธุ

ลิ

క

可

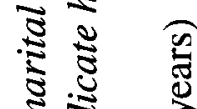

क.

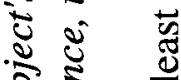

客

ฐ

ปั

ปั

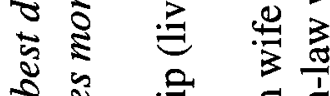

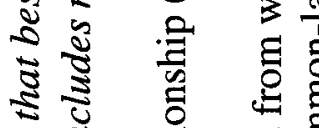

ㄱ.

\& \& 8

ปัँ

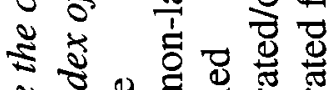

ปั.

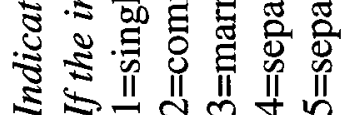




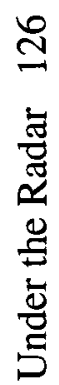

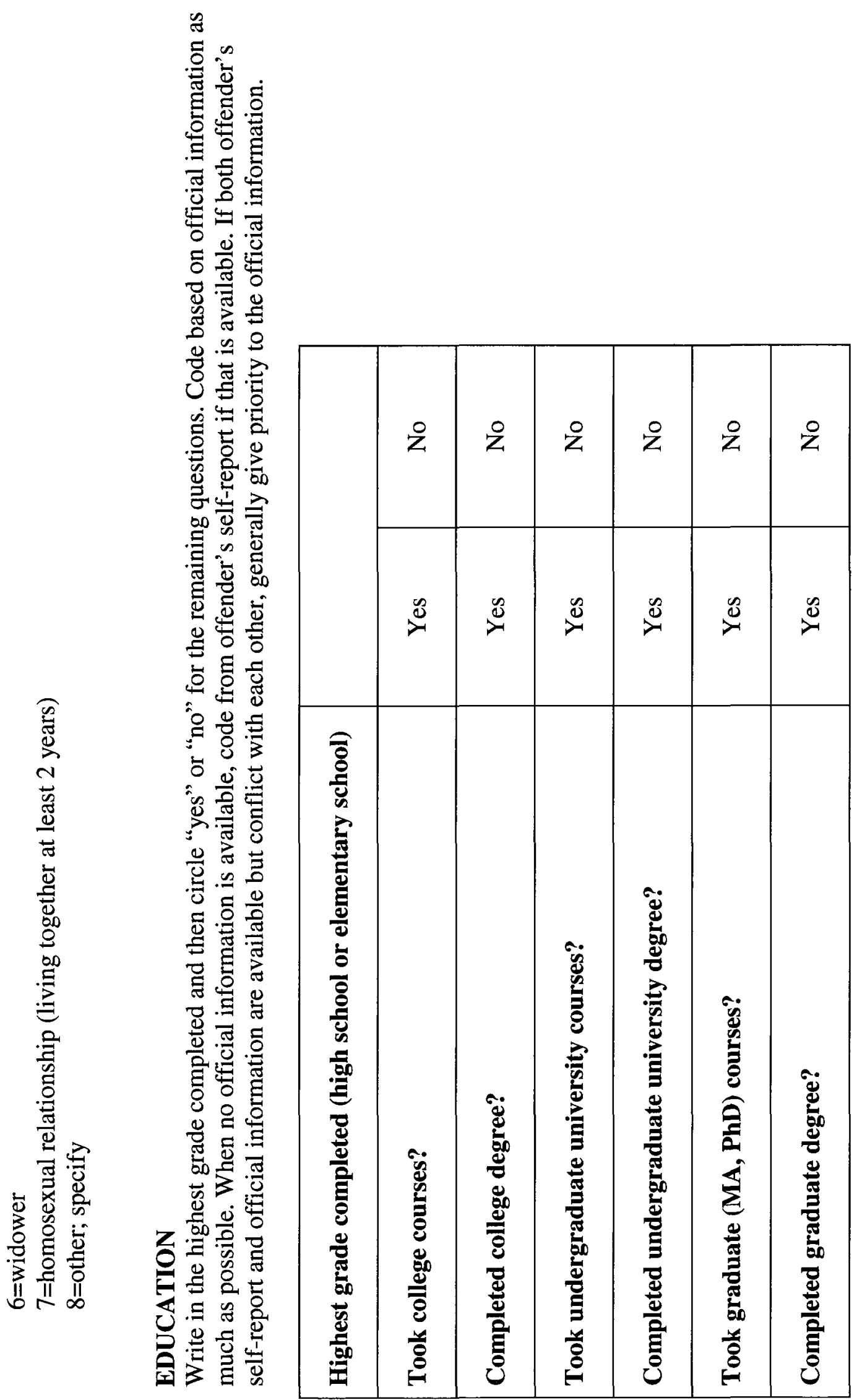




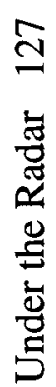

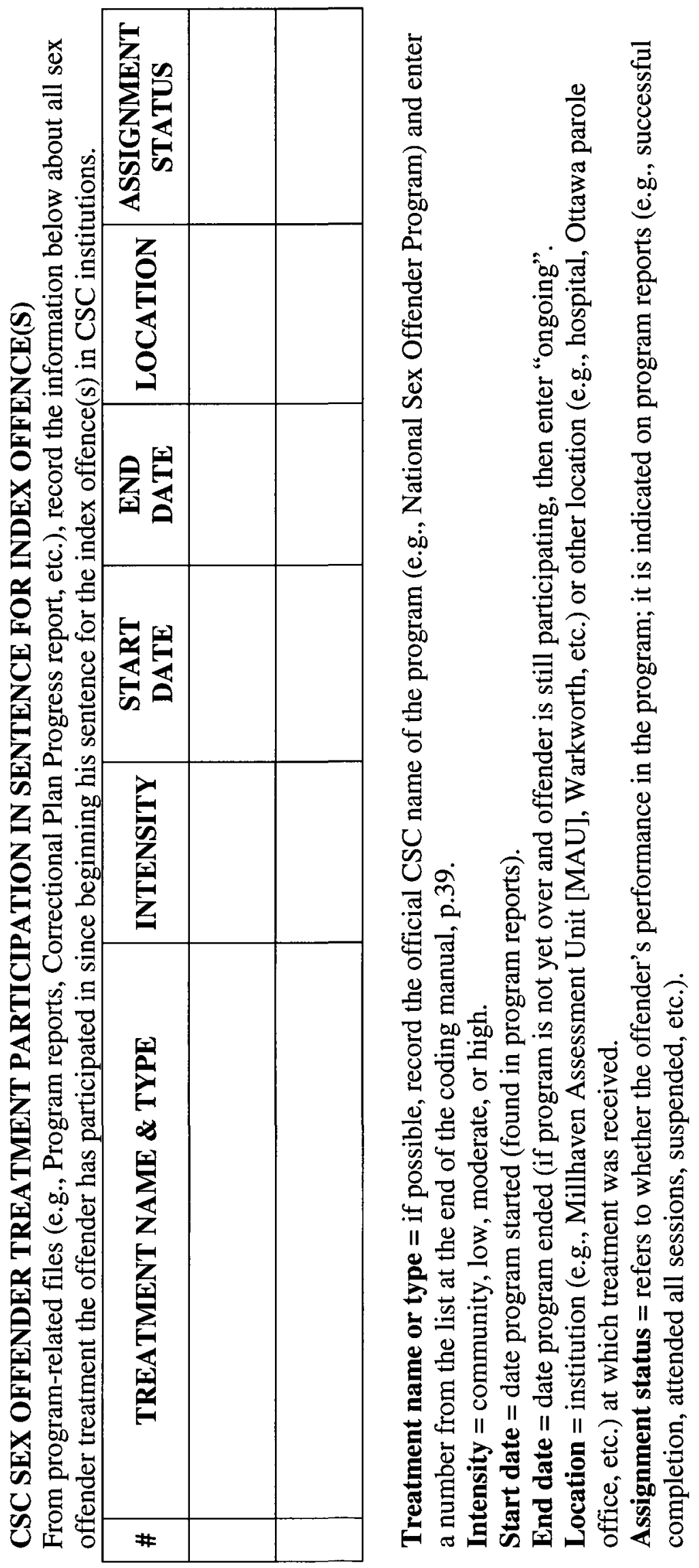




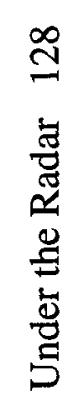

을ำ

๖

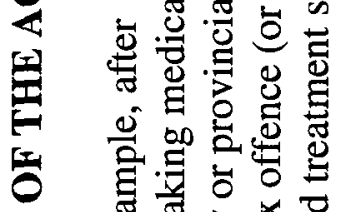

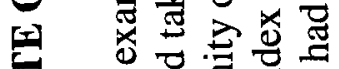

¿ i

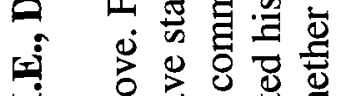

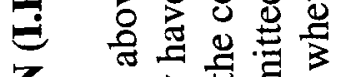

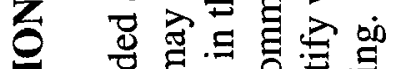

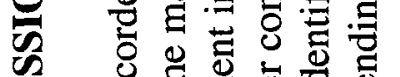

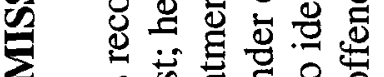

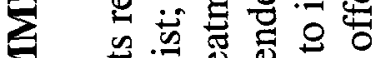

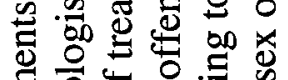

䞤 응

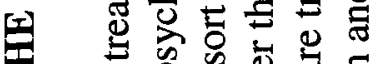

EU⿺辶寸

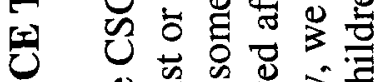

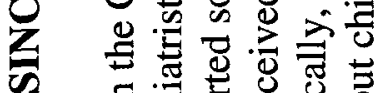

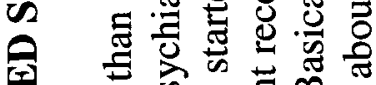

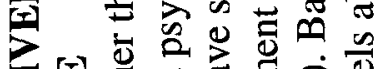

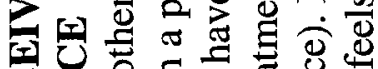

ర大

น

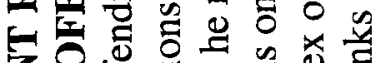

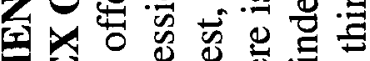

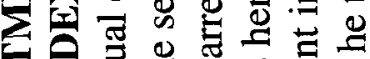

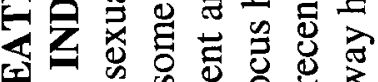
된

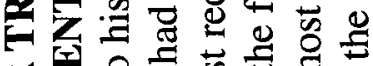

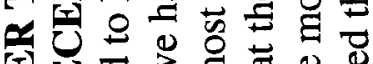

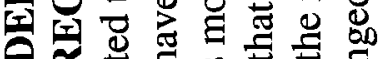
Z 는 矛过

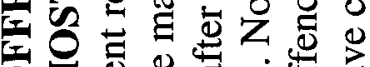

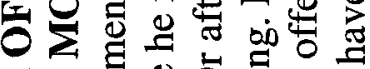

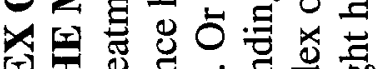

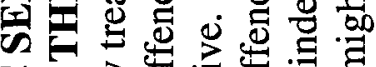

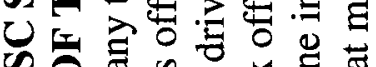
ข0

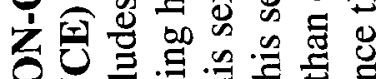
乙二 $>$ 要递它

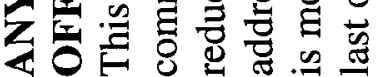

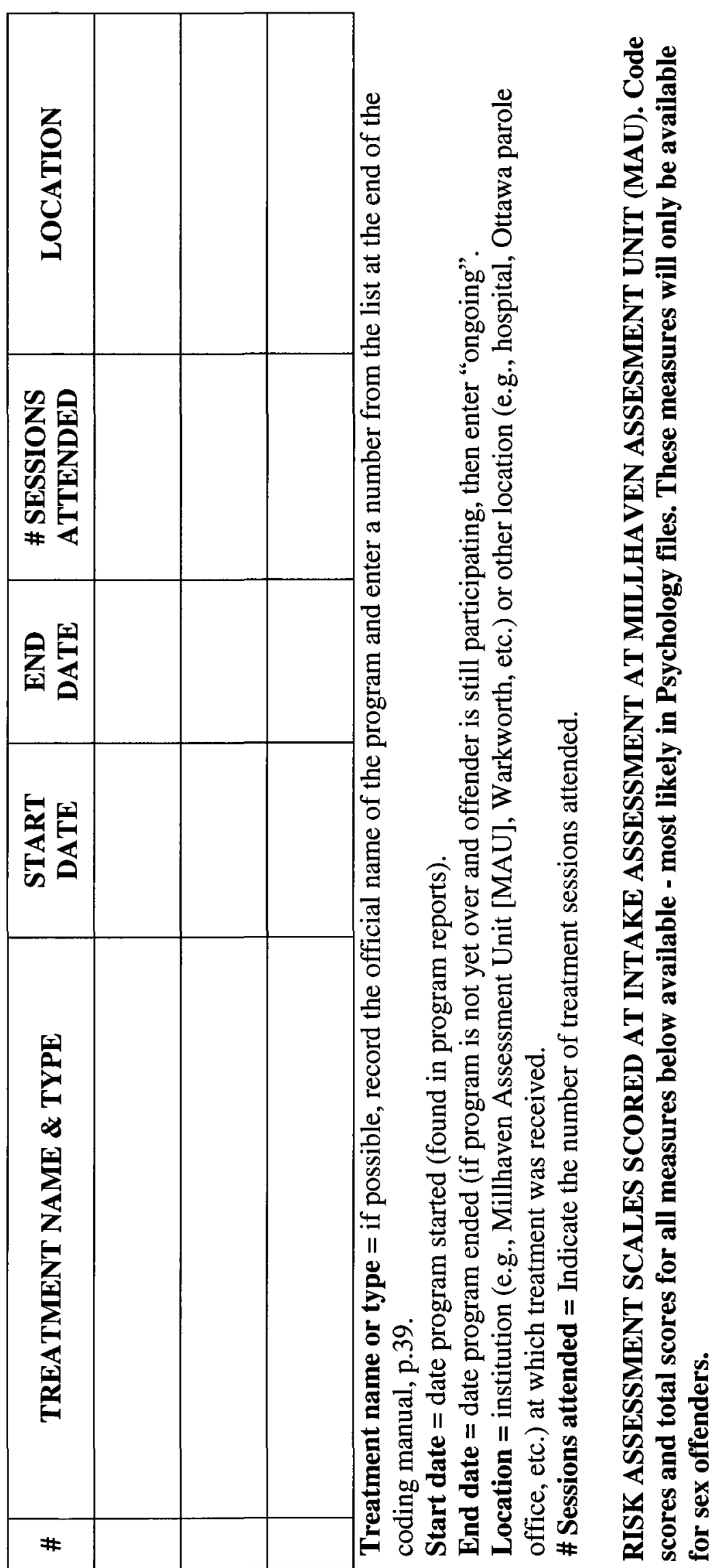


골

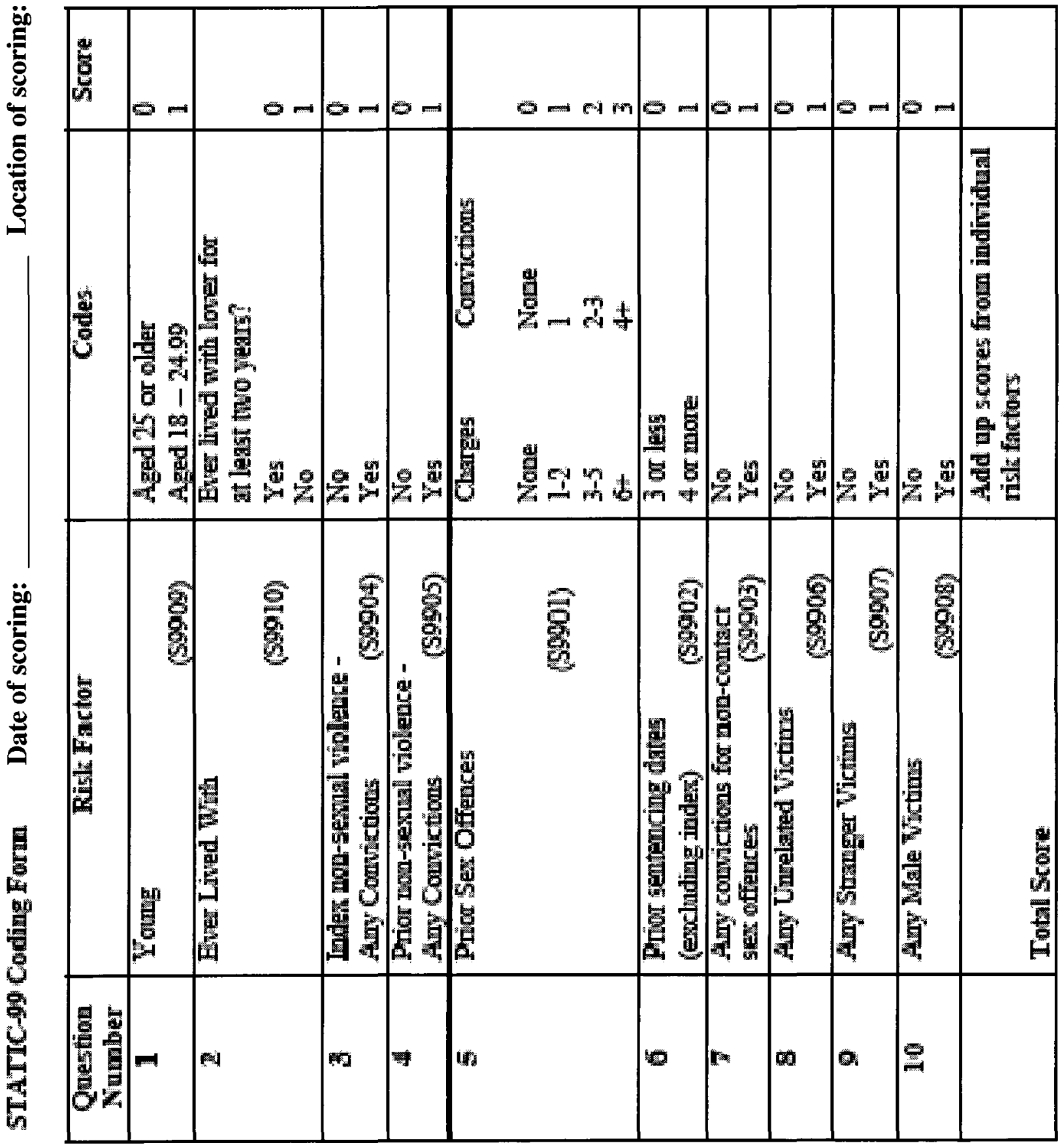




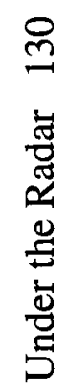

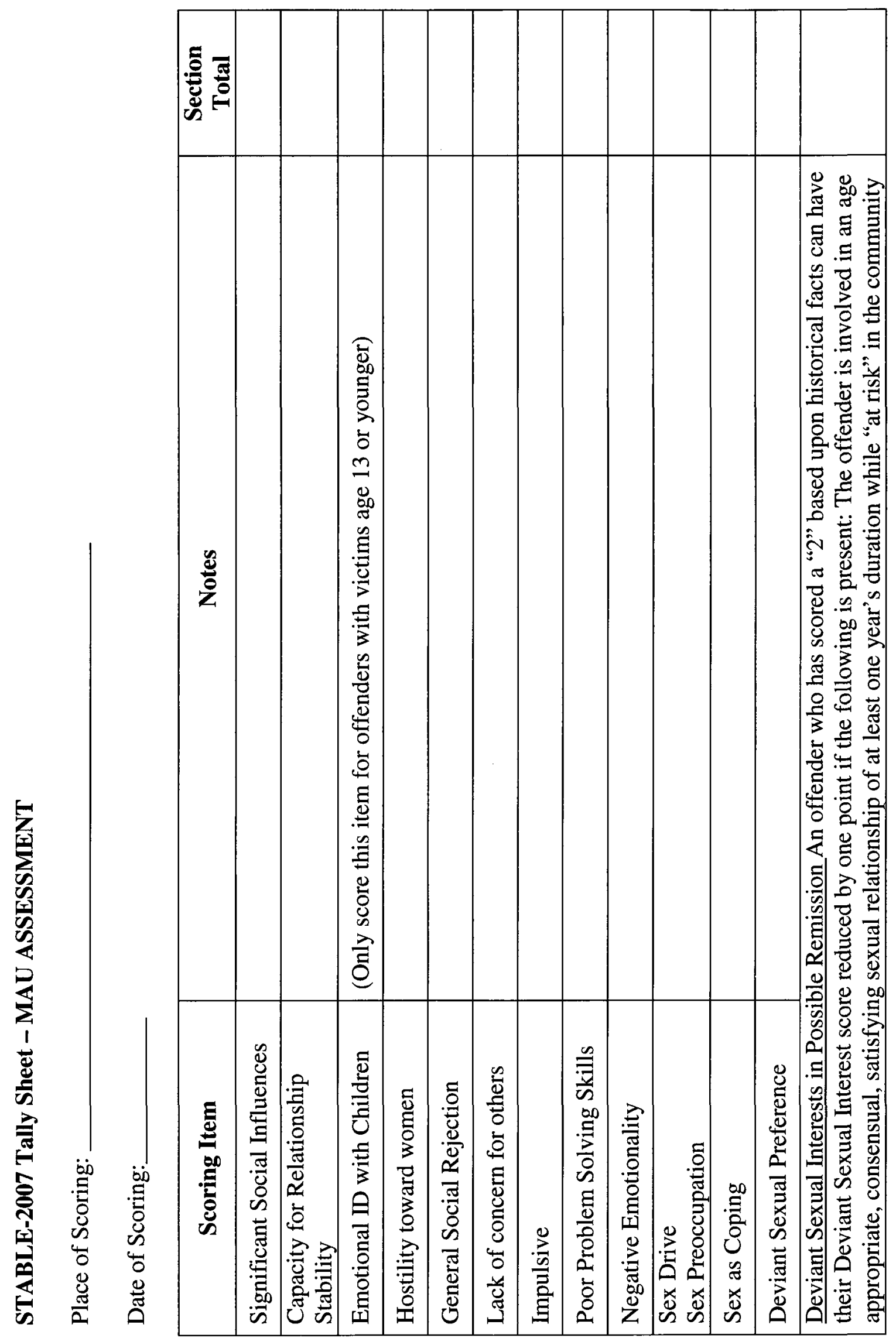




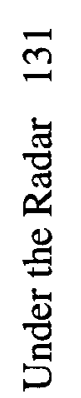
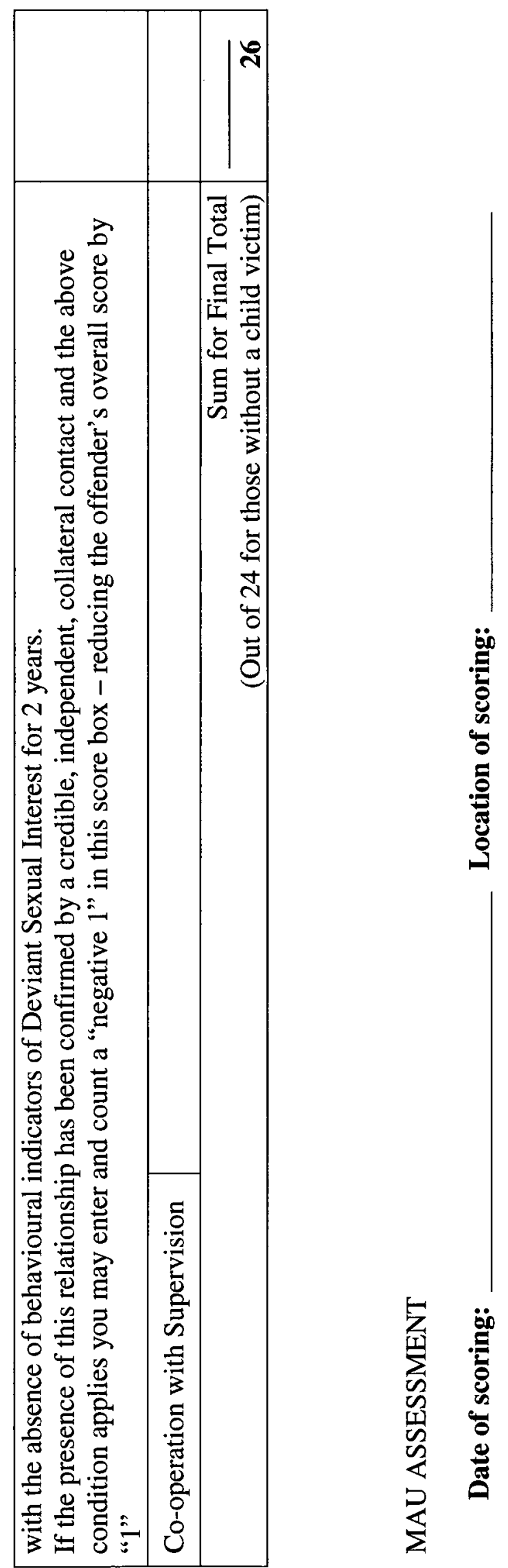
ڤึ

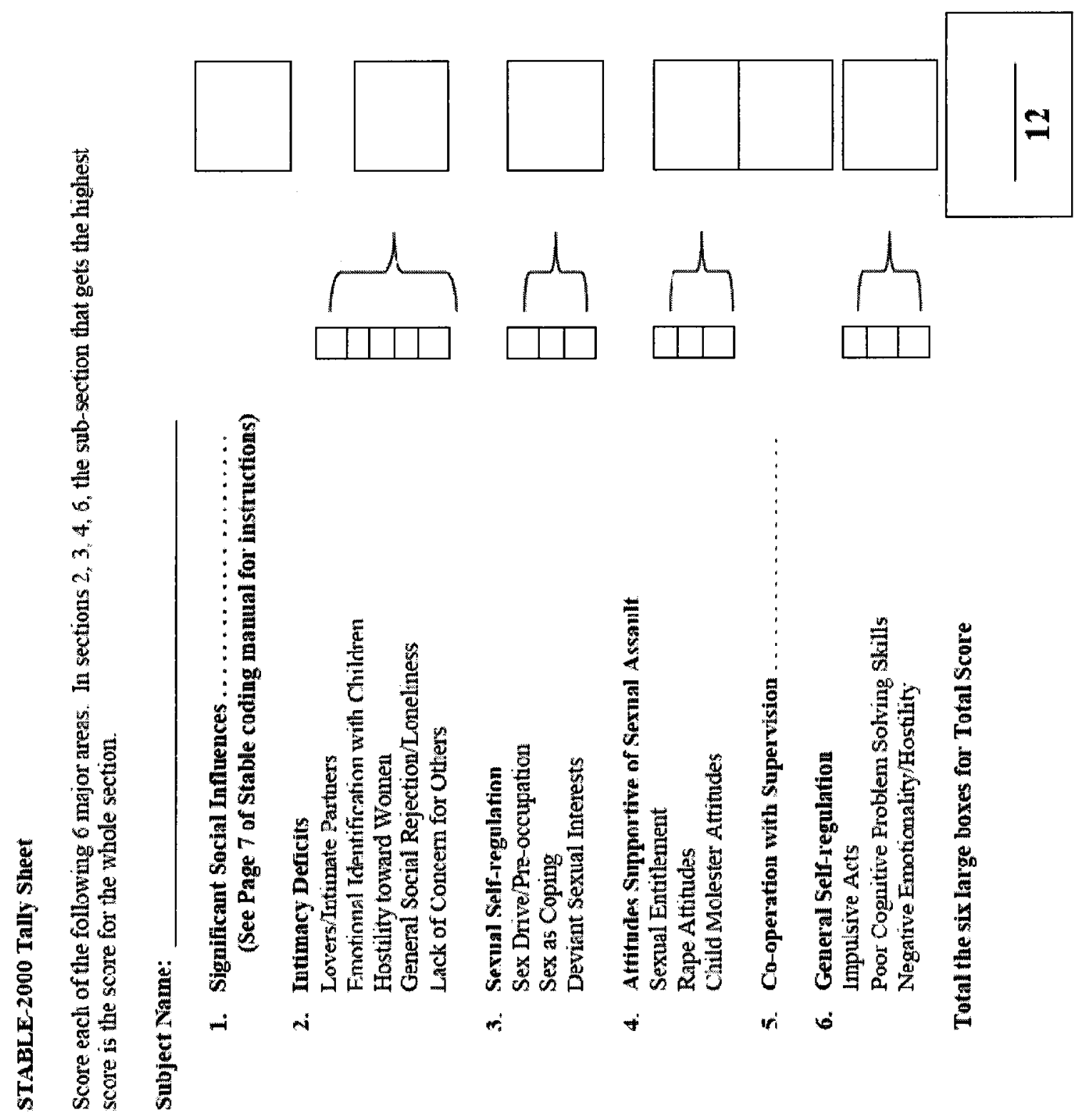




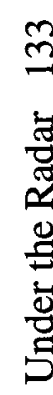
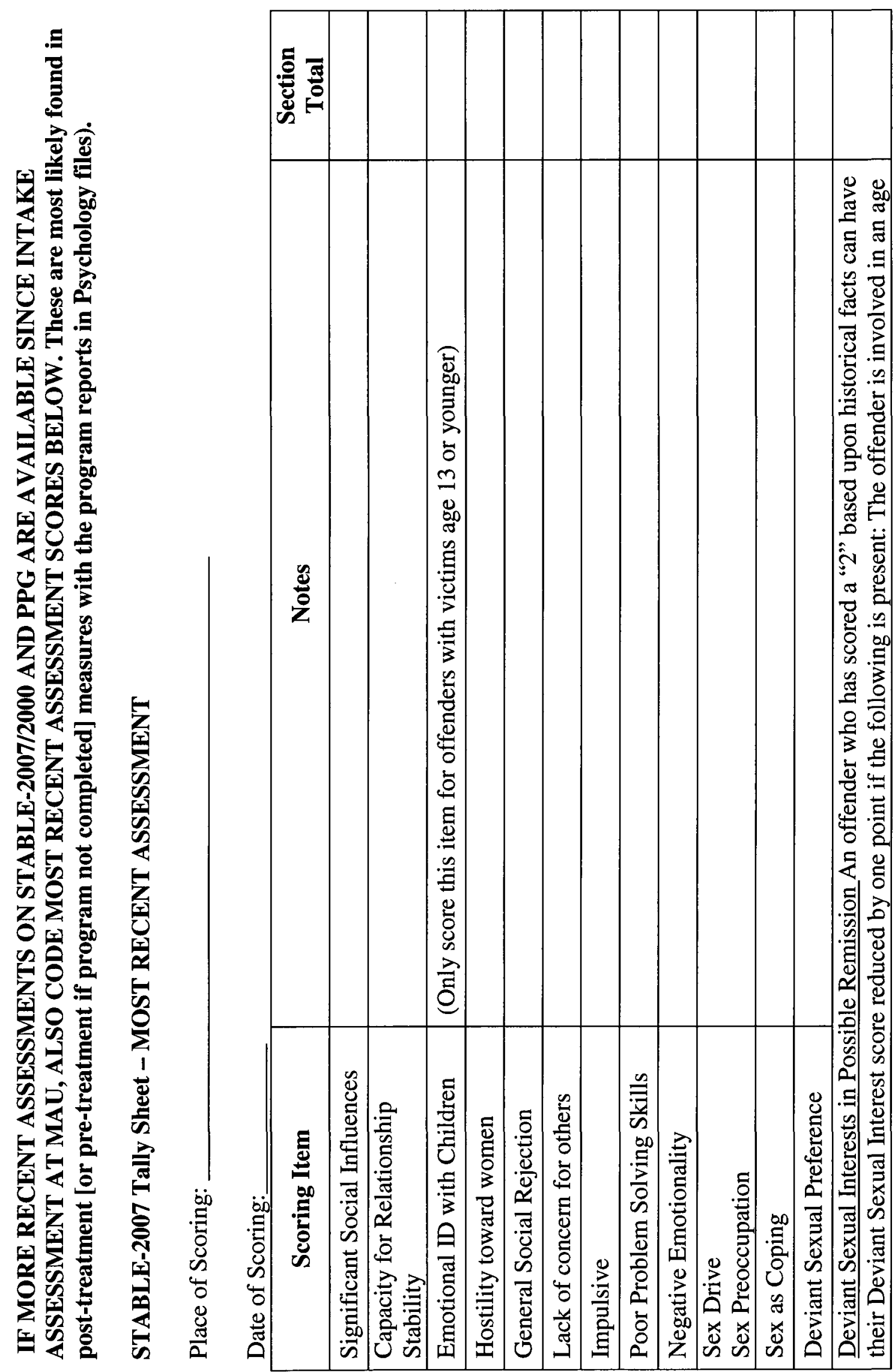


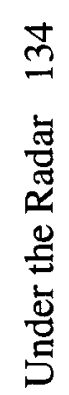

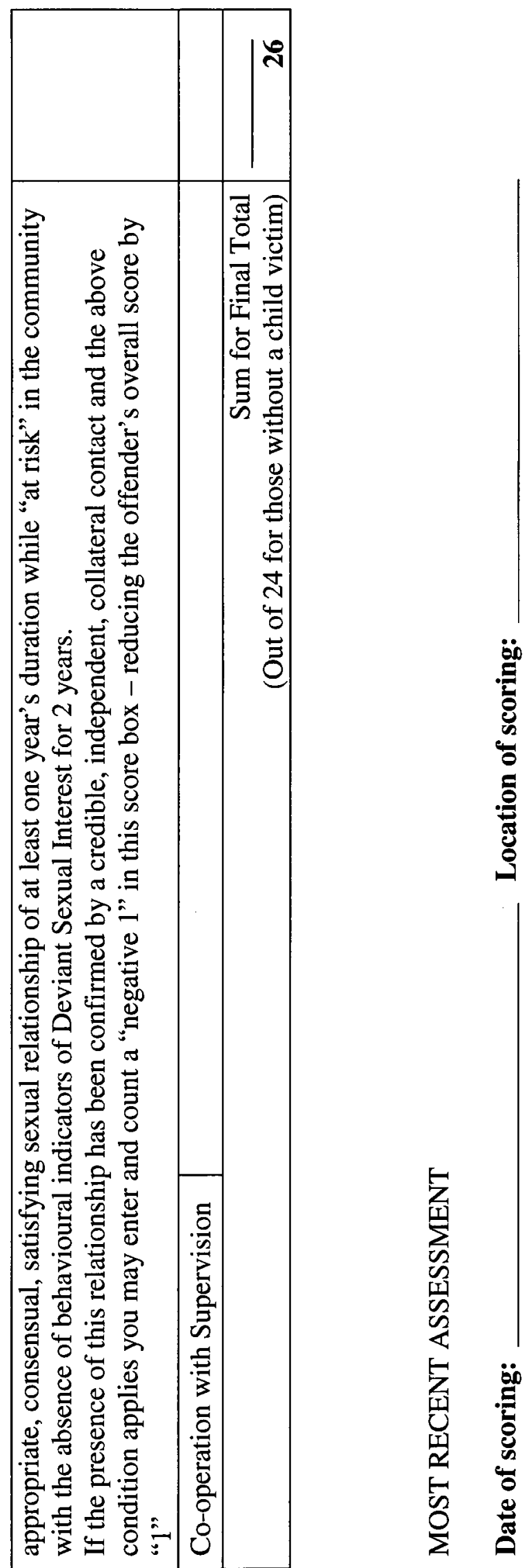


$\cong$

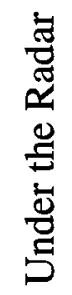

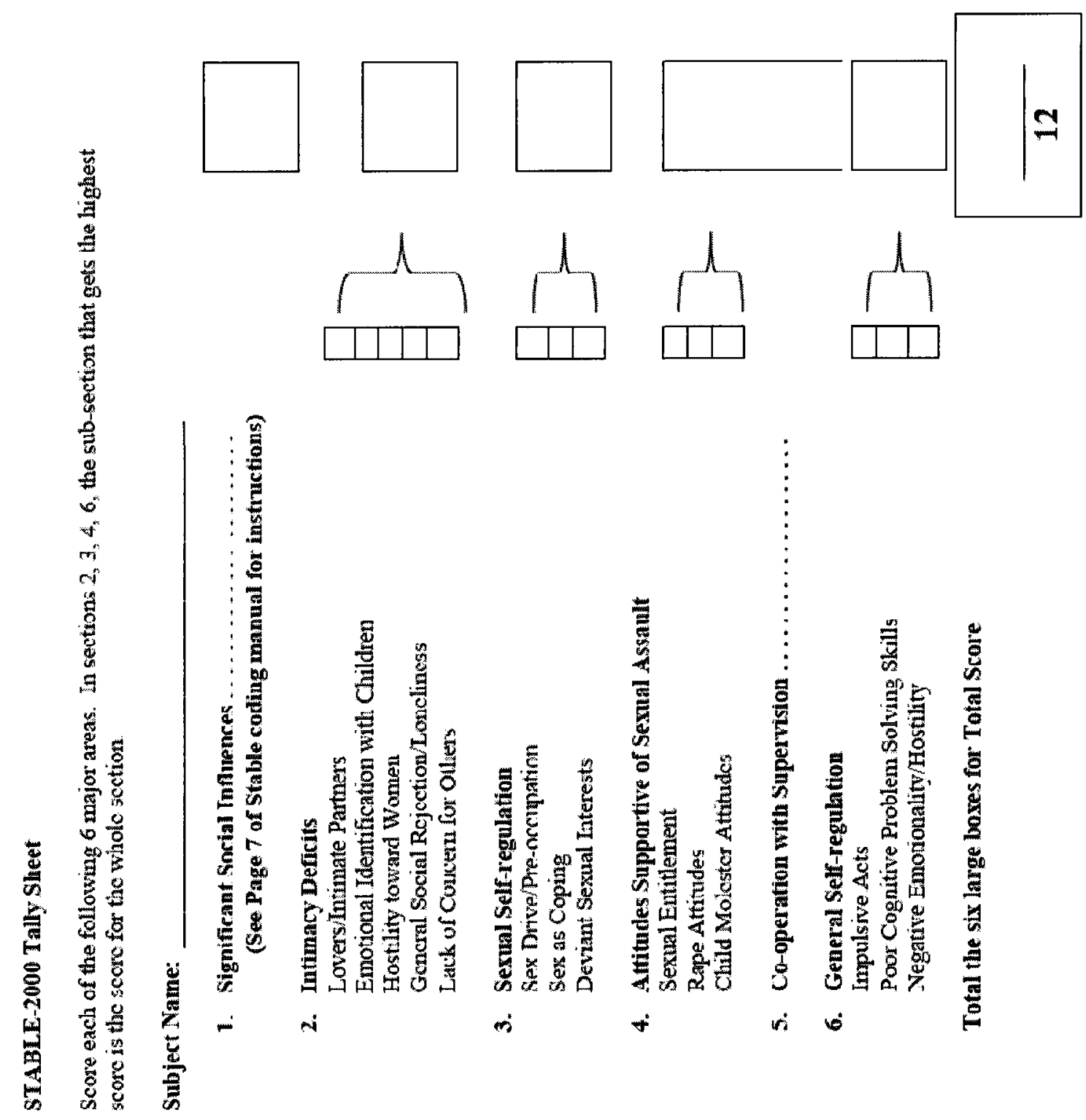




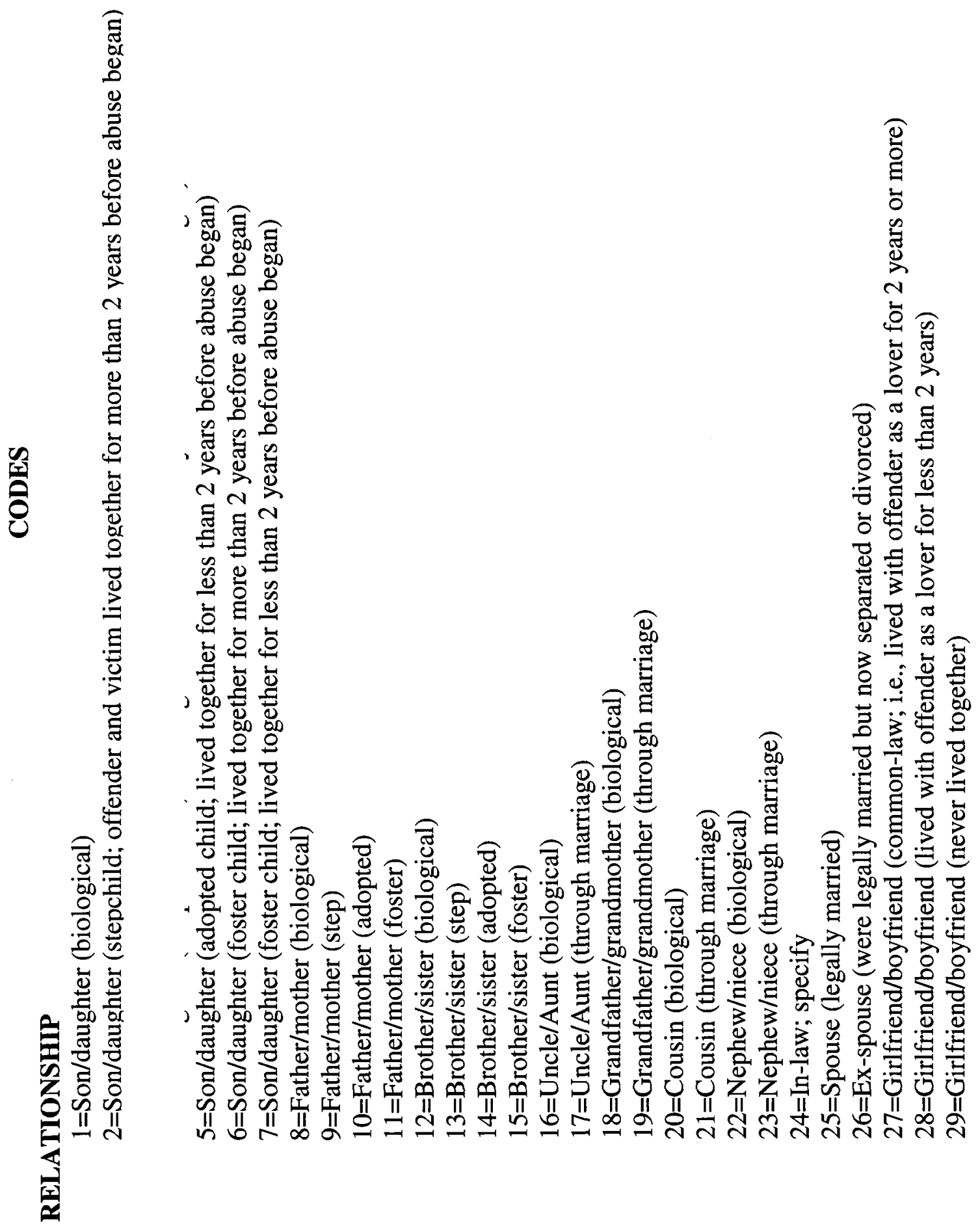




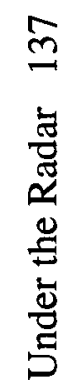
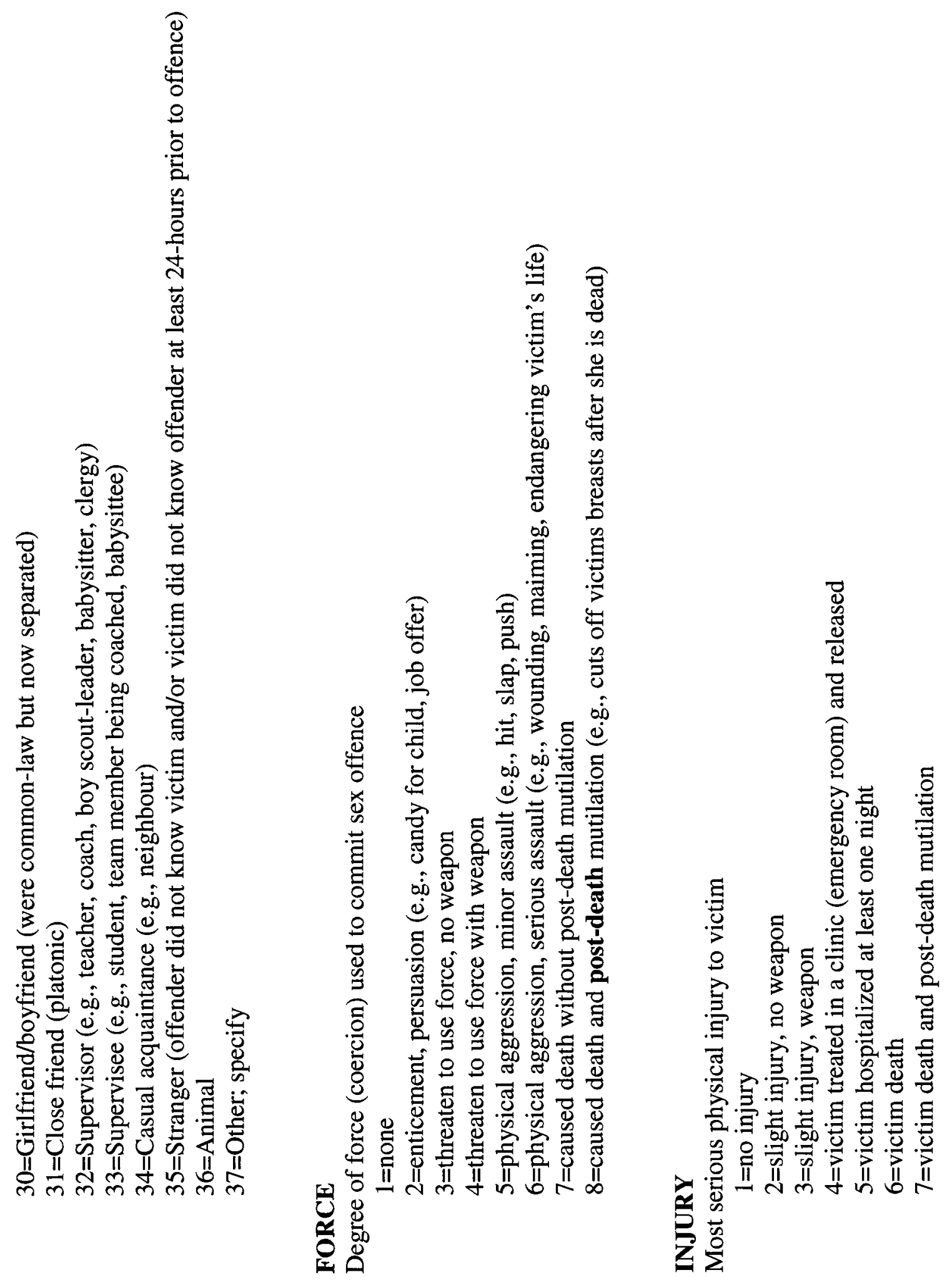


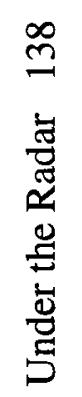

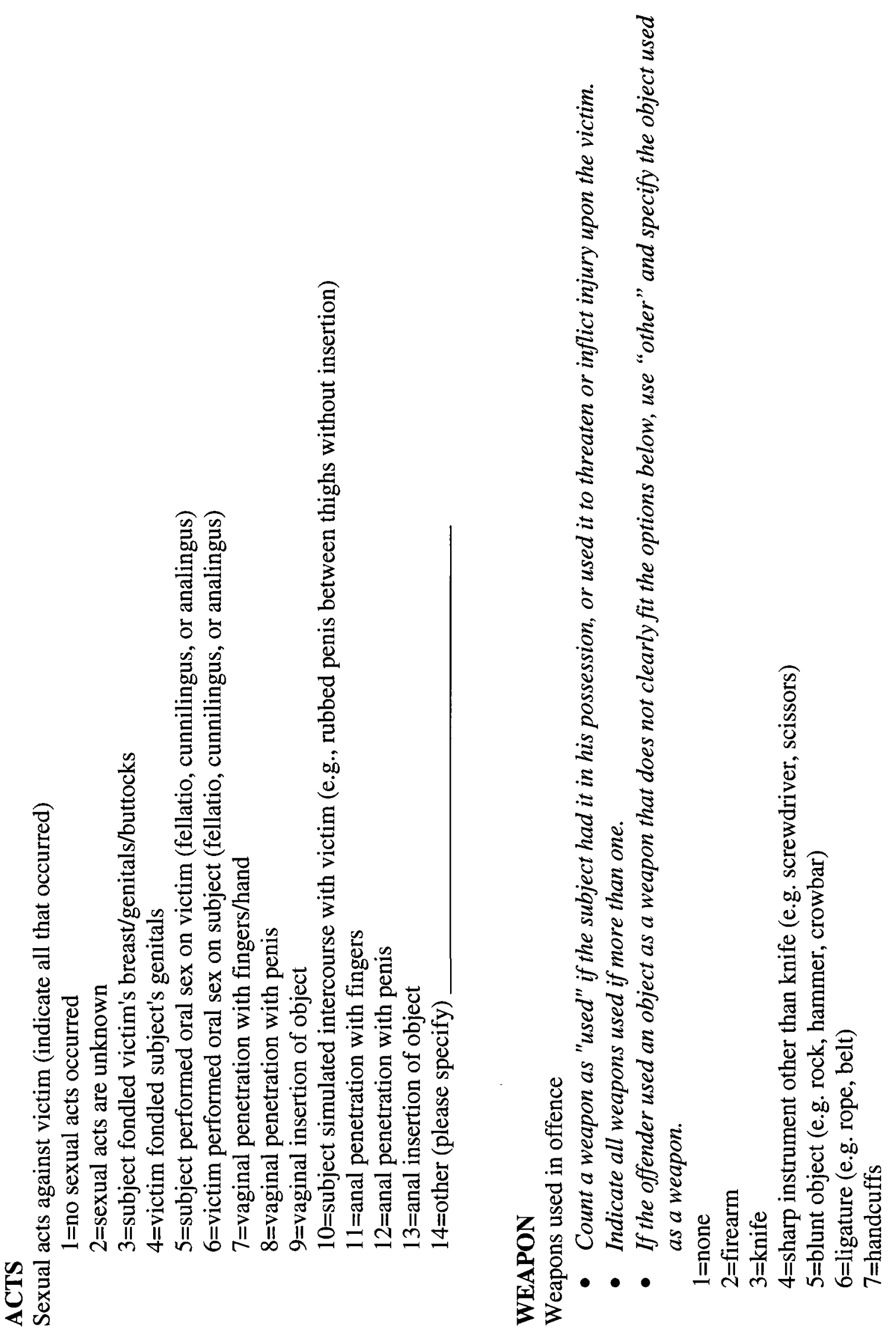




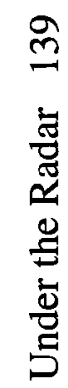
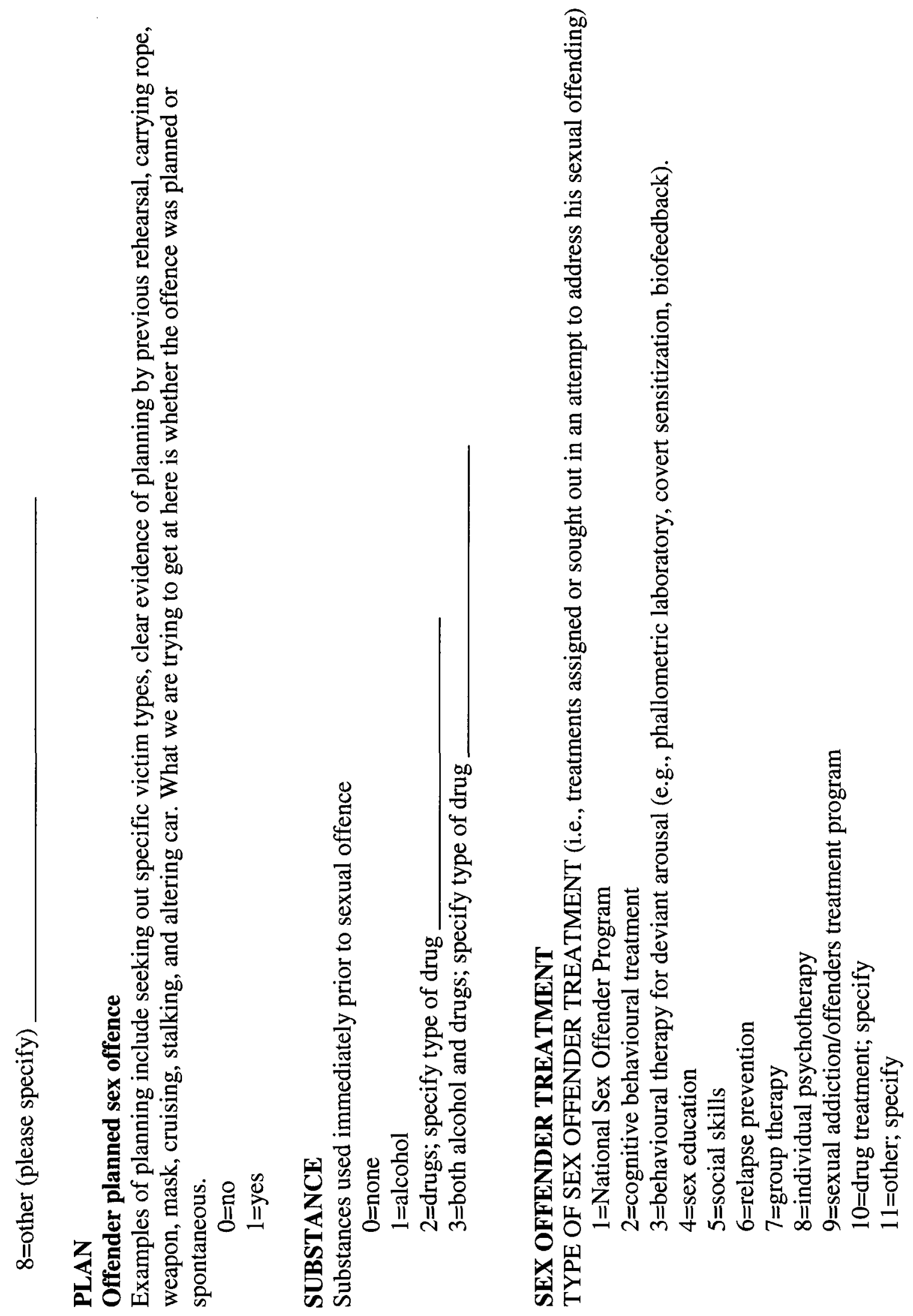